\title{
Evolution of asymmetric organocatalysis: multi- and retrocatalysis
}

\author{
Raffael C. Wende and Peter R. Schreiner* \\ Received 2nd February 2012, Accepted 26th March 2012 \\ DOI: $10.1039 / \mathrm{c} 2 \mathrm{gc} 35160 \mathrm{a}$
}

The evolution of organocatalysis led to various valuable approaches, such as multicomponent as well as domino and tandem reactions. Recently, organomulticatalysis, i.e., the modular combination of distinct organocatalysts enabling consecutive reactions to be performed in one pot, has become a powerful tool in organic synthesis. It allows the construction of complex molecules from simple and readily available starting materials, thereby maximizing reaction efficiency and sustainability. A logical extension of conventional multicatalysis is a multicatalyst, i.e., a catalyst backbone equipped with independent, orthogonally reactive catalytic moieties. Herein we highlight the impressive advantages of asymmetric organomulticatalysis, examine its development, and present detailed reactions based on the catalyst classes employed, ranging from the very beginnings to the latest multicatalyst systems.

\section{Introduction}

The development of resource-efficient and sustainable chemical methodologies and processes has become one of the most important goals of synthetic organic chemistry in the 21 st century. Various attempts were undertaken to minimize the adverse environmental impact and maximize the efficiency of chemical reactions. As one of numerous advances, multicatalysis, i.e., the modular combination of distinct catalysts for consecutive transformations in a single flask, emerged as a highly valuable tool for the construction of complex molecular frameworks from simple and readily available starting materials. ${ }^{1}$

Institute of Organic Chemistry, Justus-Liebig University, Heinrich-BuffRing 58, 35392 Giessen, Germany. E-mail: prs@org.chemie.uni-giessen.de; Fax: (+49) 6419934309
Since its fundamental "renaissance", organocatalysis became a vibrant area of research and grew rapidly to become a pillar in organic synthesis. ${ }^{2}$ Further developments mainly focused on novel catalyst classes and activation modes, and their use in iterative single step operations. ${ }^{2}$ Simultaneously, multistep processes, such as domino/cascade and tandem reactions, ${ }^{3-5}$ as well as asymmetric multicomponent reactions ${ }^{6}$ gained increasing attention and have been adopted to organocatalysis. ${ }^{5,7-9}$ Multicatalysis may condense the operational simplicity and synthetic efficiency provided by the aforementioned concepts to allow the rapid synthesis of even complex molecules in one pot syntheses. ${ }^{10-12}$ However, this concept only recently started flourishing in the field of organocatalysis. ${ }^{1}$ An approach that is even rarer and a logical extension of conventional multicatalysis is a multicatalys $\mathrm{t}^{13}$ ('assembly line' approach), i.e., an arbitrary catalyst backbone equipped with independently reactive catalytic

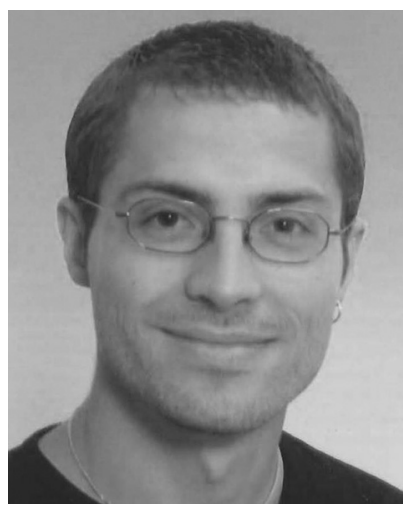

Raffael C. Wende
R. C. Wende was born in Rosenberg (Olesno), Poland, in 1984. He studied chemistry at the Justus-Liebig University, Giessen, where he obtained his B. Sc. degree in 2008 and his M. Sc. degree in 2010. Currently he is working on his $\mathrm{PhD}$ under the supervision of P. R. Schreiner. His research focuses on the development of novel synthetic oligopeptide and thiourea organocatalysts for multicatalysis reactions.

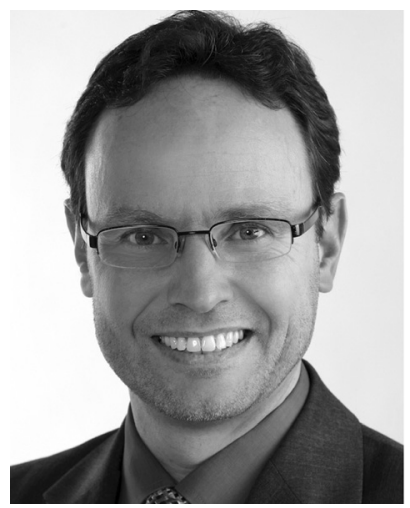

Peter R. Schreiner
P. R. Schreiner is professor of organic chemistry at the JustusLiebig University Giessen. He studied chemistry in his native city at the University of Erlangen-Nürnberg, Germany, where he received his Dr. rer. nat. (1994) in organic chemistry. Simultaneously, he obtained a $P h D$ (1995) in computational chemistry from the University of Georgia, USA. He completed his habilitation at the University of Göttingen (1999). P. R. Schreiner is the 2003 recipient of the Dirac Medal and received the ADUC-Prize for Assistant Professors in 1999 and was a Liebig-Fellow (1997-1999). 
moieties, which are separated by an appropriate spacer (Fig. 1). The design of a multicatalyst system hinges on the concept of retrosynthesis for assembling complex molecules. Whereas in retrosynthesis the target structure is disassembled into synthons (as equivalents for starting materials or intermediates) and steps, the development of a multicatalyst relies on the judicious choice of catalytic moieties that can be brought together in a single catalyst structure. Such a multicatalyst should then be able to allow the synthesis of the target structure from simple starting materials in a sequence of highly chemoselective reactions in one pot. This systematic strategy toward reverse catalyst design is therefore complementary to retrosynthesis (a target structure oriented approach) and may therefore be labelled as retrocatalysis (a reaction step oriented approach) ${ }^{14}$ to emphasize their close conceptional relationship (Fig. 1).

The main challenge in the development of multicatalytic reactions is to ensure compatibility of reactants, intermediates and catalysts throughout the whole reaction sequence. Many organocatalytic reactions are nowadays well understood. Their underlying activation modes, reaction pathways and intermediates have been precisely elucidated, experimentally ${ }^{15}$ as well as theoretically, ${ }^{16}$ for a variety of reactions, allowing reasonable predictability for the realization of organomulticatalysis (indicating that the reaction is purely organocatalyzed). In order to circumvent compatibility problems, the following strategies have been adopted: the use of obviously compatible catalysts, sequential addition of catalysts, and the site isolation or phase separation of catalysts. Additional challenges appear in the case of a multicatalyst. The choice of a proper catalyst backbone should allow easy preparation, alteration as well as modification. Moreover, appropriate spacers may be crucial for the separation of the catalytically active moieties. The envisioned multicatalyst must be compatible with all required reaction conditions and intermediates.

Interestingly, many examples of multicatalysis have not been recognized as such. Amongst other things, this may be due to the following reasons: not taking into account simple achiral Brønsted acids and bases as organocatalysts and inconsistent terminology (many multicatalytic reactions are lost amidst publications dealing with domino or tandem reactions). For this
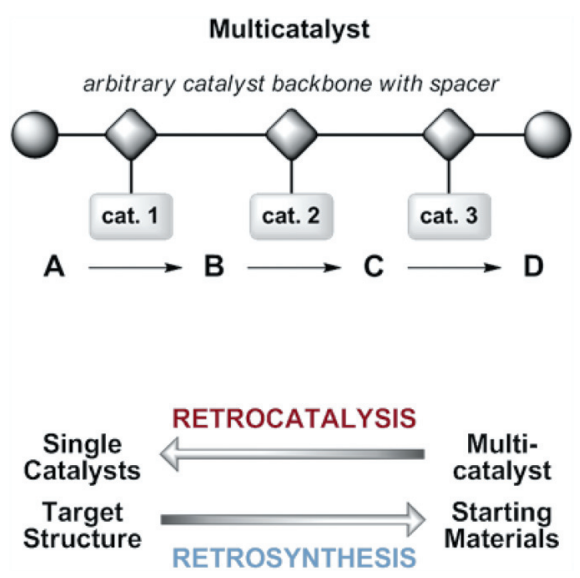

Fig. 1 Schematic representation of a multicatalyst and the concept of retrocatalysis. reason we will first define the prevalent types of one-pot organocatalysis employing multiple steps, illustrated with selected examples, before examining the advantages of multicatalysis and discussing representative examples.

\section{Multicatalysis - a survey}

\section{Taxonomy of one-pot reactions using multiple catalysts}

There are many examples of one-pot reactions where multiple organocatalysts are employed, ${ }^{10,11,17}$ and these have been termed cooperative catalysis, ${ }^{18}$ multifunctional catalysts, ${ }^{19}$ and dual catalysis. $^{20}$ For simplicity, we schematically depict the catalytic cycles for a general reaction of two starting materials (A and B) affording a product $(\mathrm{P})$. As evident from this simplified picture, multicatalysis should be clearly distinguished from cooperative catalysis where neither catalyst one nor catalyst two are sufficient to perform a desired reaction individually, and only a combination of both catalysts (sharing a single catalytic cycle) leads to a significant increase in the reaction rate (Fig. 2). ${ }^{18}$

Moreover, multicatalysis and especially a multicatalyst (compare Fig. 1) are different from multifunctional catalysts ${ }^{19}$ (Fig. 3), and dual catalyst systems ${ }^{20}$ (Fig. 4). In the case of a multifunctional catalyst, one catalytic functionality mutually enhances the activity of another catalytically active center on the same catalyst via the separate activation of multiple reaction
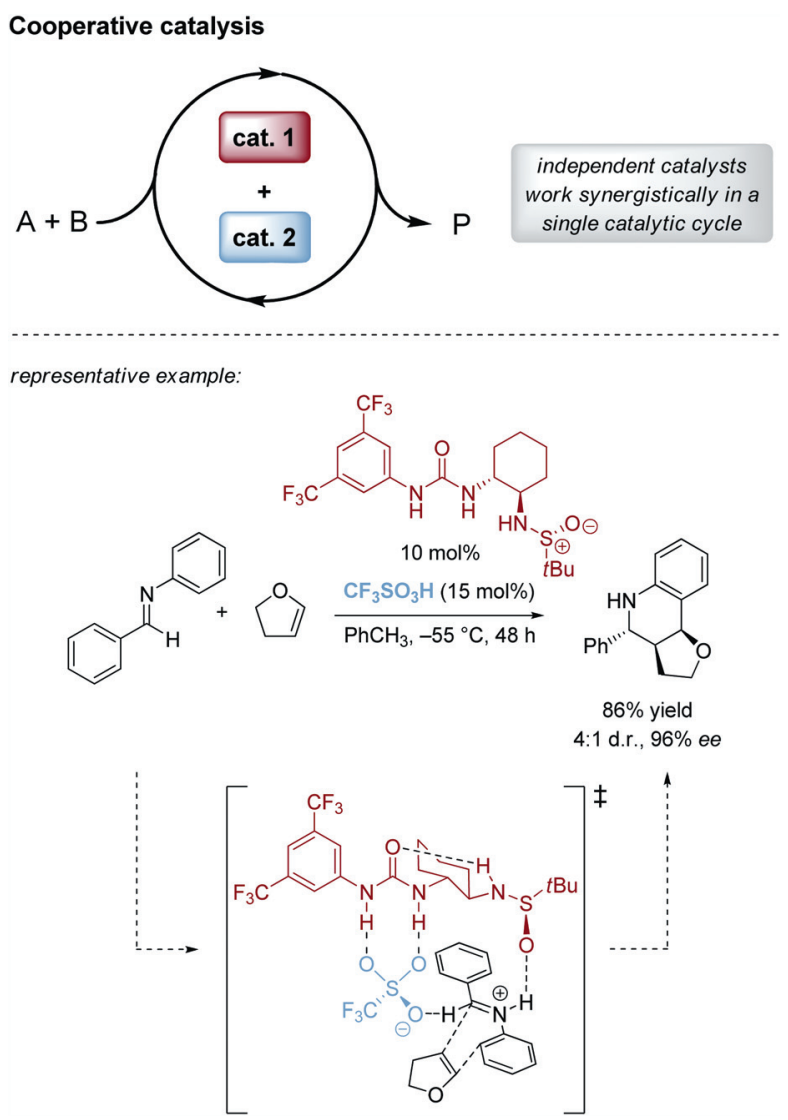

Fig. 2 The concept of cooperative catalysis taking the co-catalyzed asymmetric Povarov reaction as an example; see ref. $18 c$ and $18 d$. 


\section{Multifunctional catalyst}

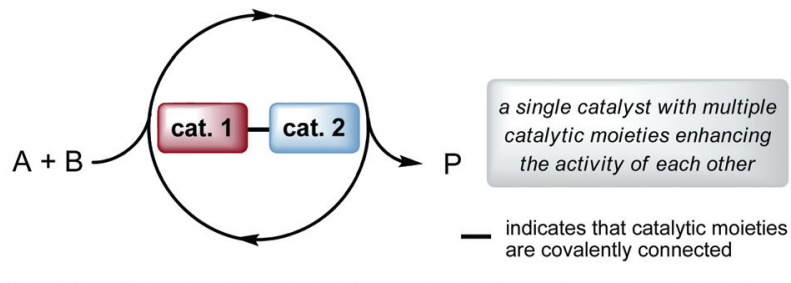

representative examples for bifunctional catalysts:

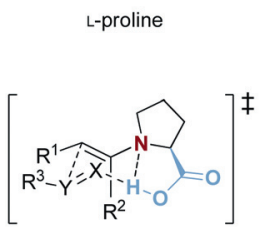

$\mathrm{R}^{1}, \mathrm{R}^{2}, \mathrm{R}^{3}=\mathrm{H}$, alkyl, aryl $\mathrm{X}=\mathrm{O}, \mathrm{NR} ; \mathrm{Y}=\mathrm{C}, \mathrm{N}, \mathrm{O}, \mathrm{S}$ $\mathrm{Nu}=$ nucleophile

Fig. 3 The concept of a multifunctional catalyst taking proline and Takemoto's catalyst as representative examples; see ref. 21 and 25.

partners (mostly a nucleophile and an electrophile). ${ }^{19}$ The types of catalysts which are able to simultaneously activate two reactants are manifold, ranging from, e.g., proline ${ }^{21}$ to cinchona alkaloid derivatives ${ }^{22,23}$ and bifunctional (thio)urea derivatives ${ }^{24}$ (such as Takemoto's catalyst; Fig. 3), ${ }^{25}$ and have proved their efficiency in a variety of reactions. ${ }^{19,21-25}$

The third type of catalysis that should be distinguished from multicatalysis is dual catalysis (Fig. 4). ${ }^{20}$ It should be mentioned that dual catalysis is inconsistently used and may lead to confusion as it is indeed used for multicatalytic reactions in some cases. Very recently, Allen and MacMillan defined synergistic catalysis as the simultaneous activation of an electrophile and a nucleophile by independent catalysts in directly coupled catalytic cycles. $^{26}$ Indeed, the same is true for dual catalysis. From our point of view synergistic catalysis is a better terminology for reactions wherein two directly coupled catalytic cycles lead to the formation of a product (see example in Fig. 4).

For clarity, the term multicatalysis should be solely used for combinations of distinct catalysts to perform consecutive reactions, whereby the starting materials (A and $\mathrm{B}$ ) react to form an intermediate (IM) in a first catalytic cycle (Fig. 5). Subsequently, this intermediate is converted to the final product $(\mathrm{P})$ by another independent catalyst (or catalytic moiety in the case of a multicatalyst) without intermittent work-up and purification procedures (Fig. 5). Based on the way of their execution, multicatalytic reactions employing two (or more) catalysts can be further categorized. For instance, the term sequential (multi)catalysis ${ }^{4,11}$ is typically used to describe multicatalytic reactions that rely on the addition of another catalyst or reagent (C, Fig. 5), or an intermittent alteration of reaction conditions (e.g., solvent, temperature) to initiate a subsequent catalytic cycle. Tandem catalysis ${ }^{4}$ or relay catalysis, ${ }^{11}$ respectively, refer to a multicatalytic reaction where the product formed in the first catalytic cycle is directly fed into a subsequent one without a change in the reaction

\section{Dual catalysis / Synergistic catalysis}
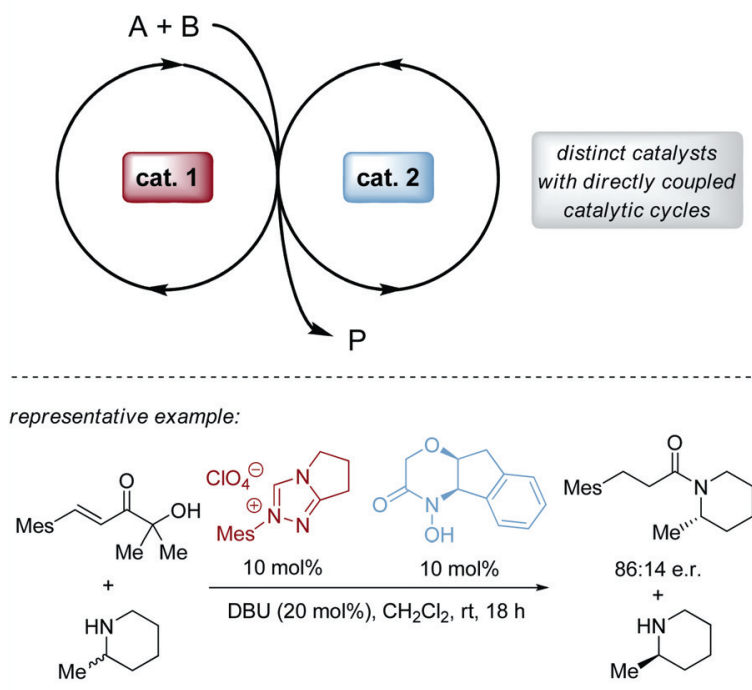

$( \pm)$

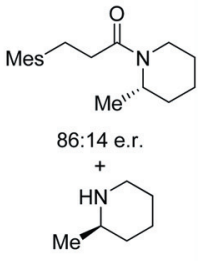

$94: 6$ e.r.

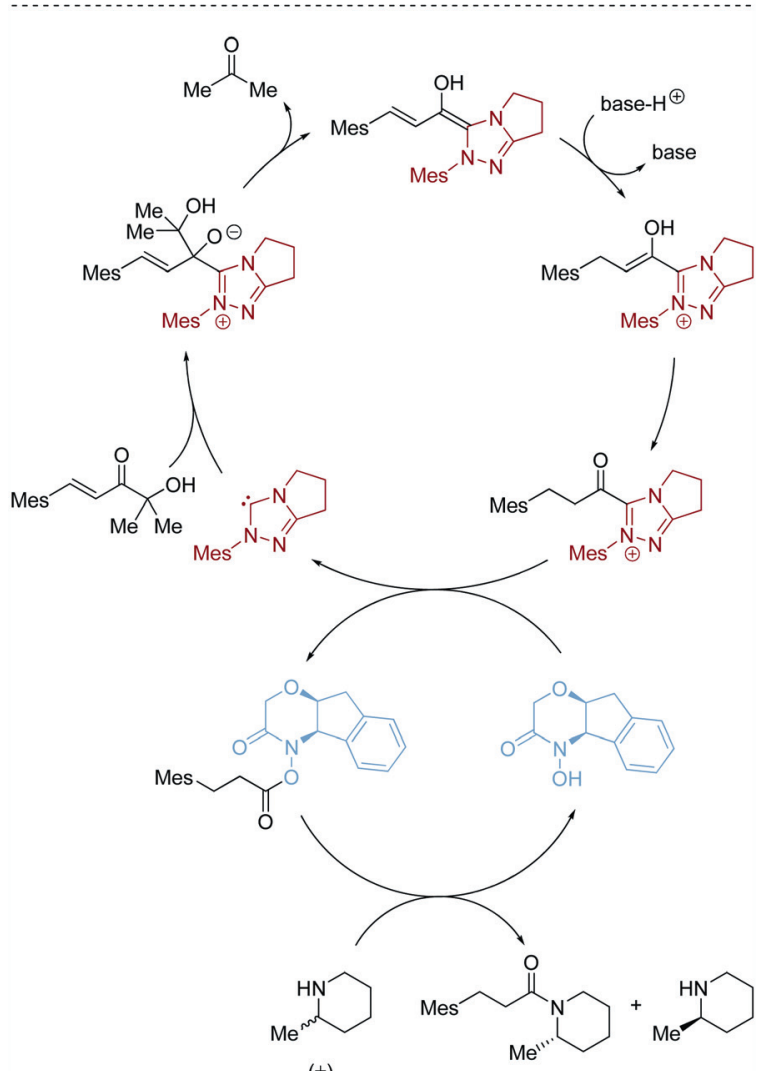

$( \pm)$

Fig. 4 The concept of dual catalysis/synergistic catalysis taking the kinetic resolution of cyclic amines as an example; see ref. 20c. DBU = 1,8-diazabicyclo[5.4.0]undec-7-ene; Mes = mesityl (2,4,6-trimethylphenyl).

conditions. Moreover, each of the employed catalysts may independently allow for domino/cascade or tandem reactions. Therefore, we recommend using the comprehensive expression organomulticatalysis for the overall reaction and more specific terms only for the distinct reactions. 


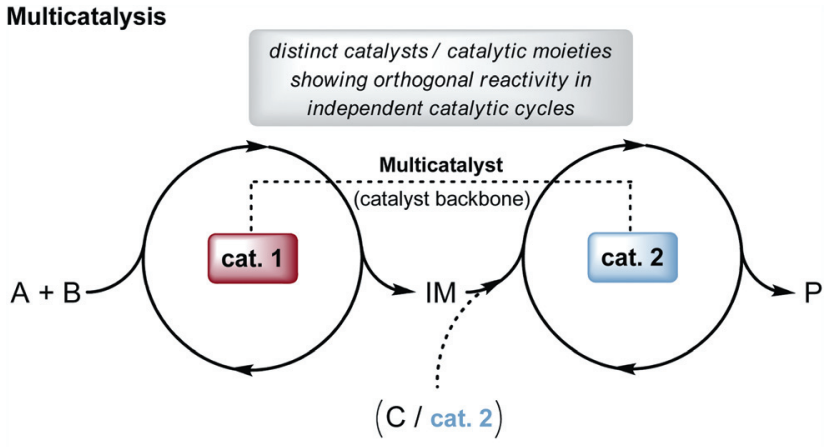

1.) Sequential multicatalysis: addition of cat. 2 , reagents, or change in reaction conditions after completion of the $1^{\text {st }}$ catalytic cycle

2.) Tandem / Relay catalysis: no change in reaction conditions required

Fig. 5 Possible types of multicatalysis.

\section{Reaction efficiency and sustainability aspects of multicatalysis}

What are the benefits of multicatalyses relative to well-established traditional synthetic strategies and domino reactions, and how do they contribute to an environmentally benign chemistry? These questions can be answered when considering multicatalysis in the context of Green Chemistry ${ }^{27-30}$ and its twelve principles, ${ }^{27,31}$ taking into account the environmental factor ( $E$ factor), ${ }^{32}$ as well as the concepts of atom economy, ${ }^{33}$ step economy, ${ }^{34}$ and redox economy ${ }^{35}$ as key parameters. ${ }^{36}$ However, the rapid increase in reaction efficiency and sustainability from the 'stop-and-go' to multicatalysis is based on some simple considerations.

Catalysis is a key to sustainability and is superior compared to the use of stoichiometric amounts of reagents. ${ }^{28}$ Organocatalysis often circumvents many of the drawbacks usually associated with transition-metal catalysis and biocatalysis. Organocatalysts are usually non-toxic, readily available (either commercially or derived from natural sources), and in many cases allow reactions under mild conditions. They are robust catalysts, e.g., tolerate air and moisture, and are compatible with a large variety of functional groups. One-pot multistep reaction sequences, whether promoted by a single organocatalyst or of multicatalytic nature, avoid costly and time-consuming intermittent work-up and purification steps, thus preventing yield losses, saving energy, time and effort, and reducing waste (indeed, most waste originates from work-up and purification procedures in the form of solvents, drying, and separation agents). As a consequence, considerably lower $E$-factors, which is the mass ratio of generated waste to desired product, can be achieved. Moreover, the mentioned functional group tolerance of organocatalysts may permit protecting-group free syntheses ${ }^{37}$ and avoid other unnecessary functional group conversions (e.g., non-strategic oxidation and reduction steps), thus leading to high $\operatorname{step}^{34}$ as well as redox economy. ${ }^{35}$ Recently, pot economy ${ }^{38}$ has been suggested with the ultimate goal of performing entire multistep syntheses in a single reaction vessel. Multicatalysis also appreciably broadens the spectrum of applicable substrates and achievable transformations when employing independent catalysts with orthogonal reactivity. Hence, it may be more easily combined with multicomponent reactions $^{6,9}$ leading to overall high atom economy, ${ }^{33}$ which is defined as the ratio of the molecular weight of desired product to the sum of molecular weights of the reactants. Equilibrium reactions can be driven to completeness, avoiding the use of excess reagents, and possible side reactions can be circumvented by direct consumption of reactive intermediates in a concurrent catalytic cycle. This is especially important in cases where potentially toxic or unstable intermediates are formed; these can be directly converted into safer or lower energy species, thus lowering the risks of transportation, storage, and handling. An additional factor for high reaction efficiency in catalysis undoubtedly is selectivity, ${ }^{39}$ namely chemo-, regio- or stereoselectivity (in cases where any other than the desired isomers can be regarded as waste). Multicatalysis may not only improve the reactivity, but lead to an amplification of stereoselectivity due to synergistic effects or to an enantioenrichment in subsequent catalytic cycles when a set of chiral catalysts is used..$^{5}$ Moreover, it provides an elegant approach to attain products with the desired stereochemistry depending on the configuration of the catalysts employed..$^{5}$

Further advantages may be offered by a multicatalyst: the close proximity of the catalytic moieties ensures higher local concentrations of the formed intermediates at the common catalyst backbone for consecutive reactions (if the reaction rates are such that each subsequent reaction is faster). This leads to an efficient feeding of the intermediates into the next catalytic cycle, therefore, improving reactivity and material balance.

This Critical Review examines and highlights the impressive developments and advances of asymmetric organocatalyzed multicatalysis (at least one chiral catalyst is used) with the focus on different organocatalyst classes. At the beginning of each chapter we will provide a short introduction in the common activation modes and reaction types discussed herein. The reactions presented are classified depending on the different catalyst classes employed and their specific activation modes. In particular, these are:

- Secondary amines - enamine/iminium activation

- $N$-heterocyclic carbenes - umpolung

- Thiourea derivatives - hydrogen bonding

- Non-natural oligopeptides - acyl transfer reactions

Wherever necessary for a better understanding we will present mechanistic details for selected transformations. We cover only enantioselective approaches; diastereoselective reactions are not included. Multicatalysis employing metal catalysts, ${ }^{1,4,11,13,40}$ multienzymatic reactions, ${ }^{41,42}$ as well as combinations of metal-, bio-, and organocatalysis ${ }^{1,4,11,42,43}$ are beyond the scope of this review and have been covered elsewhere.

\section{Secondary amine catalysts}

\section{The beginnings of organomulticatalysis - merging iminium and enamine catalysis}

Chiral secondary amines are commonly employed as organocatalysts as these are in most cases readily available and show remarkable performance in a variety of carbonyl functionalizations via iminium ion (LUMO lowering) and enamine (HOMO raising) catalysis. ${ }^{44}$ Both activation modes have been elegantly combined in asymmetric domino reactions, which now constitute possibly one of the most applied one-pot multistep approaches in organocatalysis. $^{7,44 e}$ This strategy is outlined in Fig. 6: an 

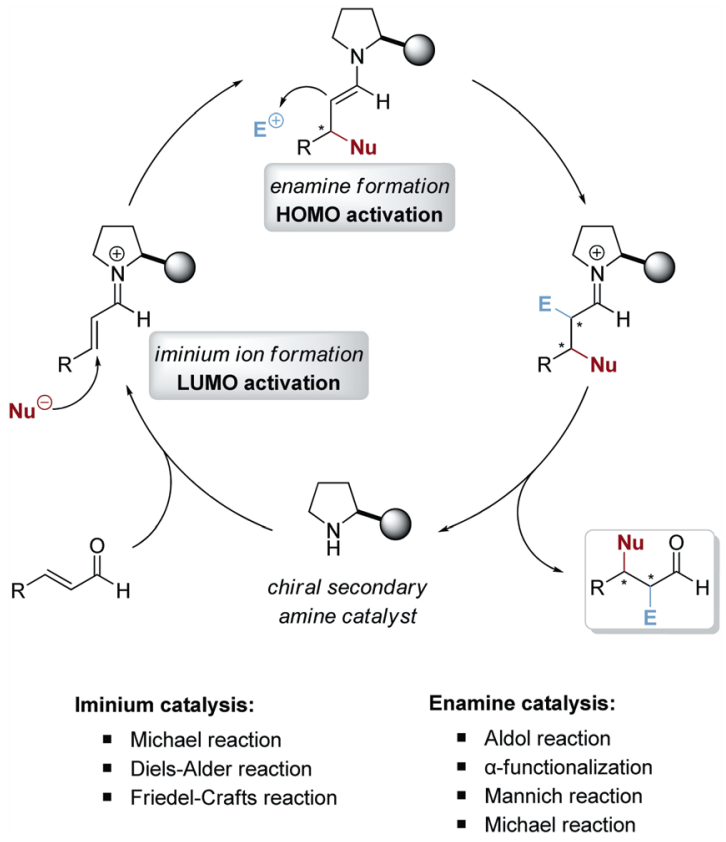

Fig. 6 Simplified general mechanism for a secondary amine catalyzed domino reaction and prevalent reaction types. $\mathrm{R}=$ alkyl, aryl; $\mathrm{Nu}=$ nucleophile; $\mathrm{E}=$ electrophile.

$\alpha, \beta$-unsaturated aldehyde (or ketone) is activated by a secondary amine catalyst, reversibly forming an iminium ion that is able to undergo a conjugate addition of a nucleophile $(\mathrm{Nu})$. The enamine intermediate formed as a result of the first reaction step enables a consecutive reaction with an electrophile (E) to afford the $\alpha, \beta$-disubstituted aldehyde usually containing two newly formed stereogenic centers.

The way to secondary amine-catalyzed multicatalytic reactions was paved by MacMillan et al. in 2005, as they realized that two discrete imidazolidinones, $\mathbf{1}$ and $\mathbf{2}$, respectively, can be combined to enforce cycle-specific selectivities (Scheme 1). ${ }^{45}$ To the best of our knowledge this was the earliest example of asymmetric multicatalysis employing two chiral organocatalysts. The transfer hydrogenation reaction ${ }^{46}$ with Hantzsch ester $\mathbf{3}$ as organic hydride source in conjunction with direct $\alpha$-fluorination using $N$-fluorodibenzenesulfonamide (NFSI; 4) as electrophile allowed the formal asymmetric addition of HF across $\beta$-methylcinnamaldehyde (5; Scheme 1). This multicatalytic reaction sequence showed for the first time one of the advantages of the multicatalysis approach, namely the easy modulation to provide the required diastereo- and enantioselectivity via the judicious choice of the enantiomeric forms of the secondary amine catalysts. For example, catalyst combination A, with iminium catalyst (5R)-1 and enamine catalyst (2S)-2, gives access to the antidiastereomer 6 in $16: 1$ d.r. with $99 \%$ ee. Employing catalyst combination $\mathrm{B}$, with enamine catalyst $(2 R)-2$, provides a direct entry to the syn-addition product epi-6 in 9:1 d.r. and $99 \%$ ee, respectively (Scheme 1). When (5R)-1 was used for both iminium and enamine activation the syn-addition product epi-6 was obtained with a diminished diastereomeric ratio of $3: 1$ (Scheme 1). ${ }^{45}$ This result clearly demonstrates that multicatalysis may not only allow controlling the diastereo- and
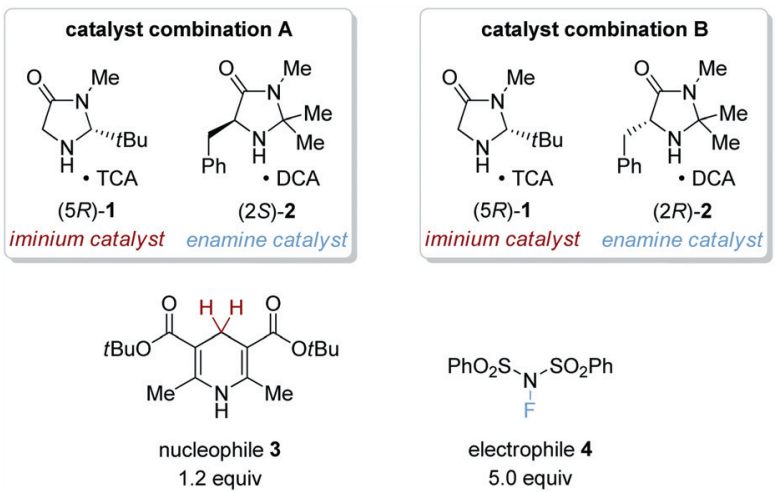

$$
\begin{gathered}
\mathrm{PhO}_{2} \mathrm{~S}_{-} \mathrm{N}^{-} \mathrm{SO}_{2} \mathrm{Ph} \\
\mathrm{F} \\
\text { electrophile } 4 \\
5.0 \text { equiv }
\end{gathered}
$$

\section{Catalyst combination A:}
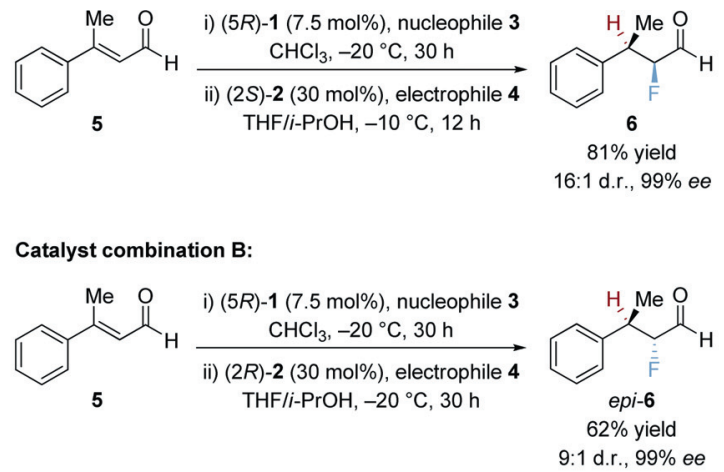

Single catalyst promoted reaction:

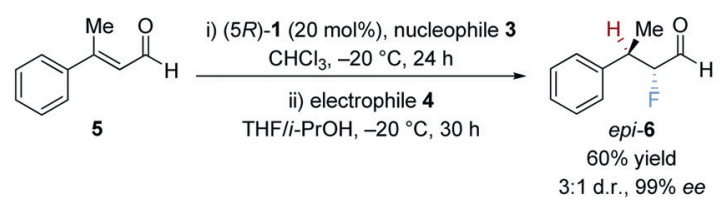

Scheme 1 Cycle-specific catalysis for the transfer hydrogenation/ $\alpha$-fluorination of $\beta$-methylcinnamaldehyde (5). TCA $=$ trichloroacetic acid; DCA = dichloroacetic acid.

enantioselectivity of the final product it may also significantly enhance stereoinduction.

Soon after MacMillan et al.'s pioneering work ${ }^{45}$ related reactions comprising the sequential iminium-enamine activation by distinct secondary amines have been published. For example, a similar procedure for a reductive Mannich-type reaction was reported by Córdova et al. (Scheme 2). ${ }^{47}$ Instead of imidazolidinone (5R)-1 used by MacMillan, they applied the JørgensenHayashi catalyst ${ }^{48}((S)-7$; TMS $=$ trimethylsilyl $)$ with benzoic acid as co-catalyst, which proved to be more reactive in the transfer hydrogenation step under the applied conditions. The reactions gave the corresponding amino acid derivatives, such as $\mathbf{1 2}$, in good yields and excellent stereoselectivities using Hantzsch ester 9, para-methoxyphenyl (PMP)-protected $\alpha$-iminoglyoxylate (10), $\alpha, \beta$-unsaturated aldehyde 11, and $(S)-7$ as catalyst for both reaction steps (Scheme 2). By analogy to the reactions reported by MacMillan et al. ${ }^{45}$ the sequential addition of Dproline $((R)-\mathbf{8})$ and electrophile $\mathbf{1 0}$ in the second reaction step altered the diastereoselectivity: the syn-product epi-12 was obtained instead of the anti-isomer 12, albeit with significantly diminished selectivity (5:1 instead of $50: 1$ d.r.; Scheme 2$)$. 


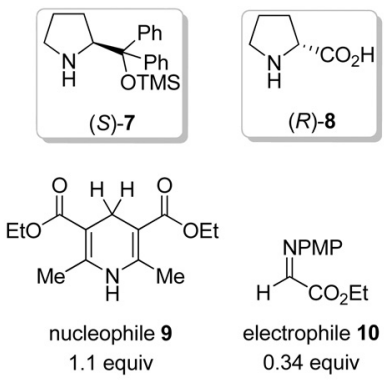

Single catalyst promoted reaction:

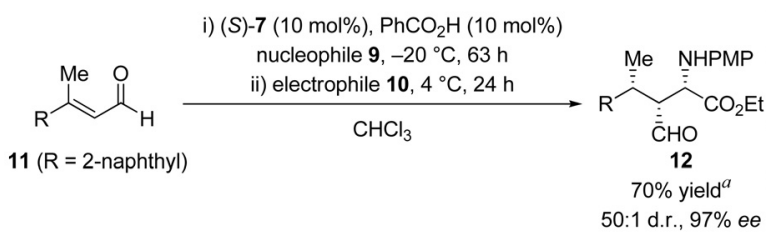

Multicatalysis approach:

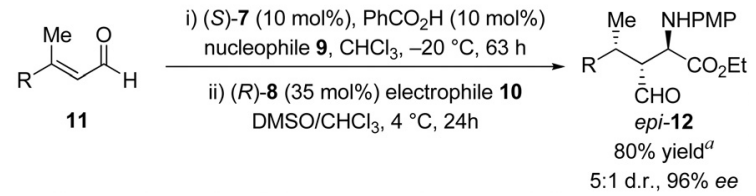

Scheme 2 Enantioselective reductive Mannich-type reaction reported by Córdova. ${ }^{a}$ Yield of isolated product based on $N$-PMP-protected $\alpha$-iminoglyoxylate (10).
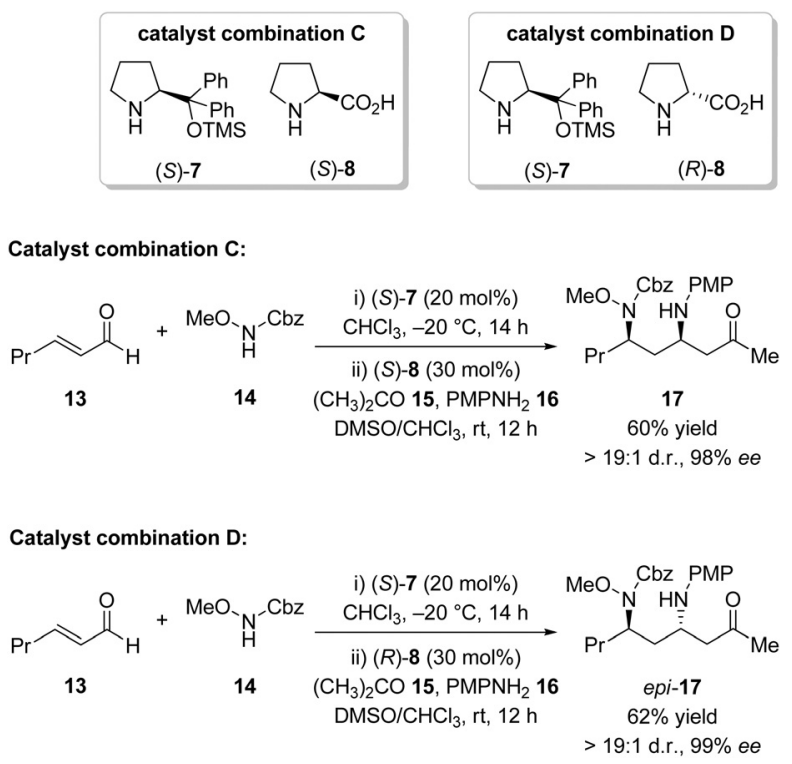

Scheme 3 Aza-Michael/Mannich reaction cascade for the synthesis of orthogonally protected diamine derivatives.

Later, the same group reported the cycle-specific four-component reaction of $(E)$-hex-2-enal (13), benzyl methoxycarbamate $(\mathbf{1 4} ; \mathrm{Cbz}=$ benzyloxycarbonyl), acetone (15) and paraanisidine (16) under multicatalysis conditions, which gives direct access to the chiral, orthogonally protected diamine derivatives 17 and epi-17 through an asymmetric aza-Michael/Mannich reaction cascade catalyzed by $(S)-\mathbf{7}$, and $(S)-\mathbf{8}$ or $(R)-\mathbf{8}$
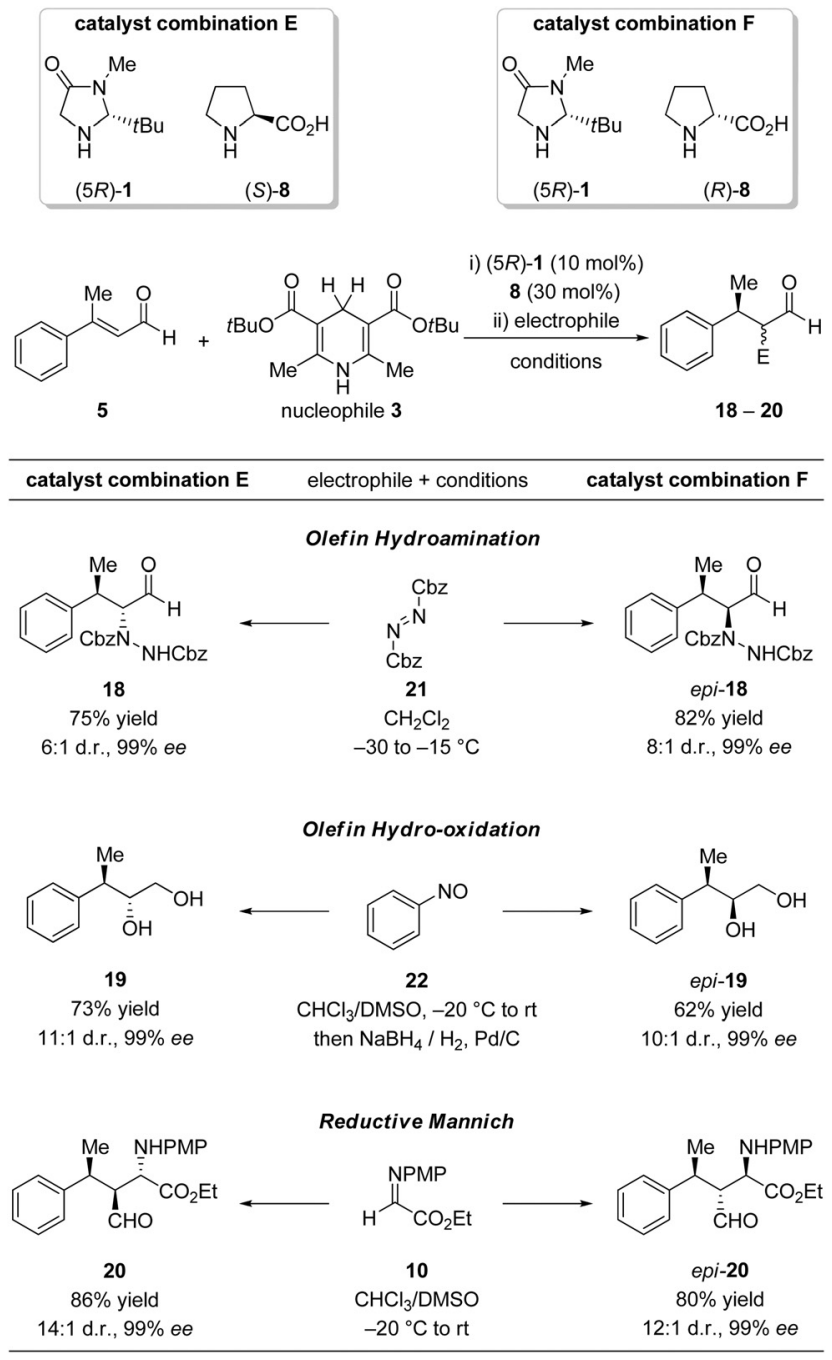

Scheme 4 Cycle-specific reaction cascades employing Hantzsch ester $\mathbf{3}$ as hydride nucleophile and different electrophiles. (5R)-1 was used as its corresponding TCA salt. $\mathrm{E}=$ electrophile.

(Scheme 3). ${ }^{49}$ The subsequent $(S)-8$ catalyzed Mannich reaction thereby kinetically resolved the $\beta$-amino aldehyde intermediate ( $96 \%$ ee) to give the diamine products 17 with $98 \%$ ee (for catalyst combination C) and epi-17 with $99 \%$ ee (for catalyst combination D), respectively, in good yields and high diastereomeric ratios (>19: 1 d.r. in both cases).

In order to expand their cycle-specific multicatalysis approach to a variety of other transformations, MacMillan and co-workers investigated imidazolidinones $(5 R)-\mathbf{1}$ and $(2 S, 5 S)-\mathbf{2 3}$ as iminium catalysts and either $(S)-\mathbf{8}$ or $(R)-\mathbf{8}$ as enamine catalyst (Schemes 4 and 5$).{ }^{50}$ While imidazolidinones are principally able to serve as iminium and enamine catalysts, they are not capable of participating in bifunctional enamine catalysis (in which activation of the electrophile is performed by the same amine catalyst). In contrast, bifunctional activation is a standard mode of activation for proline $\mathbf{8}$ (due to its acid functionality; compare Fig. 3), ${ }^{21}$ but this catalyst is generally ineffective as iminium catalyst particularly with enals or enones. Owing to this orthogonal reactivity, the combination of $(5 R)-\mathbf{1}$ or $(2 S, 5 S)-\mathbf{2 3}$ with $\mathbf{8}$ enabled a 

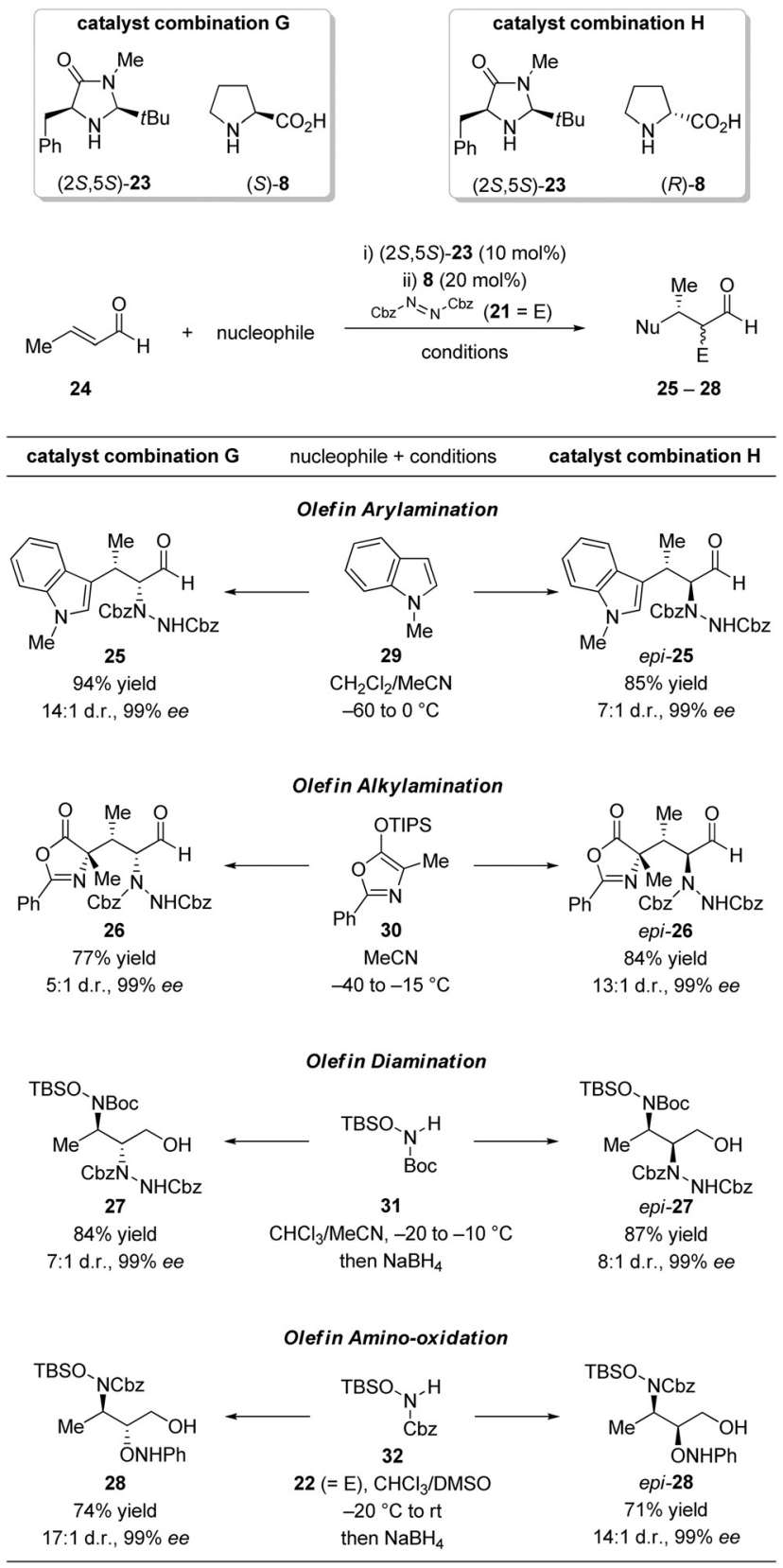

Scheme 5 Cycle-specific reaction cascades employing dibenzylazodicarboxylate (21) or nitrosobenzene (22) as electrophiles and different nucleophiles. $(2 S, 5 S)-\mathbf{2 3}$ was used as its corresponding TCA or TFA salt. $\mathrm{E}=$ electrophile; $\mathrm{Nu}=$ nucleophile.

broader spectrum of valuable transformations by using different electrophiles (Scheme 4) and nucleophiles (Scheme 5). ${ }^{50}$ For example, a combination of $(5 R)-\mathbf{1}$ and $(S)-\mathbf{8}$ as catalysts (catalyst combination E), $\beta$-methylcinnamaldehyde (5), Hantzsch ester 3 as nucleophile and dibenzylazodicarboxylate (21) as azaMichael acceptor afforded the desired hydro-amination product 18 (6:1 anti/syn, 99\% ee). As expected, the combination of $(5 R)-\mathbf{1}$ and $(R)-\mathbf{8}$ (catalyst combination $\mathrm{F}$ ) led to an inversion in diastereoselectivity furnishing epi-18 (8:1 syn/anti, 99\% ee). Employing nitrosobenzene $\mathbf{2 2}$ as electrophile provided the hydro-oxidation products 19 (11:1 anti/syn, and 99\% ee with catalyst combination E) and epi-19 (10:1 syn/anti and 99\% ee with catalyst combination F). Moreover, a reductive Mannich reaction cascade, similar to the one reported by Córdova \& Zhao $^{47}$ (compare Scheme 2) using $N$-PMP-protected $\alpha$-iminoglyoxylate (10) as electrophile could be realized. The corresponding products were obtained in high yields, diastereomeric ratios and excellent enantiomeric excess (20: $14: 1$ d.r., 99\% ee; epi-20: $80 \%$ yield, $12: 1$ d.r., $99 \%$ ee).

The same methodology was applicable for a variety of nucleophiles, using a combination of imidazolidinone $(2 S, 5 S)-\mathbf{2 3}$ and both enantiomeric forms of proline $\mathbf{8}$ as catalysts, crotonaldehyde (24) as enal substrate and dibenzylazodicarboxylate (21) as electrophilic reagent (Scheme 5). ${ }^{50}$ With 1-methylindole (29) as $\pi$-nucleophile, the corresponding arylamination products were obtained (25: $14: 1$ syn/anti, 99\% ee with catalyst combination G; epi-25: $7: 1$ anti/syn, 99\% ee with catalyst combination H). An alkylamination reaction cascade with silyloxyoxazole $\mathbf{3 0}$ (TIPS $=$ triisopropylsilyl) as nucleophile afforded the desired product 26 with three contiguous stereogenic centers $(5: 1$ d.r. and $99 \%$ ee) for catalyst combination G, whereas catalyst combination $\mathrm{H}$ gave the corresponding anti-isomer epi-26 (13:1 d.r., $99 \%$ ee). The cycle-specific reaction was also applicable to olefin diamination and amino-oxidation reactions. Employing $N$-Boc-protected silyloxycarbamate $(\mathbf{3 1}$; Boc $=$ tert-butyloxycarbonyl, TBS = tert-butyl dimethylsilyl) in conjunction with dibenzylazodicarboxylate (21) afforded the diamination products 27 (7: 1 anti/syn, 99\% ee with catalyst combination G) and epi27 (8:1 syn/anti, $99 \%$ ee with catalyst combination H). A related Cbz-protected amine nucleophile $\mathbf{3 2}$ and nitrosobenzene (22) as electrophile formed the amino-oxidation products with excellent diastereo- and enantioselectivities (catalyst combination G for 28: $17: 1$ anti/syn, $99 \%$ ee; catalyst combination $\mathrm{H}$ for epi28: 14 : 1 syn/anti, $99 \%$ ee).

In order to further demonstrate its viability, MacMillan et al. applied their multicatalysis system in combination with a metalcatalyzed olefin cross-metathesis to a triple cascade reaction for the synthesis of an intermediate of the natural product (-)-aromadendranediol ${ }^{51} 38$ (Scheme 6). Thus, the use of Grubbs' second generation catalyst 33, 5-hexene-2-one (34) and crotonaldehyde (24) allowed the formation of ketoenal 35 in the first step. The sequential addition of imidazolidinone catalyst $(2 S, 5 S)-\mathbf{2 3}$ and silyloxyfuranyl $\mathbf{3 6}$ as nucleophile led to the formation of intermediate $\mathbf{3 7}$ through an iminium-activated Mukaiyama-Michael reaction. Upon addition of $(S)-\mathbf{8}$ as enamine-catalyst, intermediate $\mathbf{3 7}$ underwent a diastereoselective intramolecular aldol reaction furnishing the complex key intermediate 38 ( $64 \%$ yield, $5: 1$ d.r., $95 \%$ ee), which already contains four of the six required stereogenic centers and 12 of the 15 necessary carbon atoms. The synthesis of (-)-aromadendranediol (39) could then be accomplished in eight further linear steps with $40 \%$ overall yield (starting from $\mathbf{3 8}$ ). For comparison, a previously reported synthesis starting from enantiomerically pure (+)-spathulenol afforded (-)-aromadendranediol (39) in only $13 \%$ total yield over three steps. ${ }^{51 a}$ Although we will exclusively focus on organocatalyzed reactions in the following, we show this example because it beautifully demonstrates the applicability of organomulticatalysis in the total synthesis of complex natural products.

Note that although Hantzsch esters (as well as analogues thereof and, e.g., benzothiazolines or benzoimidazolines) suffer 

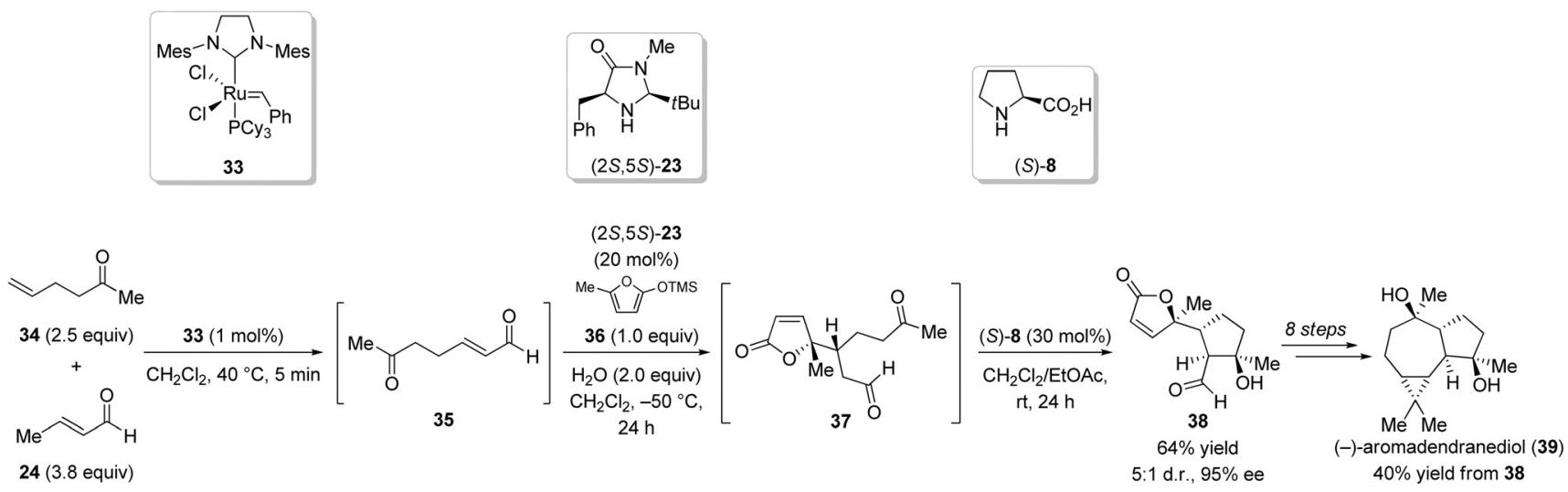

Scheme 6 Multicatalysis approach for the preparation of key intermediate $\mathbf{3 8}$ in the total synthesis of the natural product (-)-aromadendranediol (39). Catalyst $(2 S, 5 S)$-23 was used as its corresponding 2,4-dinitrobenzoic acid salt. Cy = cyclohexyl; Mes = mesityl $(2,4,6$-trimethylphenyl).
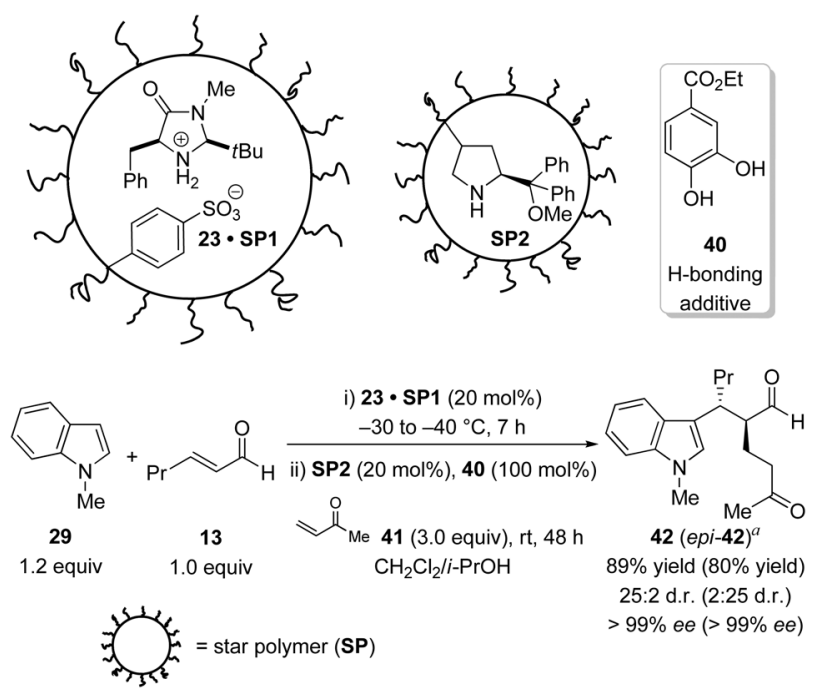

Scheme 7 Combination of iminium, enamine and H-bonding catalysis using non-interpenetrating starpolymer catalysts $(2 S, 5 S)-\mathbf{2 3} \cdot \mathbf{S P 1}$ and SP2 for the one-pot synthesis of indole derivative 42. ${ }^{a}$ Values in parentheses indicate reaction using $(2 R, 5 R)-\mathbf{2 3}$ as iminium catalyst.

from poor atom economy they are the hydride source of choice in organocatalysis. ${ }^{46}$ Metal-free transfer hydrogenations with Hantzsch esters proceed under mild reaction conditions and are compatible with various functional groups, making them ideal for domino, tandem, and multicatalytic reactions. ${ }^{46}$

In 2008, Fréchet and co-workers reported the combination of non-interpenetrating star polymers SP1 and SP2 with coreconfined catalysts, and hydrogen bonding additive $\mathbf{4 0}$ (Scheme 7). ${ }^{52}$ This site-isolation approach allowed the use of otherwise incompatible catalysts, circumventing undesired catalyst interactions. Indeed, small molecule reagents are able to freely diffuse to the core of the star polymers, allowing catalysis to take place. For example, the addition of imidazolidinone $(2 S, 5 S)-\mathbf{2 3}$ to star polymer $\mathbf{S P 1}$ resulted in the formation of salt $(2 S, 5 S)-\mathbf{2 3} \cdot \mathbf{S P 1}$, which acts as iminium catalyst, thus enabling the conjugate addition of 1-methylindole (29) to $(E)$-hex-2-enal (13). Addition of SP2, methylvinyl ketone (41) and 40 (which was expected to activate the relatively unreactive Michael
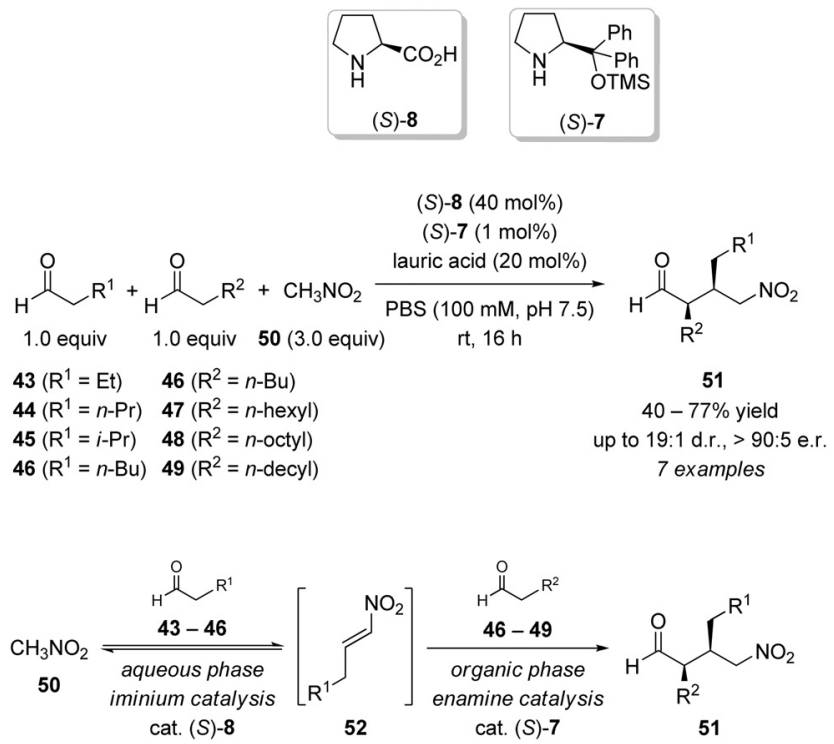

Scheme 8 Biphasic polarity-directed reaction in aqueous buffer employing two aldehydes with similar reactivity but different polarity.

acceptor 41) afforded the desired indole derivative $\mathbf{4 2}$ with high yield and excellent stereoselectivity (89\% yield, $25: 2$ d.r., $>99 \%$ ee) through the second Michael reaction. When star polymer SP1 was replaced with para-toluenesulfonic acid and/or SP2 with the analogues free secondary amine catalyst no desired product was observed. Only traces of product formed when linear polymer analogues of SP1 and SP2 were used. Additionally, the use of $(2 R, 5 R)-23$ as iminium catalyst afforded the other diastereomer epi-42 (80\% yield, $2: 25$ d.r., $>99 \%$ ee) similar to the aforementioned examples.

Later, the same group reported a multicatalysis reaction in aqueous buffer, enabling the polarity-directed chemoselective formation of desired cross-cascade products. ${ }^{53}$ Employing $(S)-8$ and $(S)-7$ as catalysts, this biphasic reaction allowed the differentiation of two aldehydes with similar chemical reactivity based on their different polarity to form a major cross-cascade product 51 (Scheme 8). Preliminary studies indicated that the success of this reaction is based on some special requirements. Hence, the 
first amine catalyst $(S)-\mathbf{8}$, dissolves well in the aqueous phase, but poor in organic solvents. The other amine catalyst $(S)-7$, in conjunction with lauric acid as hydrophobic acid co-catalyst, shows a greater miscibility with the organic phase rather than water (even slightly water-miscible organic acids turned out to be problematic because they lower the $\mathrm{pH}$ of the aqueous phase and therefore slow down the condensation reaction). Moreover, $(S)-\mathbf{8}$ is an efficient catalyst for the condensation reaction, but a poor catalyst for the conjugate addition under aqueous conditions. In sharp contrast, diphenylprolinol $(S)-7$ is inefficient in the condensation reaction, but an efficient and highly enantioselective catalyst for the conjugate addition of aldehydes to nitroalkenes. On the basis of these requirements, Fréchet and coworkers succeeded in the development of a biphasic reaction facilitating the selective activation of the two aldehydes. In aqueous phase, the use of a large amount of $(S)-8$ (40 mol\%, respectively) efficiently catalyzes the reversible condensation of the less hydrophobic aldehydes $\mathbf{4 3 - 4 6}\left(\mathrm{R}^{1}=\mathrm{Et}\right.$, n-Pr, i-Pr, n-Bu) and nitromethane (50). In the organic phase, the use of only $1 \mathrm{~mol} \%$ of catalyst $(S)-7$ slows down the addition reaction, so that the aldehydes $43-46$ are readily consumed in the condensation step, suppressing the addition of the more hydrophobic aldehydes 46-49 $\left(\mathrm{R}^{2}=\mathrm{n}\right.$-Bu, n-hexyl, n-octyl, n-decyl) to the nitroalkene intermediate $\mathbf{5 2}$, thus avoiding the formation of undesired by-products. Consequently, the aldehydes 46-49 survive the condensation step and react with the nitroalkene intermediate $\mathbf{5 2}$ in the organic phase to give exclusively 51. Indeed, only traces of by-products could be detected. This approach sheds light on the cycle-specific activation of reagents as well as intermediates based on physical (polarity) rather than chemical properties.

Contrary to the above examples, Moreau and Greck envisaged a multicatalytic reaction comprising two consecutive enamine cycles, based on two previously developed reactions, a Michael addition of aldehydes to $\beta$-nitrostyrene $(\mathbf{5 5})^{48 b}$ and a Michael addition/ $\alpha$-amination cascade reaction, ${ }^{54}$ respectively (Scheme 9 and Table 1). ${ }^{55}$ Indeed, the combination of $(S)-7$ and 9 -amino(9deoxy)-epi-cinchonine (53; $5 \mathrm{~mol} \%$ for both), propionaldehyde (54), nitrostyrene (55), and electrophilic dibenzylazodicarboxylate (21) afforded the desired $\alpha$-hydrazino aldehyde 57 a $(80 \%$ yield, $>95: 5$ d.r., $96 \%$ ee). When both reactions were performed independently, $10 \mathrm{~mol} \%$ of 7 and a tenfold excess of aldehyde 54 (instead of 1.2 equivalents) were necessary to afford the intermittent Michael addition product 56 (82\% yield, $95: 5$ d.r.) in the first reaction (Scheme 9). The second reaction, using the previously reported conditions ${ }^{54}(20 \mathrm{~mol} \% \mathbf{5 3}, 30 \mathrm{~mol} \%$ TFA, 1.5 equivalents of 21), gave the expected product 57a in $80 \%$ yield (66\% yield overall) and in $>95: 5$ d.r. Various other nitroalkenes $\mathbf{5 8}$ bearing electron-rich (57b and $\mathbf{5 7}$; Table 1, entries 2 and 3 ) and electron-deficient aryl groups (57d-57h; entries 4-8) with different substitution pattern (i.e., para- or meta-substituted) could be used under the optimized conditions, affording the corresponding products $\mathbf{5 7}$ as a single diastereomer with good yields (73-85\%) and high enantioselectivities (96-98\% ee).

Very recently, the combination of Jørgensen's TMS-protected diarylprolinol $(S)-\mathbf{5 9}^{56}$ and $(S)-\mathbf{8}$ was reported by the group of Díez to participate in the sequential Michael/Morita-BaylisHillman with concomitant Knoevenagel condensation reaction cascade of Nazarov reagent $\mathbf{6 0}$ with $\alpha, \beta$-unsaturated aldehydes

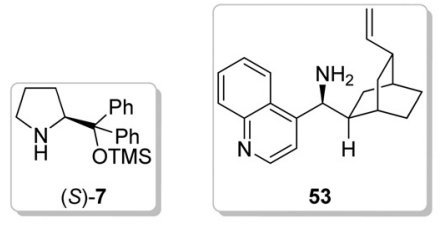

Sequential single step reactions:
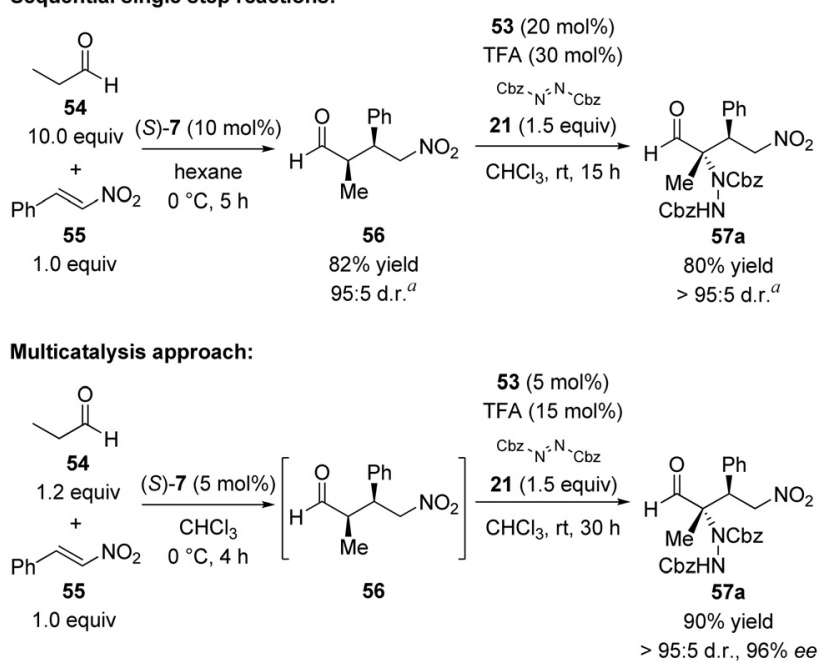

Scheme 9 Comparison of the sequential preparation and the one-pot multicatalytic synthesis of product 57a. ${ }^{a}$ No enantiomeric excess given.

Table 1 Michael addition/ $\alpha$-amination reaction sequence through double enamine activation. Table corresponds to Scheme 9

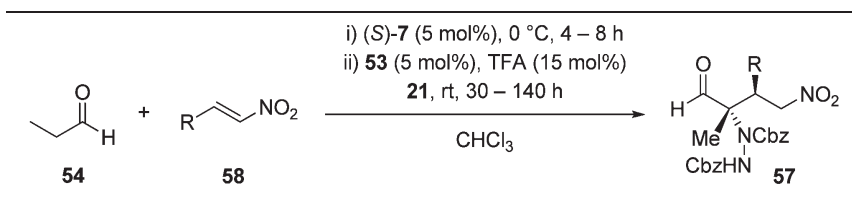

\begin{tabular}{lllll}
\hline Entry & $\mathrm{R}$ & Product & Yield [\%] & ee [\%] \\
\hline 1 & $\mathrm{Ph}$ & $\mathbf{5 7 a}$ & 90 & 96 \\
2 & 1-naphthyl & $\mathbf{5 7 b}$ & 73 & 96 \\
3 & 4-MePh & $\mathbf{5 7 c}$ & 85 & 96 \\
4 & $4-\mathrm{MeOPh}$ & $\mathbf{5 7 d}$ & 85 & 97 \\
5 & 4-ClPh & $\mathbf{5 7 e}$ & 85 & 98 \\
6 & 4-FPh & $\mathbf{5 7 f}$ & 81 & 97 \\
7 & 3-ClPh & $\mathbf{5 7 g}$ & 85 & 98 \\
$8^{a}$ & 3-MeOPh & $\mathbf{5 7 h}$ & 76 & \\
$a$ & & & \\
\end{tabular}

leading to 2-alkylidene cyclohexanones $\mathbf{6 5}$ (Scheme 10). ${ }^{57}$ The success of the reaction was based on the combination of the two amine catalysts $(S)-\mathbf{5 9}$ and $(S)-\mathbf{8}$. For example, using only $(S)-\mathbf{5 9}$ gave the Michael addition product as a mixture of diastereomers (syn/anti 1:1), but did not afford any cyclization product. The same was observed when $(S)-7$ was used as catalyst; with MacMillan's imidazolidinone $(2 S, 5 S)$-23 only starting material could be detected. When $(S)-\mathbf{8}$ was applied for the total reaction the desired products $\mathbf{6 5}$ formed with reasonable diastereomeric ratio $(E / Z=2: 1)$ and yields, but no enantioselectivity could be achieved under these conditions. In contrast, the conjugate 

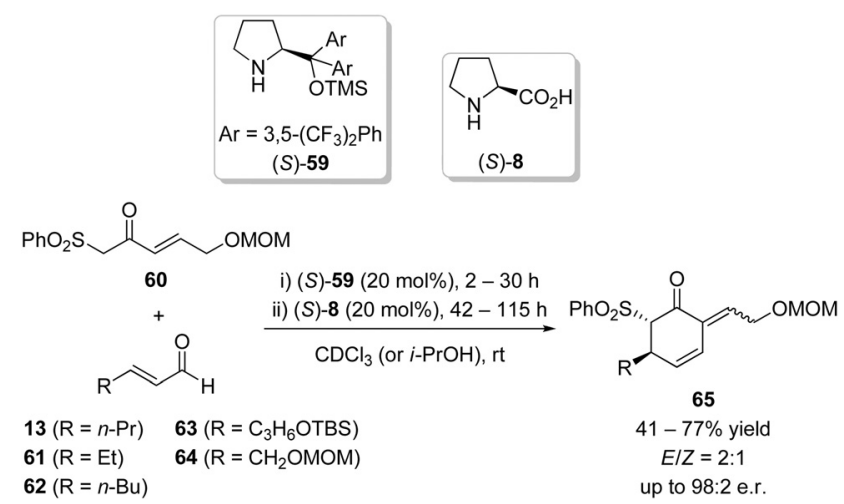

Scheme 10 Michael/Morita-Baylis-Hillman/Knoevenagel condensation reaction sequence for the preparation of 2-alkylidene cyclohexanones 65. MOM = methoxymethyl.

addition reaction of $\mathbf{6 0}$ with $\alpha, \beta$-unsaturated aldehydes $\mathbf{1 3}$ and 61-64 catalyzed by $(S)$-59 and sequential addition of $(S)-\mathbf{8}$ after consumption of the starting material afforded the cyclized products $65(E / Z=2: 1$ in all cases) with moderate to good yields and high enantiomeric ratios ( $41-77 \%$ yield; up to $98: 2$ e.r.). However, the reaction did not proceed with aryl aldehydes. ${ }^{57}$

As the scope of secondary amines is limited to carbonyl compounds the combination of these catalysts with other organocatalysts is highly desirable to provide a way to reactions otherwise not attainable.

\section{Combinations of secondary amine catalysts with Brønsted acids and bases}

During the last few years, the group of Ramachary reported a variety of multicatalytic approaches based on the sequential combination of multicomponent reactions and multicatalysis providing direct excess to a variety of valuable compounds (most of them being achiral), such as agrochemicals, fine chemicals, as well as pharmaceutical drugs, drug intermediates, and building blocks for the synthesis of natural products. ${ }^{58}$ However, as already mentioned above we focus on asymmetric organocatalyzed variants here.

After the successful demonstration of the one-pot asymmetric syntheses of the Wieland-Miescher ${ }^{59}$ and Hajos-Parrish ${ }^{60}$ ketones and their analogues via a three-component reductive alkylation and Robinson annulation, ${ }^{61,62}$ Ramachary \& Sakthidevi investigated the one-pot asymmetric synthesis of the corresponding hydrogenated derivatives by combining three components and four catalysts, triethylamine, $(S)$-8, perchloric acid, and (S)-1-(2-pyrrolidinylmethyl)pyrrolidine (66), respectively (Scheme 11). ${ }^{63}$ Therefore, they suggested a triethylaminecatalyzed regioselective Michael reaction of diketones 67 and methylvinyl ketone (41) followed by a Robinson annulation of intermediate Michael adducts 68 through amino acid/Brønsted acid catalysis furnishing the chiral Wieland-Miescher and Hajos-Parrish ketones $69(n=1,2)$. Final iminium activated stereoselective hydrogenation of the respective intermediates 69 with Hantzsch ester 9 and diamine catalyst $\mathbf{6 6}$ would then lead to hydrogenated Hajos-Parrish ketone 70a or Wieland-Miescher ketone 70b. Indeed, the sequential combination of $\mathbf{6 7}$ and $\mathbf{4 1}$ with Hantzsch ester $\mathbf{9}$ and catalytic amounts of triethylamine, (S)-8, perchloric acid, and $\mathbf{6 6}$ afforded the hydrogenated Wieland-Miescher ketone $\mathbf{7 0 b}$ in $45 \%$ yield with $>99 \%$ d.r. and $75 \%$ ee. However, the hydrogenated Hajos-Parrish ketone 70a was obtained in $45 \%$ yield and $>99 \%$ d.r., but only $20 \%$ ee (the corresponding $(S)-\mathbf{8}$ catalyzed two-component reaction affords the intermediate Hajos-Parrish ketone $(\mathbf{6 9}, n=1)$ with $86 \%$ ee).$^{62}$ This was proposed to be because of the involvement of triethylamine in the transition state of the $(S)-\mathbf{8}$ promoted intramolecular aldol reaction. ${ }^{63}$

Another multicatalysis reaction was reported by the same group, combining amino catalysis and Brønsted acid catalysis for the synthesis of a chiral chromane $\mathbf{7 6}$ (Scheme 12). ${ }^{64}$ The trans4-hydroxy-L-proline (71) catalyzed reaction of acetone (15) and 2-hydroxybenzaldehyde (73) via Barbas-List aldol reaction gave intermediate $\mathbf{7 4}$ which is in a fast dynamic equilibrium with its lactol form 75. Subsequent treatment with para-toluenesulfonic acid ( $p$-TSA; 72) in methanol selectively afforded the chiral trans-2-methoxy-2-methylchroman-4-ol (76) in 55\% yield with $>95 \%$ de and $77 \%$ ee (Scheme 12). ${ }^{64}$

An impressive example of stereocontrol was reported by Jørgensen et al. employing (S)-7 and piperidine (77) as catalysts for the formation of complex chiral bicyclo[3.3.1]non-2-enes 80, starting from simple $\alpha, \beta$-unsaturated aldehydes $\mathbf{7 8}$ and dimethyl 3-oxopentanedioate (79; Table 2). ${ }^{65}$ Four new carbon-carbon bonds formed, affording the desired product 80 bearing six stereogenic centers with excellent diastereo- and enantioselectivity (up to $>99: 1$ d.r. and $96 \%$ ee) out of 64 theoretically possible stereoisomers. Jørgensen and co-workers proposed the

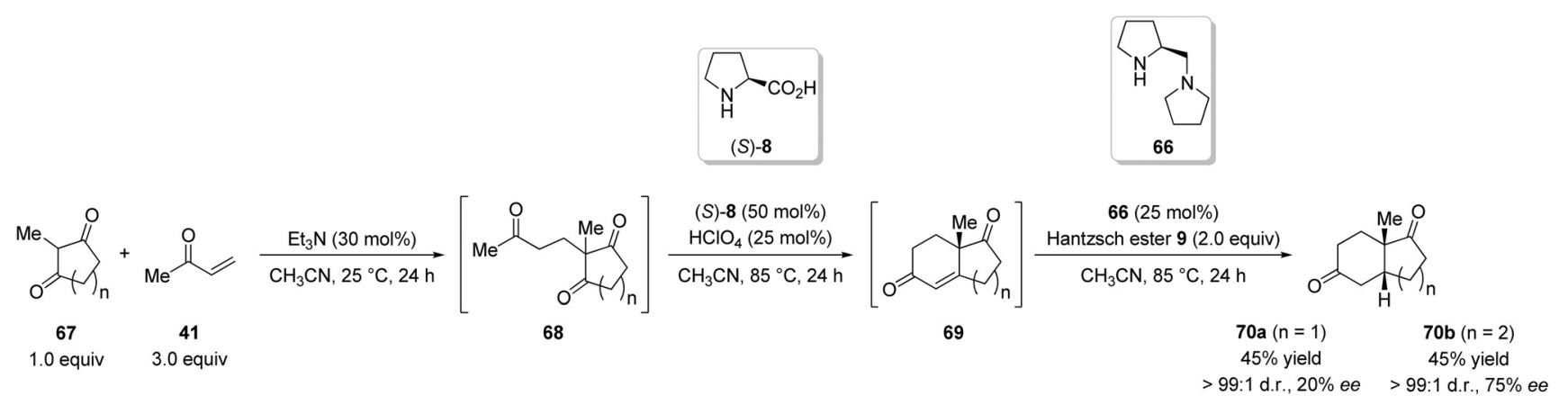

Scheme 11 Asymmetric synthesis of hydrogenated Hajos-Parrish ketone 70a and Wieland-Miescher ketone 70b through the one-pot combination of three components and four catalysts reported by Ramachary. 


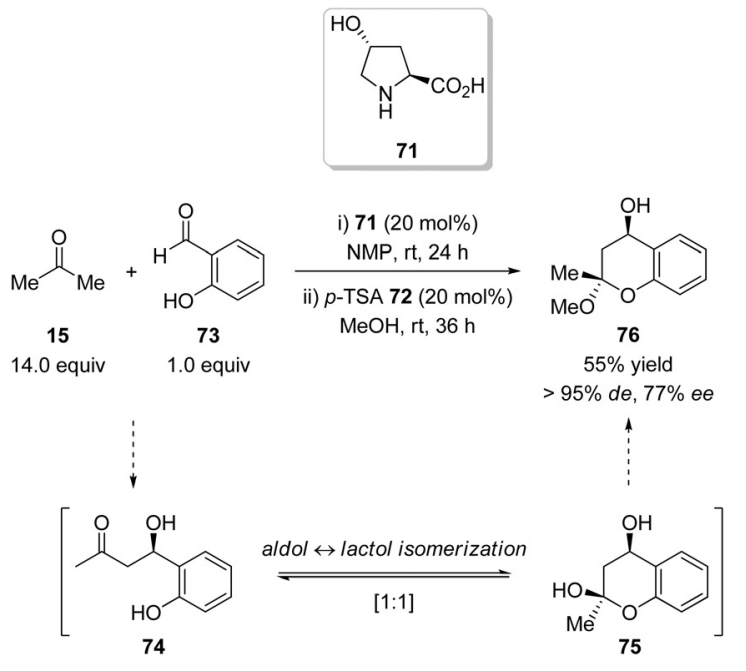

Scheme 12 Multicatalytic synthesis of chromane derivatives reported by Ramachary. NMP $=N$-methylpyrrolidinone.

Table 2 Asymmetric two-component reaction for the formation of bicyclo[3.3.1]non-2-enes

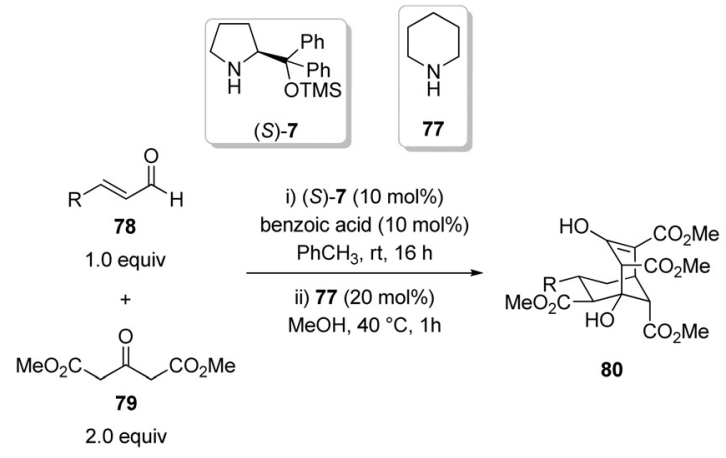

\begin{tabular}{llllll}
\hline Entry & $\mathrm{R}$ & Product & Yield [\%] & d.r. & ee [\%] \\
\hline 1 & Et & $\mathbf{8 0 a}$ & 48 & $>99: 1$ & 94 \\
2 & i-Pr & $\mathbf{8 0 b}$ & 65 & $>99: 1$ & 96 \\
3 & n-heptyl & $\mathbf{8 0 c}$ & 69 & $88: 12$ & 95 \\
4 & EtO $_{2} \mathrm{C}$ & $\mathbf{8 0 d}$ & 38 & $>99: 1$ & 89 \\
5 & (Z)-hex-3-enyl & $\mathbf{8 0 e}$ & 51 & $94: 6$ & 94 \\
6 & Ph & $\mathbf{8 0 f}$ & 70 & $>99: 1$ & 93 \\
7 & 4-MeOPh & $\mathbf{8 0 g}$ & 93 & $92: 8$ & 91 \\
8 & 2-furyl & $\mathbf{8 0 h}$ & 86 & $94: 6$ & 90 \\
9 & 2-BrPh & $\mathbf{8 0 i}$ & 86 & $>99: 1$ & 96 \\
\hline
\end{tabular}

following mechanism for the formation of the six stereogenic centers in $\mathbf{8 0}$ (Scheme 13) ${ }^{65}$ The reaction is initiated by standard iminium ion catalysis by diphenylprolinol silylether $(S)-7$ with enals $\mathbf{7 8}$ generating $\mathbf{8 1}$, which is nucleophilically attacked at the $\beta$-carbon atom by dimethyl 3-oxopentanedioate (79), thus leading to enamine 82. Formation of iminium ion intermediate $\mathbf{8 3}$ and subsequent hydrolysis releases $\mathbf{8 4}$ with the first two stereogenic centers. In the second catalytic cycle, piperidine (77) catalysis enables several concurrent reaction steps. Hence, the cyclization reaction of intermediate $\mathbf{8 4}$ with its second activated methylene functionality leads to $\mathbf{8 5}$ which, after elimination of water, gives intermediate 86. The cyclization step is possibly preceded by hydrolysis of secondary amine catalyst $(S)-7$, however, this could not be clarified. Conjugate addition with a second molecule of $\mathbf{7 9}$ leads to $\mathbf{8 7}$ (the stereoinduction in this step arises from steric hindrance of the former created stereogenic center bearing R). ${ }^{65}$ Final ring closure between the last free activated methylene and the central ketone furnishes product 88. Due to strong intramolecular hydrogen bonding, tautomeric equilibration leads to the more stable enol form 80 . This reaction showed a broad scope with respect to the employed $\alpha, \beta$-unsaturated aldehydes 78. For example, aliphatic aldehydes $(\mathbf{8 0} \mathbf{a}-\mathbf{8 0}$; Table 2, entries 1-3), esters (80d; entry 4), and olefins (80e; entry 5) were applicable. Superior yields were achieved employing aromatic compounds, e.g., para- and ortho-substituted phenyls (80g and 80i; entries 7 and 9) or heteroaromatic substituents, such as furyl $(\mathbf{8 0 h}$; entry 8$)$. Importantly, the products $\mathbf{8 0}$ could be purified by crystallization after completion of the reaction, thus avoiding waste-generating chromatographic steps. ${ }^{65}$

One year later, the same group reported an organocatalytic Michael-Knoevenagel domino reaction for the synthesis of optically active 3-diethoxyphosphoryl-2-oxocyclohex-3-ene-carboxylates. ${ }^{66}$ In order to demonstrate the synthetic feasibility of these products, Jørgensen et al. performed consecutive reactions, one of them being multicatalytic. Hence, Jørgensen and coworkers envisioned a hydrolysis/decarboxylation reaction as an entry to 5-substituted 2-diethoxyphosphorylcyclohex-2-enones, such as 90 (Scheme 14). In this example, the (S)-59 catalyzed domino Michael-Knoevenagel condensation reaction of 4-diethoxyphosphoryl-3-oxobutanoate (90) and cinnamaldehyde (91) afforded tert-butyl-2-oxocyclohex-3-carboxylate (92). Subsequent methanesulfonic acid (MSA; 89) catalyzed hydrolysis/ decarboxylation then gave the target compound 2-diethoxyphosphoryl-5-phenylcyclohex-2-enone (93) in 52\% yield and $96 \%$ ee. The stepwise synthesis yielded 93 in slightly lower yield (43\% over two steps) and same enantiomeric excess. ${ }^{66}$ However, the one-pot synthesis avoids intermediate work-up, isolation, and purification of 92, and thus is more time and cost efficient.

In the same year, García Ruano and Alemán reported the successful combination of amino catalysis and fluoride catalysis using $(S)$-59 and n-tetrabutylammonium fluoride (TBAF; 94) for the synthesis of pentasubstituted cyclohexanes 96 (Table 3) ${ }^{67}$ The reaction proceeds via a Michael addition of diketones 95 to $\alpha, \beta$-unsaturated aldehydes $\mathbf{7 8}$ promoted by (S)-59. Subsequent addition of nitromethane (50) and TBAF (94) leads to the generation of a nitromethane anion (by fluoride) which first reacts with the Michael adduct in an intermolecular Henry reaction, thus affording a nitroalcohol intermediate. This subsequently undergoes a second intramolecular Henry reaction catalyzed by $\mathbf{9 4}$ to give the densely functionalized cyclohexanes 96 with high stereoselectivities ( $>98: 2$ d.r., 92 to $>99 \%$ ee) although in only moderate yields (35-57\%). The stereochemical outcome of the reaction was proposed to be due to the reversibility of the two Henry reactions, leading to the thermodynamically favoured product (equatorial arrangement of all substituents except the hydroxyl group that is intramolecularly associated to the nitro group) instead of the kinetically favoured product. Therefore, the enantioselectivity is defined by amine catalyst $(S)$ $\mathbf{5 9}$ in the first step (employing $(R)-\mathbf{5 9}$ as amine catalyst afforded the enantiomer ent-96b; Table 3, entry 4). When other fluoride sources were used instead of $\mathbf{9 4}$ the corresponding product was 


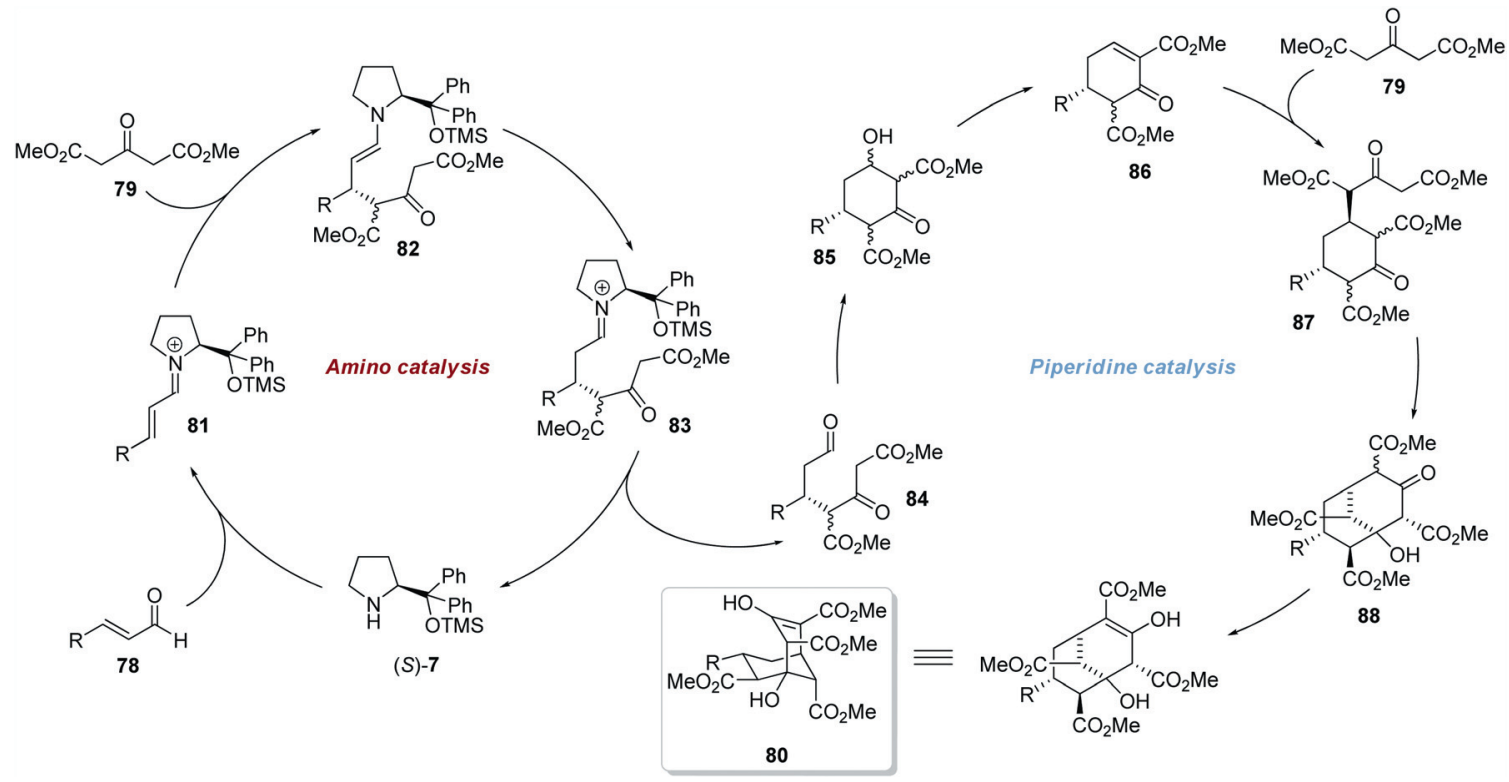

Scheme 13 Mechanistic proposal for the formation of bicyclo[3.3.1]non-2-enes 80.

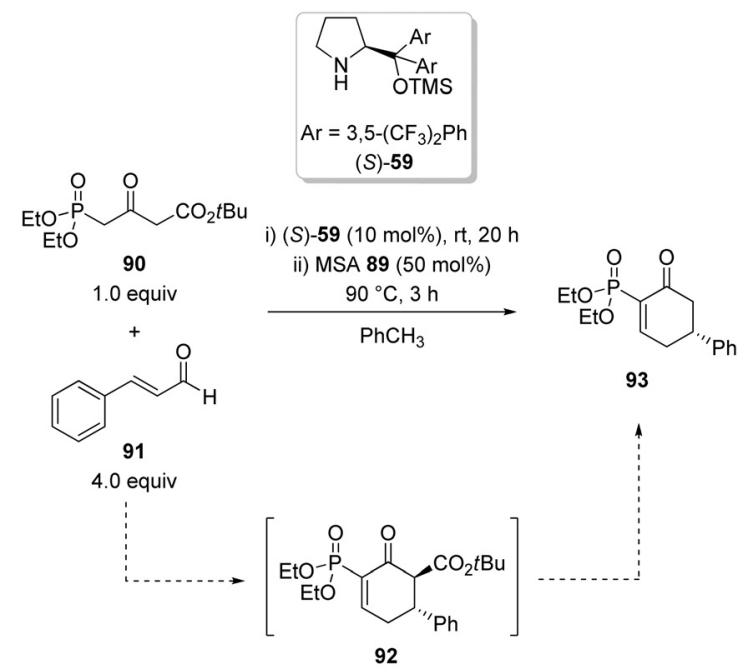

Single step reactions:

One-pot multicatalytic reaction:

92: $86 \%$ yield, $>95: 5$ d.r., $94 \% e e^{a}$

93: $50 \%$ yield, $96 \%$ ee

Scheme 14 Stepwise and multicatalytic synthesis of 2-diethoxyphosphoryl-5-phenylcyclohex-2-enone 93. ${ }^{a}$ First reaction was performed in dichloromethane.

isolated with decreased enantioselectivity, possibly due to a retro-Michael side-reaction. ${ }^{67}$

\section{Miscellaneous combinations with secondary amines}

In 2009, Jørgensen and coworkers reported the combination of prolinol $(S)-59$ and chiral Lygo-type ammonium salt $(S)-97^{68}$ as phase-transfer catalyst ${ }^{69}$ for a novel one-pot synthesis of 4,5-substituted isoxazoline- $N$-oxides 101 (Scheme 15). ${ }^{70}$ The reaction is initiated by the asymmetric epoxidation of $\alpha, \beta$-unsaturated
Table 3 Combination of amino and fluoride catalysis for the synthesis of cyclohexane derivatives with five contiguous stereogenic centers
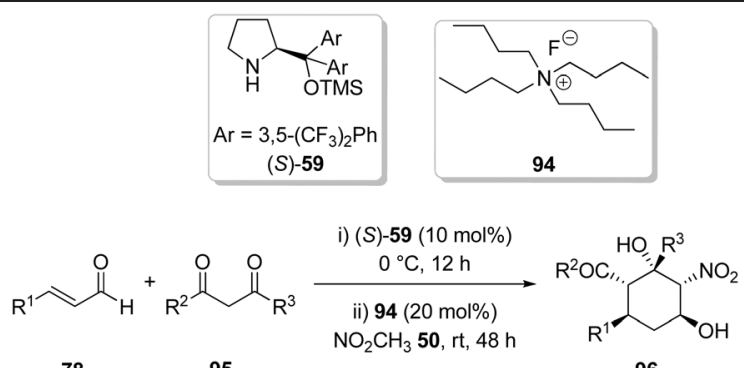

78

95

\begin{tabular}{llllllll}
\hline & & & & \multicolumn{5}{c}{ Yield } & $\begin{array}{l}\text { ee } \\
{[\%]}\end{array}$ \\
Entry & $\mathrm{R}^{1}$ & $\mathrm{R}^{2}$ & $\mathrm{R}^{3}$ & Product & {$[\%]$} & d.r. & {$[\%$} \\
$1^{a}$ & $\mathrm{Et}$ & $\mathrm{Ph}$ & $\mathrm{Ph}$ & $\mathbf{9 6 a}$ & 45 & $>98: 2$ & 99 \\
$2^{a}$ & $\mathrm{Me}$ & $\mathrm{Ph}$ & $\mathrm{Ph}$ & $\mathbf{9 6 b}$ & 55 & $>98: 2$ & $>99$ \\
$3^{a, b}$ & $\mathrm{Me}$ & $\mathrm{Ph}$ & $\mathrm{Ph}$ & $\mathbf{9 6 b}$ & 47 & $>98: 2$ & 99 \\
$4^{c}$ & $\mathrm{Me}$ & $\mathrm{Ph}$ & $\mathrm{Ph}$ & ent- & 57 & $>98: 2$ & $>99$ \\
& & & & $\mathbf{9 6 b}$ & & & \\
5 & n-Pr & $\mathrm{Ph}$ & $\mathrm{Ph}$ & $\mathbf{9 6 c}$ & 46 & $>98: 2$ & 92 \\
6 & n-pentyl & $\mathrm{Ph}$ & $\mathrm{Ph}$ & $\mathbf{9 6 d}$ & 40 & $>98: 2$ & $>99$ \\
7 & n-nonyl & $\mathrm{Ph}$ & $\mathrm{Ph}$ & $\mathbf{9 6 e}$ & 40 & $>98: 2$ & 92 \\
8 & n-Bu & $\mathrm{Ph}$ & $\mathrm{Ph}$ & $\mathbf{9 6 f}$ & 43 & $>98: 2$ & 92 \\
9 & n-hexyl & $\mathrm{Ph}$ & $\mathrm{Ph}$ & $\mathbf{9 6 g}$ & 42 & $>98: 2$ & $>99$ \\
10 & $(Z)-h e x-3-$ & $\mathrm{Ph}$ & $\mathrm{Ph}$ & $\mathbf{9 6 h}$ & 42 & $>98: 2$ & 94 \\
& enyl & & & & & & \\
11 & $\mathrm{C} \mathrm{H}_{4} \mathrm{Ph}$ & $\mathrm{Ph}$ & $\mathrm{Ph}$ & $\mathbf{9 6 i}$ & 46 & $>98: 2$ & $>99$ \\
12 & $\mathrm{Me}$ & $\mathrm{PMP}$ & $\mathrm{PMP}$ & $\mathbf{9 6 j}$ & 35 & $>98: 2$ & 98 \\
13 & $\mathrm{Me}$ & $\mathrm{Ph}$ & $\mathrm{Me}$ & $\mathbf{9 6 k}$ & 44 & $>98: 2$ & 98 \\
14 & $\mathrm{Et}$ & $\mathrm{Ph}$ & $\mathrm{Me}$ & $\mathbf{9 6 1}$ & 47 & $>98: 2$ & 94 \\
$15^{c}$ & $\mathrm{Ph}$ & $\mathrm{Ph}$ & $\mathrm{Ph}$ & $\mathbf{9 6 m}$ & - & - & -
\end{tabular}

${ }^{a}$ First step was performed at $\mathrm{rt}$ for $4 \mathrm{~h}$; second step was performed for $18 \mathrm{~h}^{b}{ }^{b}$ Preparative experiment on $2.0 \mathrm{mmol} \mathrm{scale}{ }^{c}(R)-\mathbf{5 9}$ was used.

aldehydes by hydrogen peroxide through iminium catalysis, followed by a base-mediated intermolecular Henry reaction with nitroacetate $\mathbf{1 0 0}$ under phase-transfer conditions. Consecutive 

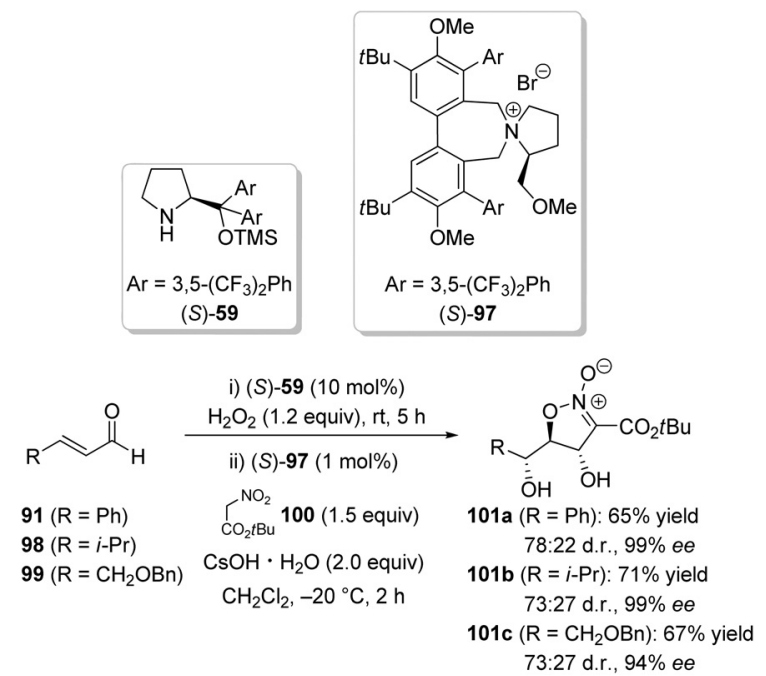

Scheme 15 Merging amino and phase-transfer catalysis for the synthesis of isoxazoline $N$-oxides.

intramolecular $\mathrm{S}_{\mathrm{N}}$ 2-like $O$-alkylation then affords the isoxazoline- $N$-oxides 101. Aromatic, aliphatic and functionalized aldehydes 91, 98, and 99 were applicable providing the desired products 101 in good yields $(65-71 \%)$ and diastereomeric ratios (up to $78: 22$ d.r.), and excellent enantioselectivities (94 and $99 \%$ ee, respectively). These products are only a few reaction steps from highly valuable synthetic targets. For instance, 101c could be readily converted into a $\beta, \gamma, \delta$-trihydroxylated $\alpha$-amino acid derivative. $^{70}$

The concept of photoredox catalysis was first disclosed by MacMillan through the combination of organometallic complexes and secondary amine catalysts. ${ }^{71}$ However, the applied ruthenium and iridium salts are expensive and potentially toxic, which represents a major drawback of these catalysts. A metalfree, organocatalytic photoredox reaction was presented recently by Zeitler et al. using MacMillan's imidazolidinone $\mathbf{1 0 2}^{\mathbf{7 1}}$ in conjunction with readily available, inexpensive xanthene dye eosin Y (103) as photosensitizer (Table 4) ${ }^{72}$ The reaction gave the desired products $\mathbf{1 0 5}$ with good yield and high enantioselectivities. However, the selectivities were temperature dependent (Table 4, entries 1, 4, and 5). For instance, at room temperature 105a was isolated with $77 \%$ ee (Table 4 , entry 1 ) whereas a decrease of the reaction temperature to $-5{ }^{\circ} \mathrm{C}$ led to an increase of the enantioselectivity to $88 \%$ ee (entry 5 ). Conducting the reaction under direct sunlight led to faster conversion $(4 \mathrm{~h})$ but again decreased enantioselectivity, possibly due to the higher reaction temperature (approximately $30^{\circ} \mathrm{C}$; entry 6). The methodology was also applicable to the stereoselective addition of nitrophenacyl (105b; entry 7) and polyfluorinated alkyl substituents (105d; entry 9) which showed superior selectivities up to $96 \%$ ee. Additionally, an example was presented using phenylpropionaldehyde instead of diethyl bromomalonate (104). Although the mechanism of this reaction is not yet fully understood (initially irradiated samples that were kept in the dark showed an increase in yield), a possible reaction path is depicted in Scheme 16. Thus, eosin Y (103; EY) is excited with visible light to its singlet state $\left({ }^{1} \mathrm{EY}^{*}\right)$ which in turn converts to its more stable triplet state $\left({ }^{3} \mathrm{EY}^{*}\right)$ through intersystem crossing (ISC).
Table 4 Metal-free asymmetric organophotoredox catalysis with visible light
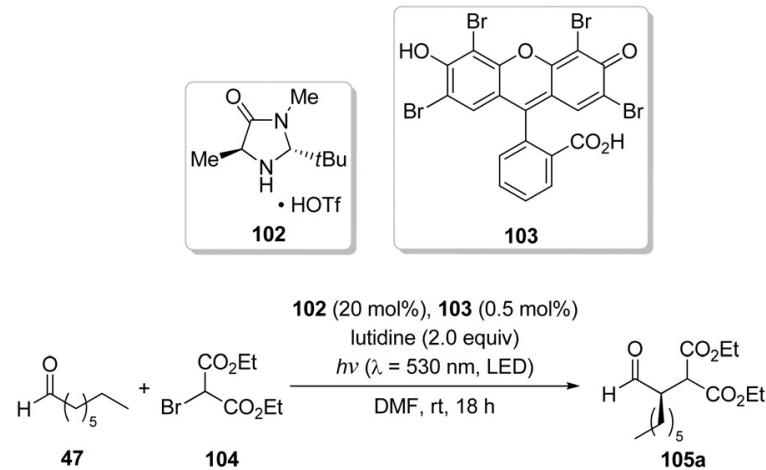

\begin{tabular}{|c|c|c|c|c|}
\hline Entry & Conditions & Product & $\begin{array}{l}\text { Yield } \\
{[\%]}\end{array}$ & $\begin{array}{l}\text { ee } \\
{[\%]}\end{array}$ \\
\hline 1 & As shown above & & 63 & 77 \\
\hline
\end{tabular}

$\begin{array}{llll}2 & 23 \mathrm{~W} \text { fluorescent bulb } & \mathbf{1 0 5 a} & 78\end{array}$ was used instead of LED

$323 \mathrm{~W}$ fluorescent bulb and $\left[\mathrm{Ru}(\mathrm{bpy})_{3}\right] \mathrm{Cl}_{2}$ were used instead of LED

4 Reaction was performed at $0{ }^{\circ} \mathrm{C}$

5 Reaction was performed at $-5^{\circ} \mathrm{C}$

$6^{a} \quad$ Sunlight; reaction performed at $\approx 30{ }^{\circ} \mathrm{C}$

$7^{b} \quad$ Reaction was performed at $5{ }^{\circ} \mathrm{C}$

$105 a$

$75 \quad 76$

$105 a$

70

81

105a

85

88

$105 a$

77<smiles>CCC(CC(=O)c1ccc([N+](=O)[O-])cc1)C(=O)O</smiles>

$105 b$

$8^{c} \quad$ As described above<smiles>CCOC(=O)C(C=O)C(Cc1ccccc1)C(=O)OCC</smiles>

76

86

$105 c$

$9^{d} \quad$ Reaction was performed at $-15^{\circ} \mathrm{C}$

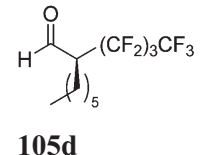

${ }^{a}$ Full conversion after $4 \mathrm{~h} .{ }^{b}$ para-Nitrophenacyl bromide was used instead of diethyl bromomalonate (104). ${ }^{c}$ Phenylpropionaldehyde was used instead of octanal (47). ${ }^{d} 1$-Iodoperfluorobutane was used instead of diethyl bromomalonate (104).

Simultaneously, the amino catalysis cycle is initiated by the formation of iminium ion 106, consequently generating enamine 107. Addition of the electron-deficient alkyl radical to $\mathbf{1 0 7}$ gives amino radical 108, which is subsequently oxidized to iminium species 109, thereby providing the necessary electron for the reductive quenching of the dyes excited state $\left({ }^{3} E Y^{*}\right)$ through single-electron transfer (SET). The thus-generated radical anion $\left(\mathrm{EY}^{\cdot-}\right)$ in turn acts as a reductant to furnish the alkyl radical by SET with the alkyl halide. According to the proposed reaction pathway a catalytic amount of $\mathbf{1 0 8}$ has to be present as the initial 
<smiles>[R]CC=O</smiles><smiles>[10BH2][11CH]</smiles><smiles>CC1CCCCCC1</smiles><smiles>C[C@@H]1NC([18CH3])[C@H](C)C1=O</smiles>

103
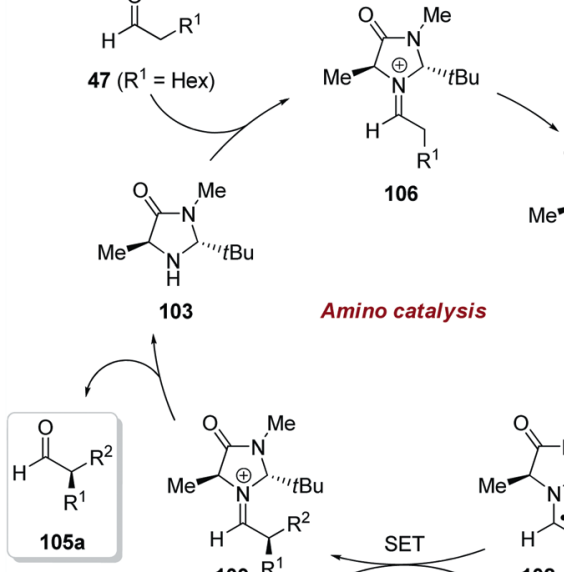

106

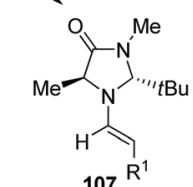

Amino catalysis
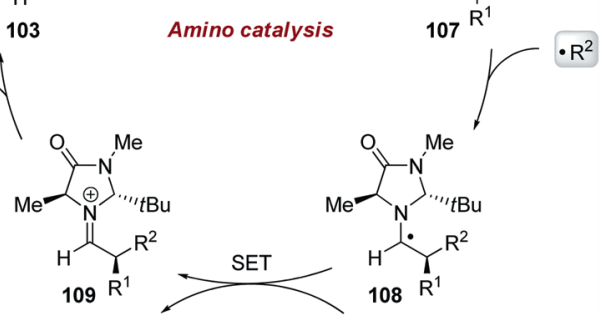

$\mathrm{EY}^{--}$

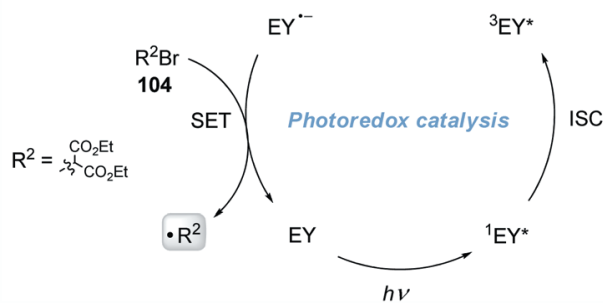

Scheme 16 Proposed mechanism for the organophotoredox catalysis reported by Zeitler et al.

electron reservoir. ${ }^{72}$ This type of reaction is at the border to a dual or synergistic catalysis reaction as the two catalytic cycles are directly coupled. ${ }^{26}$ However, the radical produced in the photoredox cycle independently enters the next cycle.

\section{$\mathrm{N}$-Heterocyclic carbene catalysts}

$N$-Heterocyclic carbenes (NHCs) are versatile organocatalysts 8,73 due to their ability to render aldehydes nucleophilic, hence inverting their classical reactivity ("umpolung"). ${ }^{74}$ The nucleophilic addition of a carbene to an aldehyde leads to the formation of a tetrahedral intermediate which undergoes proton transfer to a nucleophilic enaminol, commonly referred to as the Breslow intermediate. $^{75}$ This can act as an acyl anion equivalent $\left(\mathrm{d}^{1}-\right.$ synthon), allowing reactions with electrophiles to take place. Depending on the kind of electrophilic component utilized, either benzoin condensation (the electrophile is an alkyl/aryl aldehyde or ketone) or Stetter reaction (the electrophile is an $\alpha, \beta$-unsaturated aldehyde or ketone) takes place (Fig. 7). ${ }^{8,73}$ In the case of aldehydes bearing a leaving group at the $\alpha$-position the enaminol can undergo an intramolecular redox reaction (extended umpolung). ${ }^{8,73 b, e, f}$ The elimination of the leaving group generates an enol and after isomerization an activated carboxylate, which is prone to nucleophilic attack.

\section{Combinations with secondary amine catalysts}

Apart from the mentioned combinations of secondary amines with other organocatalysts, multicatalytic reactions employing combinations of chiral secondary amine catalysts and NHCs have begun growing rapidly in the last years. Due to their
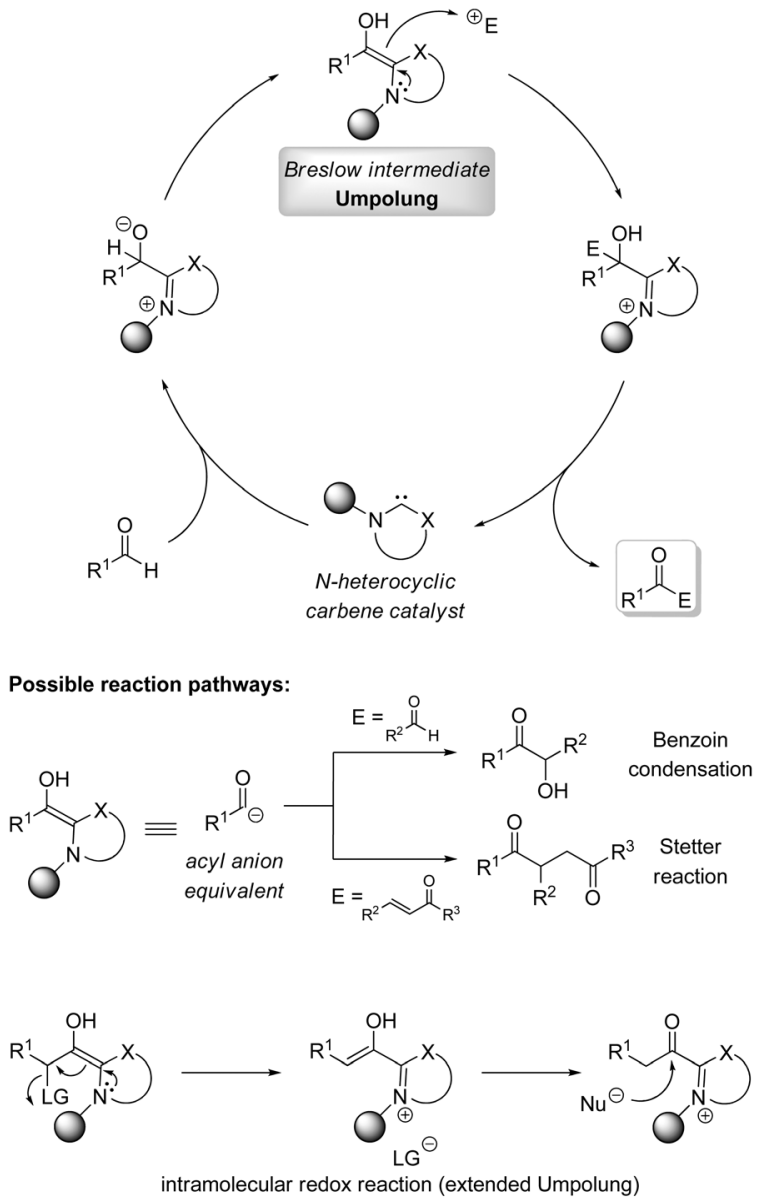

$X=N R, S$

$\mathrm{R}^{1}, \mathrm{R}^{2}, \mathrm{R}^{3}=$ alkyl, aryl

$\mathrm{LG}=$ leaving group

$\mathrm{E}=$ electrophile; $\mathrm{Nu}=$ nucleophile

Fig. 7 General representation of $N$-heterocyclic carbene catalysis and reactions important in the context of this publication.

inherently Lewis basic nature these two catalyst classes can be combined in one pot; both act on carbonyl compounds but show complementary reactivities.

The approach of asymmetric amino and heterocyclic carbene catalysis (AHCC) was first demonstrated in 2007 by Córdova et al. for epoxidation-esterification, cyclopropanation-esterification, and aziridination-esterification reactions (Scheme 17). ${ }^{76}$ Employing diphenylprolinol silylether $(S)-7$ and thiazolium salt $\mathbf{1 1 0}^{77}(\mathrm{Bn}=$ benzyl $)$ as catalysts, and hydrogen peroxide, diethylbromomalonate (104), or Cbz-protected carbamate 117 enabled the enantioselective synthesis of $\beta$-hydroxy esters 113 (up to $82 \%$ yield, 95\% ee), $\beta$-malonate esters 116 (up to 74\% yield, $97 \%$ ee), and $\beta$-amino ester derivative 118 (41\% yield, 61\% ee) from various readily available $\alpha, \beta$-unsaturated aldehydes through the intermediacy of the corresponding 2,3-epoxy, cyclopropyl, and 2,3-aziridine aldehydes (Scheme 17). ${ }^{76}$ Although very useful chiral molecules were accessible by this approach, the reactions suffered from relatively high catalyst loadings of 10-20 $\mathrm{mol} \%$ for amine catalyst $(S)-7$ and up to $40 \mathrm{~mol} \%$ for carbene catalyst $\mathbf{1 1 0}$. 


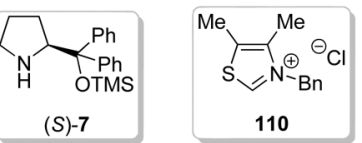

a) Epoxidation/esterification:

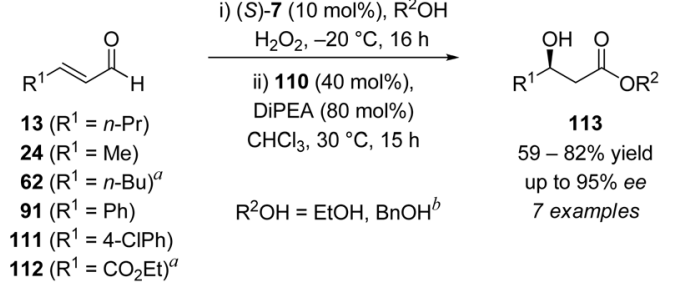

b) Cyclopropanation/esterification:

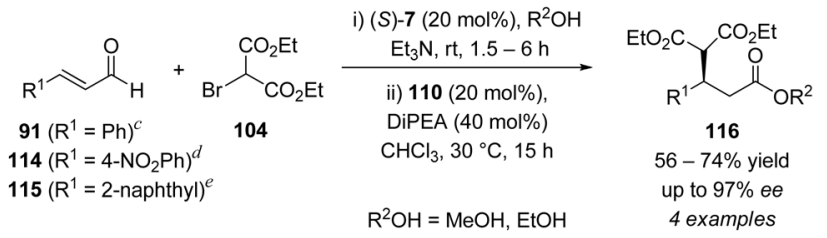

$$
\text { c) Aziridination'esterification: }
$$

Scheme 17 AHCC catalysis for the synthesis of $\beta$-substituted esters reported by Córdova. ${ }^{a}$ Epoxidation was performed at $4{ }^{\circ} \mathrm{C}$ for $6 \mathrm{~h}$; ${ }^{b} \mathrm{BnOH}$ was added after completion of the epoxidation; ${ }^{c} 30 \mathrm{~mol} \% \mathbf{1 1 0}$ were used for the esterification with $\mathrm{MeOH} ;{ }^{d}$ Cyclopropanation was performed for $1.5 \mathrm{~h} ;{ }^{e}$ Cyclopropanation was performed at $4{ }^{\circ} \mathrm{C}$ for $6 \mathrm{~h}$.

By employing (S)-59 and Rovis et al.'s $N$-heterocyclic carbene catalyst precursor $119,{ }^{78}$ Jørgensen and co-workers could employ drastically lower catalyst loadings $(2.5 \mathrm{~mol} \%$ of amine catalyst (S)-59 and down to $1 \mathrm{~mol} \%$ for the carbene 119) for similar transformations, thus significantly improving the efficiency and sustainability of these reactions (Scheme 18). ${ }^{79}$ The addition of $4 \AA$ molecular sieves to remove excess water from the epoxidation step that competes as nucleophile with the alcohols in the final esterification step proved to be crucial to achieve high yields. Linear and $\gamma$-branched, as well as functionalized $\alpha, \beta$-unsaturated aldehydes provided the $\beta$-hydroxylated esters in good yields and enantioselectivities (up to $84 \%$ yield, $98 \%$ ee). However, cinnamaldehyde (91) as the enal component required higher catalyst loading of $(S)$-59 $(10 \mathrm{~mol} \%)$ for the epoxidation step (Scheme 18). Various alcohols were applicable as nucleophiles (i-PrOH gave only poor yields due to increased steric bulk and reduced nucleophilicity; for $\mathbf{1 2 4}$ used as enal: $34 \%$ yield). Moreover, employing different enals and 125 (Tos = 4-toluenesulfonyl (tosyl)) significantly higher yields and enantioselectivities compared to the previously reported procedure could be achieved for the preparation of $\beta$-amino esters $\mathbf{1 2 6}{ }^{80}$ The active carbene catalyst was generated by remaining $\mathrm{NaOAc}$ from the aziridination step, thus avoiding the addition of Hünig's base for the second reaction. Note, however, that the carbamate 117 used by Córdova is more environmentally friendly and atom

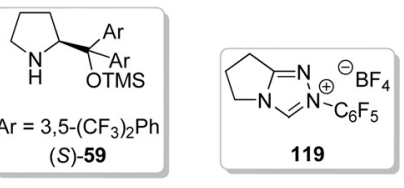

a) Epoxidation esterification:
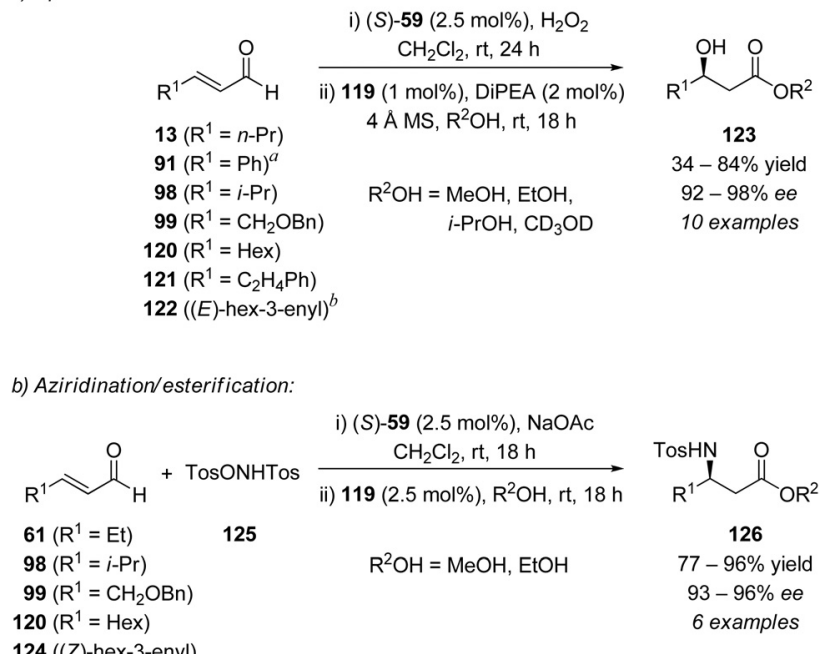

Scheme 18 AHCC catalysis for the synthesis of $\beta$-substituted esters reported by Jørgensen. ${ }^{a} 10$ mol\% $(S)-59$ were used; $5 \mathrm{~h}$ for epoxidation. ${ }^{b} 2.5 \mathrm{~mol} \%(R)-59,2 \mathrm{~mol} \% \mathbf{1 1 9}$, and $4 \mathrm{~mol} \%$ DiPEA were used.
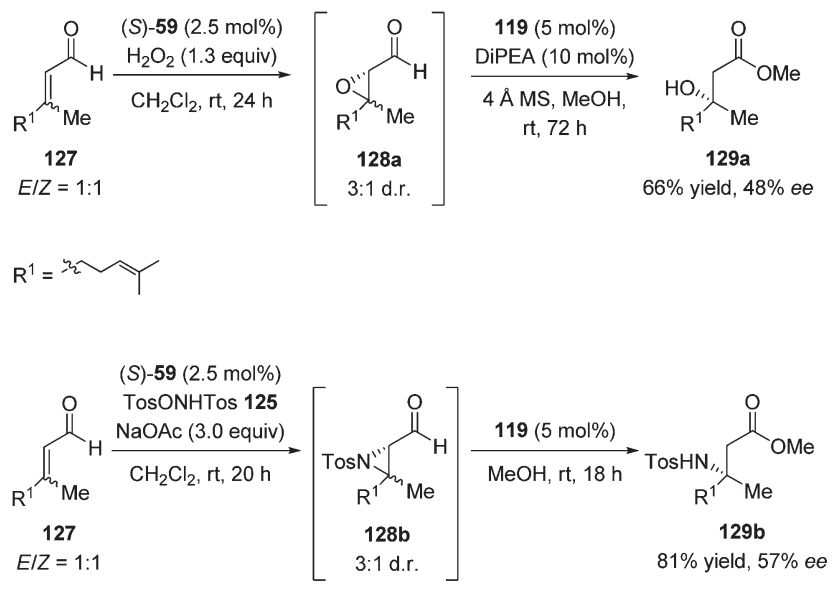

Scheme 19 AHCC reactions for the preparation of $\beta$-substituted esters bearing a quaternary carbon center.

economy is better compared to $\mathbf{1 2 5}$ due to the release of acetate instead of tosylate. Both epoxidation-esterification as well as aziridination-esterification were additionally tested employing the commercially available citral $\mathbf{1 2 7}$ as enal substrate under the developed conditions (Scheme 19). Starting from a 1:1(E/Z) mixture of $\mathbf{1 2 7}$ the intermediate 2,3-epoxy aldehyde 128a and aziridine aldehyde 128b formed in $3: 1$ diastereomeric ratio, due to possible isomerisation during the reaction. Subsequent ringopening gave the desired products $\mathbf{1 2 9}$ bearing tertiary hydroxyl or amino moieties, however, with moderate enantioselectivities (the significant amount of the minor diastereomers 128a and 128b possibly leads to the formation of the wrong enantiomer; 129a: $66 \%$ yield, $48 \%$ ee; $129 b$ : $81 \%$ yield, $57 \%$ ee). ${ }^{79}$ 
A generalized mechanistic picture for the mentioned combinations of amino and $N$-heterocyclic carbene catalysis is presented in Scheme 20. The reaction is initiated through the reversible formation of an iminium ion $\mathbf{1 3 0}$ allowing the conjugate addition of the $\mathrm{O}$-, $\mathrm{C}$-, or $\mathrm{N}$-nucleophiles to the $\beta$-carbon at the $R e$ face generating the chiral enamine intermediate 131 (similarly to the examples described above for combinations of secondary amines). In the next step, 131 performs an intramolecular 3-exo-tet cyclization from its $R e$ face under release of the leaving group forming 132. This cyclization step is irreversible and governs the stereoselective outcome of the overall reaction. Hydrolysis gives the corresponding epoxide, cyclopropyl, or aziridine aldehydes 133. After in situ generation of the NHC 134 from its corresponding precatalyst, it nucleophilically attacks the carbonyl carbon of 133, thus forming the zwitterionic species 135. Subsequent generation of the Breslow intermediate 136, and following intramolecular redox reaction leads to the activated carboxylate $\mathbf{1 3 8}$ via intermediate 137. Final transesterification with an alcohol as nucleophile releases the carbene catalyst and gives the corresponding products (compare Fig. 7).

In 2011, Córdova et al. reported a related enantioselective AHCC three-component reaction of $\alpha, \beta$-unsaturated aldehydes, tosylated hydroxycarbamates 139 and 140, and different alcohols yielding $\mathrm{Cbz}$ - or Boc-protected $\beta$-amino acid ester derivatives 141 (Scheme 21). ${ }^{81}$ Similarly to Jørgensen's work, the use of $(S)-7$ and 119 as catalysts afforded various $\beta$-amino acid ester derivatives 141 in moderate to good yields (up to $80 \%$ yield) with $92-99 \%$ ee. When aromatic enals such as $\mathbf{9 1}$ or $\mathbf{1 1 5}$ were used the corresponding products were obtained with significantly lower yield (25-54\% yield) although with excellent stereoselectivities (94-99\% ee) due to a base-catalyzed rearrangement sidereaction. According to the mechanistic picture provided in Scheme 20 the use of $\alpha$-substituted enal 142 formed the intermediate aziridine 143 with high $95 \%$ ee (Scheme 22). Subsequent ring-opening/esterification afforded nearly racemic $\beta^{2}$ amino acid ester 144 in 69\% yield. However, employing enal
145 the corresponding product 146 was isolated in 59\% yield with low diastereoselectivity, albeit with excellent

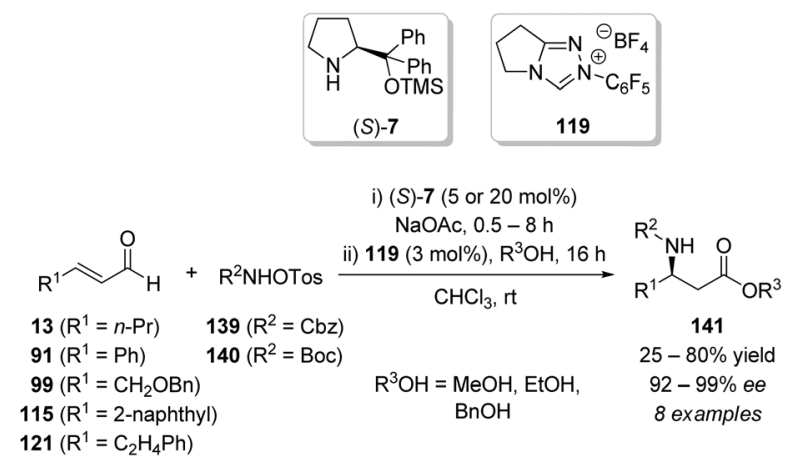

Scheme 21 AHCC reactions for the enantioselective synthesis of protected $\beta$-amino acid ester derivatives.
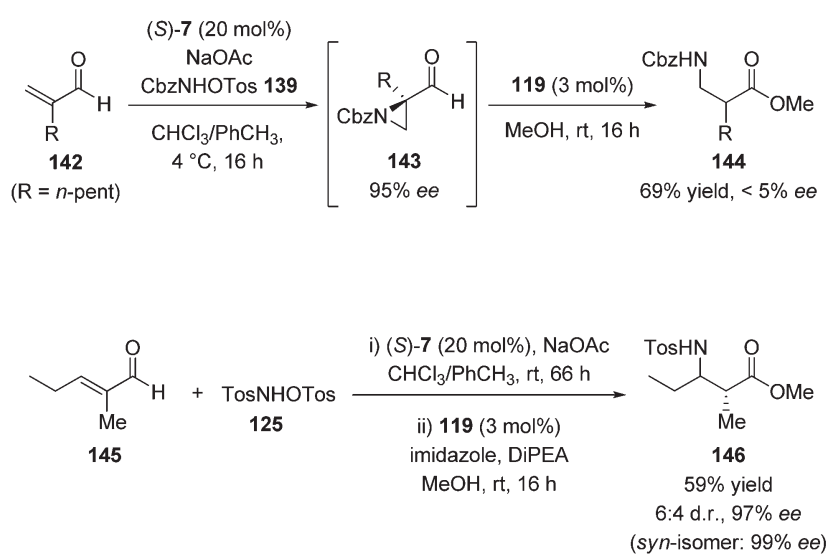

Scheme 22 AHCC reactions for the preparation of $\alpha, \beta$-substituted amino acid ester derivatives.

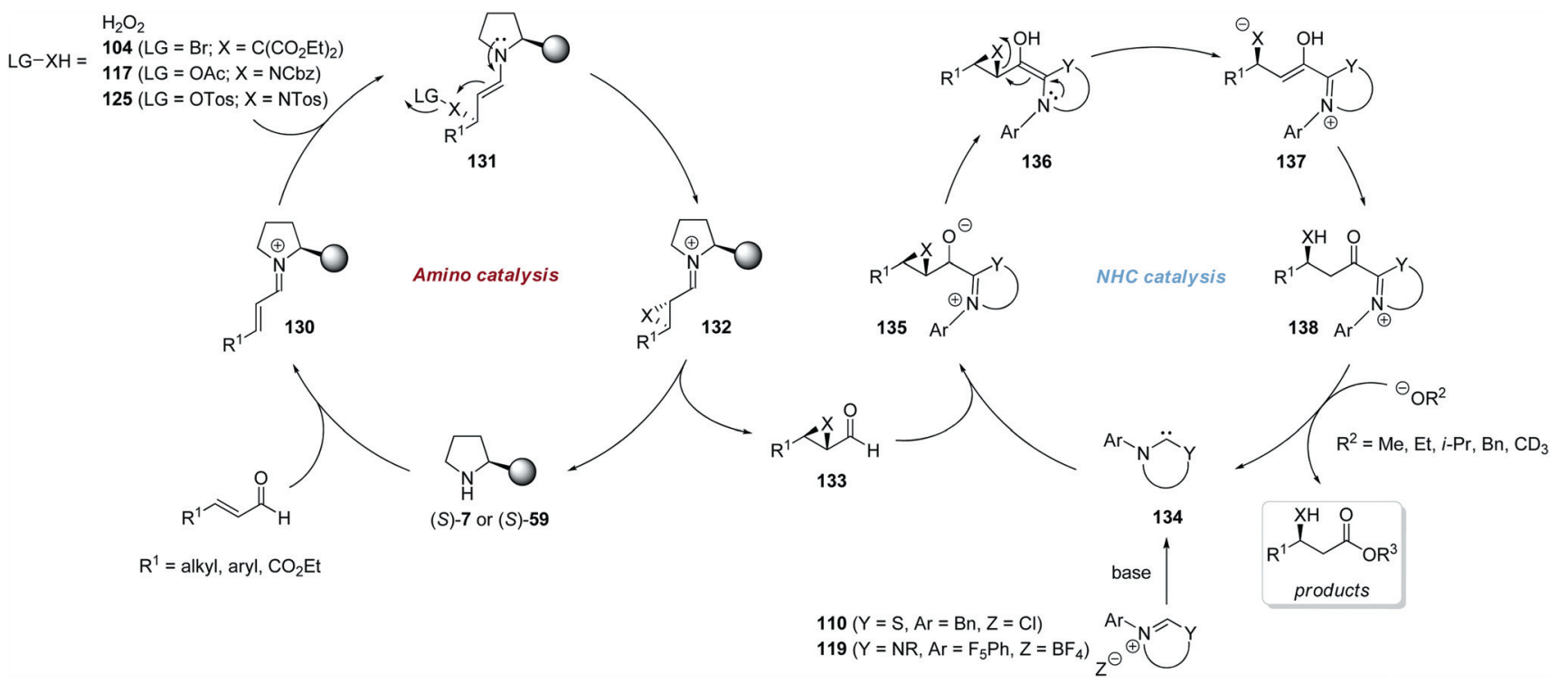

Scheme 20 Possible general mechanistic picture for the AHCC reactions shown in Schemes 17 and 18, and Scheme 15 (secondary amine catalyzed epoxidation step only). 
enantioselectivity for both isomers (anti-isomer: 97\%; synisomer: 99\% ee) as shown in Scheme 22.

In 2009, Lathrop and Rovis demonstrated another example of AHCC for the realization of a Michael addition/cross-benzoin reaction (Scheme 23). ${ }^{82}$ This multicatalytic tandem reaction enabled the synthesis of highly functionalized cyclopentanones 147 containing three stereogenic centers (including a quaternary stereogenic center) from readily available starting materials.

By using silyl-protected prolinol catalyst $(S)-59$, asymmetric conjugate addition of $\alpha, \beta$-unsaturated aldehydes to $\beta$-dicarbonyl compounds 151-159 was induced via iminium activation. The following carbene 119 catalyzed intramolecular benzoin condensation produced the densely substituted cyclopentanones $\mathbf{1 4 7}$ in high yields and enantioselectivities, however, with only moderate diastereoselectivities (Scheme 23). The reaction showed a broad scope with respect to the aldehyde and the $\beta$-dicarbonyl starting materials leading to a variety of possible products, while branched aliphatic aldehydes (such as 98) gave considerably lower yields. For example, bicyclic products $147 p$ and $147 q$ could be obtained using $\beta$-ketoesters 158 or 159. Mechanistic investigations revealed that the performance of iminium catalyst (S)-59 and carbene 119 in a tandem reaction is crucial for the high yield and selectivity of this reaction. When the transformation is performed in stepwise manner the intermediate aldehydes probably undergo retro-Michael reaction in the presence of $(S)$ 59 and are prone to epimerization during purification by column chromatography. ${ }^{82}$ As a consequence, the desired products 147 are obtained in lower yield and significantly lower enantioselectivity ( $46 \%$ yield, $58 \%$ ee for two sequential reactions), showing the sharp contrast to the yield and enantioselectivity of the onepot tandem reaction ( $93 \%$ yield, $86 \%$ ee). When the two steps are combined into a tandem reaction, the carbene catalyst 119 effectively suppresses the retro-Michael reaction by direct consumption of the intermediate aldehyde in the following benzoin reaction, hence achieving the high enantioselectivity (Scheme 23). This work further emphasizes one of the advantages of multiple catalysts promoted asymmetric tandem reactions: the fast consumption of intermediates in a concurrent catalytic cycle allows catalysts to work synergistically, thereby suppressing side reactions.

The orthogonal reactivity of secondary amines and $N$-heterocyclic carbenes for the asymmetric synthesis of highly functionalized cyclopentanones was shown with another example by Ozboya and Rovis in 2011 (Scheme 24). ${ }^{83}$ In contrast to the previous work which relied on iminium catalysis as the first step, this reaction was initiated by enamine activation using secondary amine catalyst 7 followed by direct benzoin condensation catalyzed by chiral triazolium catalyst precursor $160 .^{78,84}$ Aliphatic aldehydes and various $\alpha, \beta$-unsaturated ketones provided the desired products in good yield and high enantio- and diastereoselectivity. Employing isovaleraldehyde (45) competitively formed the corresponding Stetter product in a $1: 1$ ratio with the desired product 161c. However, the sequential addition of $\mathbf{1 6 0}$ after complete formation of the corresponding intermediate avoided the formation of the side-product, thus affording 161c (98\% yield, $96: 4:<1:<1$ d.r., 88\% ee). Aldehydes 163 and 164, and $\alpha, \beta$-unsaturated ketones 167 and 173 bearing sterically more demanding substituents were also applicable but usually required longer reaction times and led to lower yields.
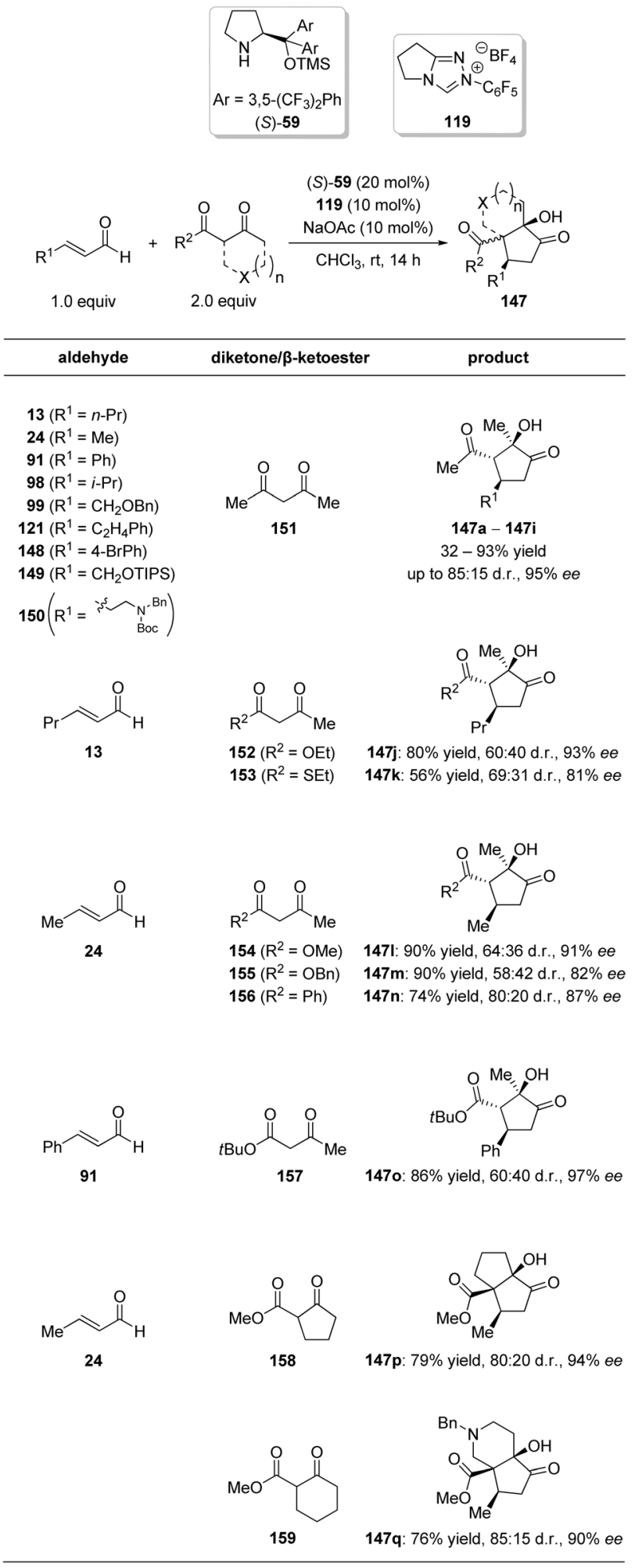

Scheme 23 AHCC tandem reaction for the synthesis of cyclopentanone derivatives reported by Lathrop and Rovis. Diastereomeric ratios are shown for major diastereomer:sum of three possible minor diastereomers.

When, for example, 173 was used as enone the intramolecular benzoin reaction could only be accomplished using smaller achiral carbene catalyst 119, however with diminished 

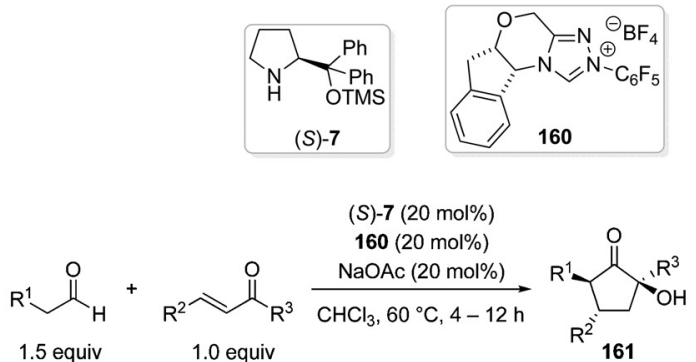

1.5 equiv $\quad 1.0$ equiv

161

Aldehyde scope:

\begin{tabular}{|c|c|c|}
\hline aldehyde & $\alpha, \beta$-unsaturated ketone & product \\
\hline $\begin{aligned} & \mathrm{R}^{1} \\
& 43\left(\mathrm{R}^{1}=\mathrm{Et}\right) \\
& 44\left(\mathrm{R}^{1}=n-\mathrm{Pr}\right) \\
& 45\left(\mathrm{R}^{1}=i-\mathrm{Pr}\right)^{a} \\
& 54\left(\mathrm{R}^{1}=\mathrm{Me}\right) \\
& 162\left(\mathrm{R}^{1}=\mathrm{Bn}\right) \\
& 163\left(\mathrm{R}^{1}=\mathrm{C}_{2} \mathrm{H}_{4} \mathrm{OPMB}\right) \\
& 164\left(\mathrm{R}^{1}=\mathrm{N}^{\mathrm{S}} \approx\right)\end{aligned}$ & $\mathrm{EtO}_{2} \mathrm{C} \underset{165}{\curvearrowright}$ & $\begin{array}{c}\mathrm{EtO}_{2} \mathrm{C} \\
161 \mathrm{a}-\mathbf{1 6 1 \mathrm { g }} \\
50-98 \% \text { yield } \\
\text { up to } 96: 4 \text { d.r., } 95 \% \text { ee }\end{array}$ \\
\hline
\end{tabular}

$\alpha, \beta$-unsaturated ketone scope:

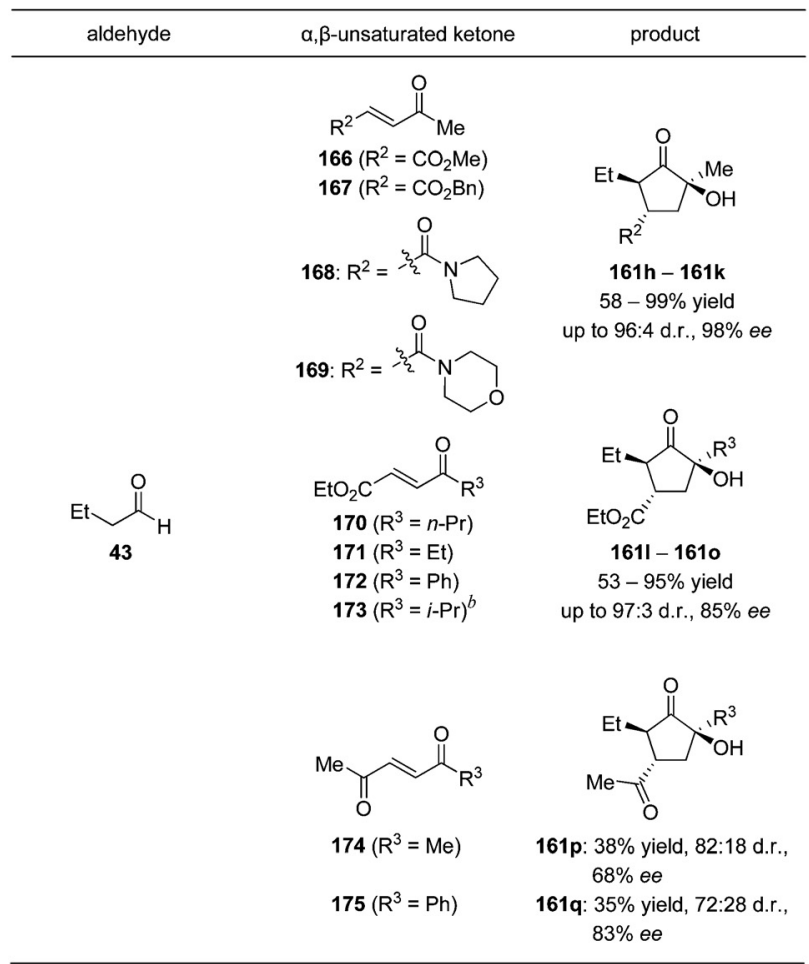

Scheme 24 AHCC tandem reaction for the synthesis of cyclopentanone derivatives reported by Ozboya and Rovis. Diastereomeric ratios are shown for major diastereomer:sum of three possible minor diastereomers. $\mathrm{PMB}=$ para-methoxybenzyl. ${ }^{a}$ Catalyst 160 was added after complete consumption of starting material. ${ }^{b}$ Carbene precatalyst 119 was used instead of $\mathbf{1 6 0}$.

enantioselectivity (51\% ee). Diketones $\mathbf{1 7 4}$ and $\mathbf{1 7 5}$ gave the corresponding products $161 \mathrm{p}$ and $\mathbf{1 6 1 q}$ in considerably lower yields. Additional mechanistic investigations again showed that the one-pot tandem reaction leads to better selectivities
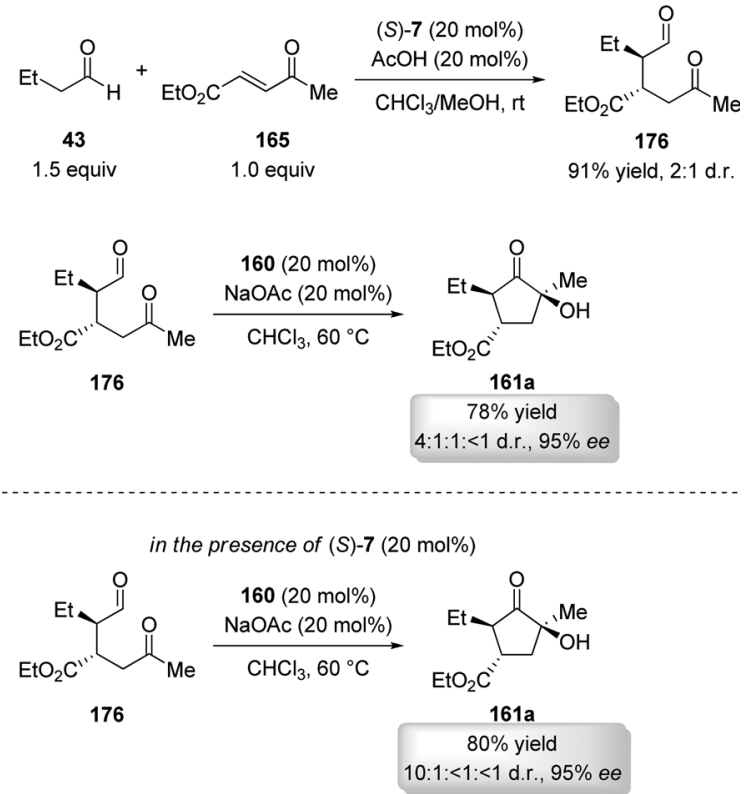

Scheme 25 Single step reactions for the preparation of 161a.

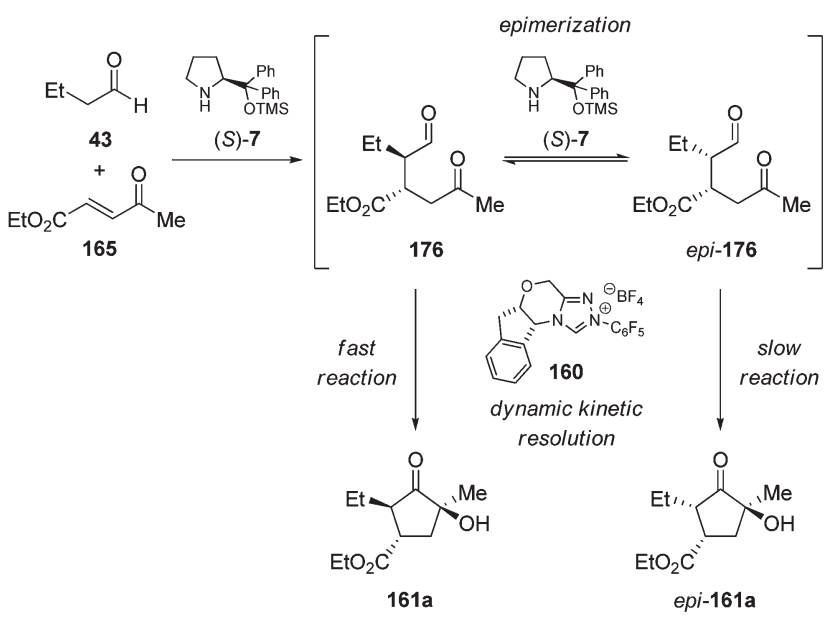

Scheme 26 Mechanistic proposal for the observed reaction outcome in the multicatalytic synthesis of 161a.

compared to the single step reactions via a dynamic kinetic resolution of intermediate $\mathbf{1 7 6}$ by chiral NHC $\mathbf{1 6 0}$ (Schemes 25 and 26). Control experiments revealed that when prepared from butyraldehyde (43) and enone 165 with catalyst $(S)-7$ and catalytic acetic acid the corresponding intermediate aldehyde $\mathbf{1 7 6}$ formed in $91 \%$ yield with only $2: 1$ diastereomeric ratio. The consecutive benzoin reaction afforded 161a in comparable yield and enantioselectivity to the multicatalytic one-pot reaction, but in lower diastereomeric ratio (78\% yield, $4: 1: 1:<1$ d.r., $95 \%$ ee for two consecutive reactions; $87 \%$ yield, $19: 1:<1:<1$ d.r., $95 \%$ ee for the tandem reaction). Indeed, in the presence of $(S)-7$ the diastereoselectivity of the final product could be significantly improved $(10: 1:<1:<1$ d.r.; Scheme 25).

Thus, the secondary amine catalyst $(S)-7$ possibly epimerizes the $\alpha$-position of the intermediate aldehyde $\mathbf{1 7 6}$, leading to epi$\mathbf{1 7 6}$, and the chiral triazolium catalyst 160 preferentially reacts 
with intermediate $\mathbf{1 7 6}$ instead of epi-176 to form the enantioenriched product 161a (Scheme 26).

In the same year, Enders et al. employed (S)-59 and $\mathbf{1 1 9}$ for the sequential multicatalytic Michael addition/cross-benzoin reaction of $\alpha, \beta$-unsaturated aldehydes and $\beta$-oxo sulfones 178-189 for the preparation of polysubstituted cyclopentanones 177 (Scheme 27). ${ }^{85}$ Hence, they first applied the conditions reported previously for the reaction of $\beta$-dicarbonyl compounds with enals by Lathrop and Rovis. ${ }^{82}$ Under these conditions (compare Scheme 23) the reaction of crotonaldehyde (24, 1.0 equivalents) with phenylsulfonylacetone (178, 2.0 equivalents) afforded mainly two of the four possible diastereomers of $\mathbf{1 7 7 b}$ in high yield and enantioselectivity, however in an only moderate diastereomeric ratio ( $85 \%$ yield, $63: 37$ d.r., $88 \%$ ee). After reoptimization of reaction conditions, the desired product $\mathbf{1 7 7 b}$ could be obtained in quantitative yield while stereoselectivity was retained. With these conditions at hand, Enders and coworkers studied the scope of the reaction. A wide range of different sulfones 179-189 was applicable using 24 as aldehyde component to generate cyclopentanones $\mathbf{1 7 7} \mathbf{d}-\mathbf{1 7 7} \mathbf{k}$ in $70-96 \%$ yield, in most cases as a single diastereomer (99:1 d.r.), and with up to $97 \%$ ee. Interestingly, the benzoin condensation proceeded with cis-selectivity (contrary to the reactions reported by Lathrop and Rovis; compare Scheme 23) ${ }^{82}$ when sulfones bearing an aromatic moiety were employed. Using $\alpha$-substituted $\alpha$-(phenylsulfonyl)ketones as nucleophiles significantly decreased the reaction rate and the yield. For instance, the cyclic sulfone $\mathbf{1 8 7}$ formed product $\mathbf{1 7 7 1}$ in 53\% yield even when the reaction time was prolonged to three days with moderate selectivities (67:33 d.r.), whereas $\mathbf{1 8 8}$ gave $\mathbf{1 7 7} \mathbf{m}$ in only $20 \%$ yield, albeit with very good stereoselectivity (99:1 d.r., 91\% ee). When acyclic 189 was used as sulfone component the desired product was not produced. Similarly to the reactions reported by Rovis and co-workers ${ }^{83}$ Enders observed epimerization of the corresponding Michael adduct. Hence, the achieved diastereoselectivities result from the preference of one of the diastereomers to react with the carbene catalyst (also compare Scheme 26).

Encouraged by the previous reports by the groups of Rovis (Scheme 23) ${ }^{82}$ and Enders (Scheme 27), ${ }^{85}$ Jørgensen et al. envisioned an AHCC reaction sequence for the formation of optically active 2,4-disubstituted cyclopent-2-enones (Scheme 28). ${ }^{86}$ Similar to the previous reports the reaction is initiated by an iminium activated Michael addition of sulfones 204-207 to $\alpha, \beta$-unsaturated aldehydes employing (S)-59. The successive NHC 119-catalyzed benzoin reaction subsequently leads to a Smiles rearrangement, ${ }^{87}$ thus affording the desired 2,4-disubstituted cyclopentan-2-enones 197 (Scheme 28). Various aliphatic aldehydes (24, 61 and 120), olefinic aldehydes (190 and 291), and the aldehyde 192 bearing a TBS-protected alcohol were used affording the corresponding products in $51-69 \%$ yield and enantioselectivities up to $98 \%$. Nucleophiles bearing an aliphatic ketone substituent were found to be inapplicable, presumably because of the formation of a stable pyranose intermediate. ${ }^{86,88}$

\section{Miscellaneous combinations with $\mathrm{N}$-heterocyclic carbenes}

In 2010, Lathrop and Rovis reported an asymmetric MichaelStetter tandem reaction for the synthesis of valuable
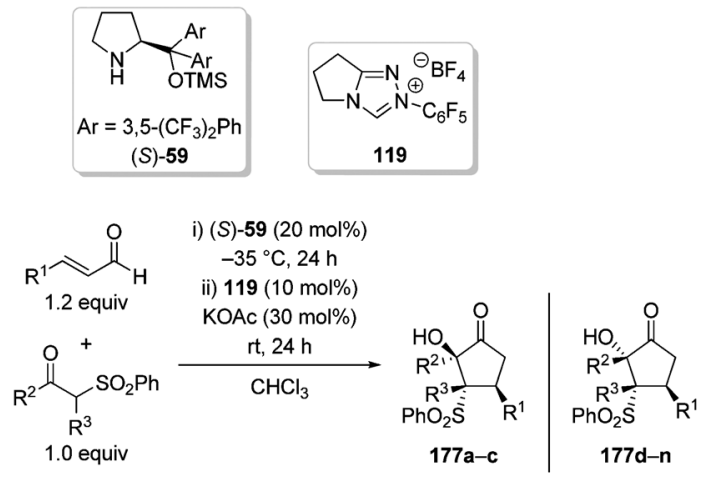

Aldehyde scope:

\begin{tabular}{lll}
\hline aldehyde & sulfone & \\
& & $177 \mathrm{a}: 67 \%$ yield, $58: 42$ d.r., $96 \%$ ee \\
$\mathbf{2 4}\left(\mathrm{R}^{1}=\mathrm{Me}\right)$ & & $177 \mathrm{~b}: 99 \%$ yield, $66: 34$ d.r., $86 \%$ ee \\
$91\left(\mathrm{R}^{1}=\mathrm{Ph}\right)$ & & $177 \mathrm{c}: 33 \%$ yield, $99: 1$ d.r., $94 \%$ ee \\
\hline
\end{tabular}

Sulfone scope:

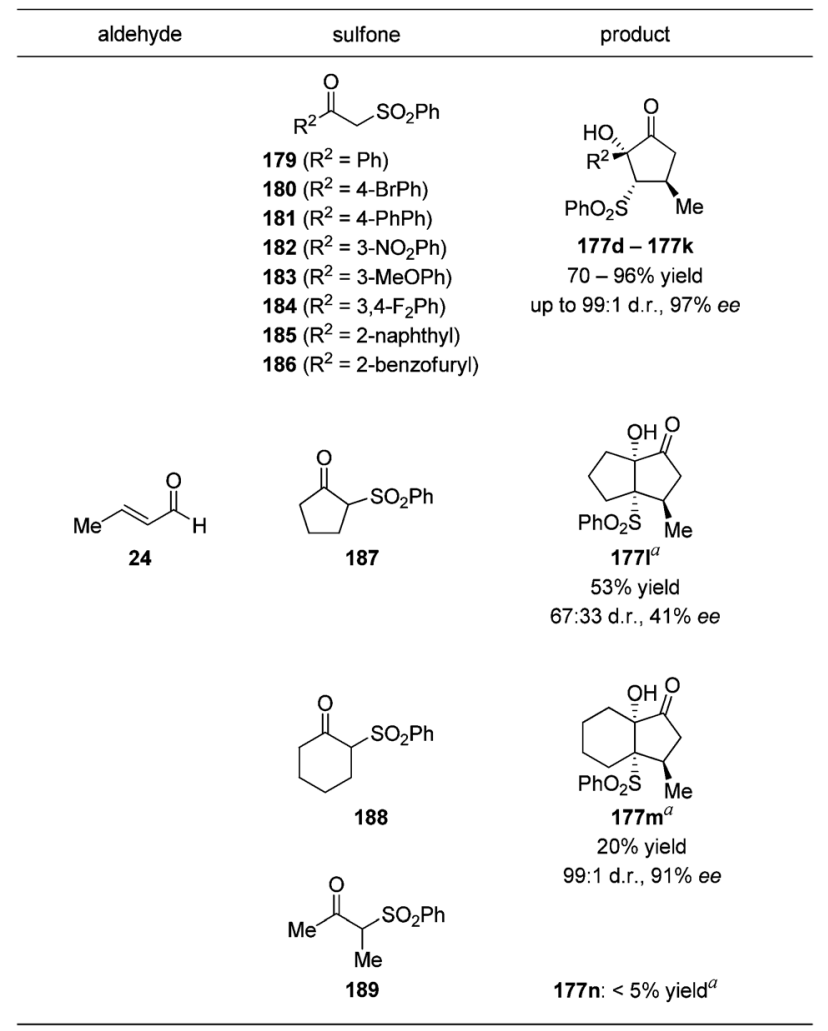

Scheme 27 AHCC cascade reactions for the synthesis of cyclopentanone derivatives reported by Enders. Diastereomeric ratios are shown for major diastereomer: sum of three possible minor diastereomers. ${ }^{a}$ First reaction was prolonged to $3 \mathrm{~d}$.

benzofuranones from readily available starting materials (Scheme 29). ${ }^{89}$ Based on other preliminary studies which showed that 1,4-diazabicyclo[2.2.2] octane (DABCO, 198) 


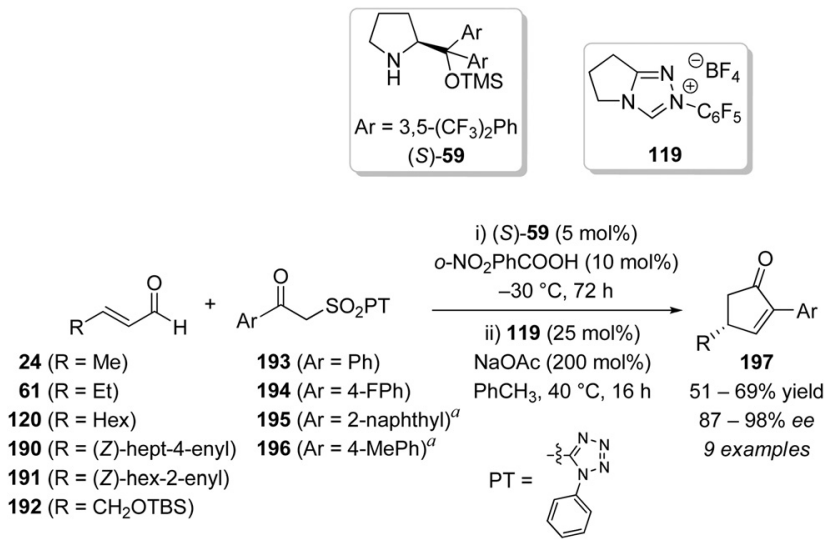

Scheme 28 AHCC cascade reactions for the synthesis of cyclopentenone derivatives. ${ }^{a} 10 \mathrm{~mol} \%(S)-\mathbf{5 9}$ and $20 \mathrm{~mol} \% o-\mathrm{NO}_{2} \mathrm{PhCOOH}$ were used.
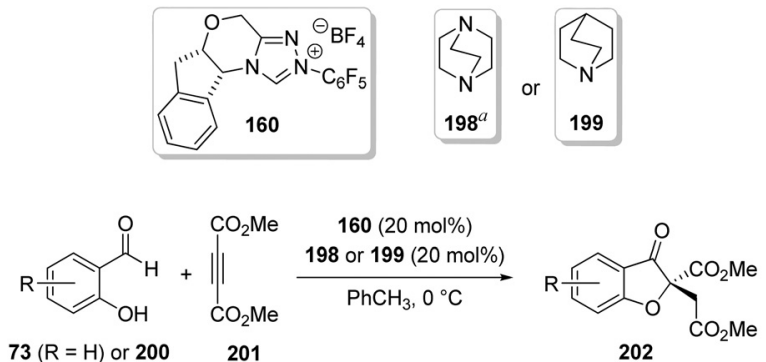

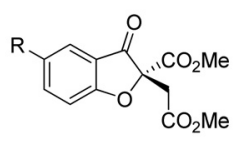

202a $(R=H): 78 \%$ yield, $89 \%$ ee 202b $(\mathrm{R}=\mathrm{Cl}): 65 \%$ yield, $89 \% e^{a}$ 202c $(\mathrm{R}=\mathrm{Br}): 64 \%$ yield, $94 \% \mathrm{ee}^{a}$ 202d $(R=I): 68 \%$ yield, $94 \%$ ee 202e $(R=M e): 77 \%$ yield, $86 \%$ ee 202f $(R=t$-Bu): $80 \%$ yield, $85 \%$ ee $202 \mathrm{~g}(\mathrm{R}=\mathrm{OMe}): 66 \%$ yield, $86 \% e e^{a}$

Scheme 29 Michael-Stetter tandem reaction of different salicylaldehydes with DMAD (201). ${ }^{a} 198$ was used.

allows the addition of amine and oxygen nucleophiles to dimethyl acetylenedicarboxylate (DMAD; 201) ${ }^{90}$ the authors envisioned the combination of $\mathbf{1 6 0}$ and a tertiary amine, such as DABCO (198) or quinuclidine (199), acting as both nucleophilic catalyst for the Michael addition and as base for the deprotonation of the carbene precatalyst. The combination of both catalysts should then allow performance of a tandem Michael-Stetter reaction (Scheme 29). Indeed, the combination of 160 and 198 or 199, respectively, facilitated the reaction of salicylaldehydes $\mathbf{7 3}$ or $\mathbf{2 0 0}$ with different substitution patterns, and DMAD (201) to furnish the desired products 202. Interestingly, the tertiary amine (198 or 199) not the carbene 160 acts as nucleophilic catalyst for the Michael reaction although both are present from the outset of the reaction, which was confirmed by control experiments. ${ }^{89}$ Further investigations indicated that the

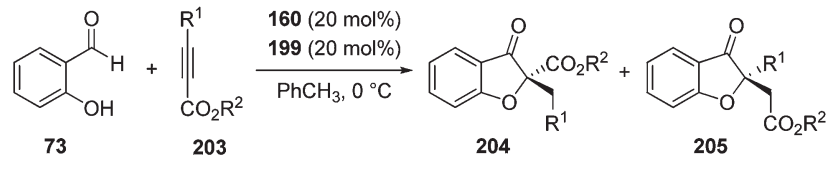<smiles>CCOC(=O)C1(CC(=O)c2ccccc2)Oc2ccccc2C1=O</smiles><smiles>CC(=O)CC1(CC(=O)P)Oc2ccccc2C1=O</smiles><smiles>CCOC[C@@]1(CC(=O)CCP)Oc2ccccc2C1=O</smiles><smiles>CCOC(=O)C1(OP(=O)(COc2ccccc2)OCC)Oc2ccccc2C1=O</smiles>

204a/205a $(>20: 1) \quad 204 b / 205 b(>20: 1)$ $60 \%$ yield, $12 \%$ ee $58 \%$ yield, $18 \%$ ee
Scheme 30 Michael-Stetter tandem reaction of salicylaldehyde (73) with unsymmetrical alkynes 203.

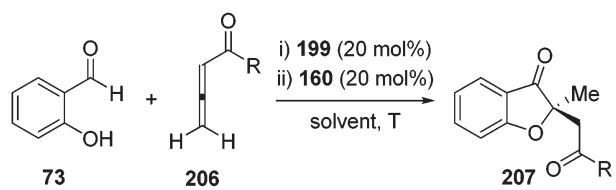

207a: $R=$ Me: $60 \%$ yield, $78 \%$ ee; solvent: THF; first reaction: $23^{\circ} \mathrm{C}$, second reaction: $0^{\circ} \mathrm{C}$ 207b: $R=$ OEt: $50 \%$ yield, $98 \%$ ee; solvent: $\mathrm{PhCh}_{3} ; \mathrm{T}=23^{\circ} \mathrm{C}$ for both reaction steps
Scheme 31 Michael-Stetter tandem reaction of salicylaldehyde (73) with activated allenoates 206.

enantioselectivity of the reaction is possibly enhanced by traces of strong hydrogen bonding donors, such as catechols, ${ }^{91}$ derived from Dakin-oxidation of salicylaldehydes. When the reaction was performed stepwisely the final products were isolated in good yields, however, in lower and more uniform enantioselectivities. Contrary, addition of a salicylaldehyde or a catechol slightly improved the selectivity of the Stetter reaction. ${ }^{91}$ Unsymmetrical alkynes $\mathbf{2 0 3}$ were tested as Michael acceptors as well (Scheme 30) under the developed reaction conditions. Thus, reaction of salicylaldehyde (73) with two different ketoalkynoates regioselectively afforded the products 204a and 204b in moderate yields and poor enantioselectivities. The use of a less electrophilic alkyne resulted in higher enantioselectivity for product 204c $(51 \%$ ee), but low regioselectivity (204c/205c: $2.8: 1)$. Interestingly, the minor regioisomer $205 \mathrm{c}$ formed with appreciably higher enantioselectivity ( $89 \%$ ee). Employing a phosphonate ester as alkyne component afforded 204d in low yield and with better selectivity. ${ }^{89}$

In order to achieve better yields and high regio- and enantioselectivities, Lathrop and Rovis examined the reaction of salicylaldehyde (73) with alkynes bearing a single electronwithdrawing group ${ }^{89,92}$ (the thus-generated intermediate aldehydes have been used previously in the Stetter reaction affording the corresponding products in high enantioselectivity). However, an initial attempt resulted in the isolation of starting materials only. As the Stetter reaction is significantly influenced by olefin geometry ( $E$-isomers react with higher yield and enantioselectivity) the authors performed the reaction sequence with allenoates 206 (Scheme 31). ${ }^{89}$ These starting materials (as well as 201) formed the intermediate aldehydes with high 


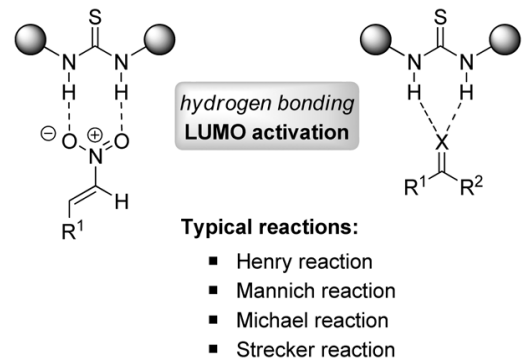

Fig. 8 Hydrogen bonding catalysis. $\mathrm{R}^{1}, \mathrm{R}^{2}=\mathrm{H}$, alkyl, aryl; $\mathrm{X}=\mathrm{O}$, NR.

$E$-selectivity, whereas ketoalkynoates gave mixtures of $E$ and $Z$ isomers. Thus, employing 73 and 206 in a sequential multicatalytic reaction afforded the desired products $\mathbf{2 0 7}$ in reasonable yields and with up to $98 \%$ ee (Scheme 31 ).

\section{Thiourea catalysts}

During the last decade, thiourea derivatives have received great attention and have displayed their efficiency as hydrogen bonding organocatalysts ${ }^{22,24,93}$ and anion-receptors. ${ }^{94}$ In hydrogen bonding catalysis the interaction between the catalyst and an electrophilic substrate generally results in LUMO activation of the latter, thus allowing nucleophilic attack (Fig. 8). Therefore, the combination of thioureas with other catalysts allows additional valuable transformations.

\section{Combinations of thioureas with secondary amine catalysts}

In 2009, Dixon et al. combined bifunctional thiourea (S)-208 and either secondary amine $(S)$-209 (catalyst combination I) or (R)-209 (catalyst combination $\mathrm{J}$ ) for a three-component tandem reaction comprising malonate esters, nitroolefins and $\alpha, \beta$-unsaturated aldehydes to form polysubstituted cyclohexanes 219 (Scheme 32). ${ }^{95}$ The reaction was applicable for a wide range of starting materials, leading to a broad product scope. Thus, the products 219 were formed with catalyst combination I (45-87\% yield, $9.3: 1.8: 1$ d.r., up to $>99 \%$ ee). Four additional examples were reported using catalyst combination $\mathrm{J}$ (with $(R)-209$ ) and dimethylmalonate ester $\mathbf{1 5 1}$ under variation of the nitroalkene and enal component affording epi-219 (47-69\% yield, $7.1: 1.8: 1$ d.r., up to $>99 \%$ ee). The reaction has been suggested to proceed via bifunctional activation of malonate esters and nitroalkene through base and Brønsted acid catalysis by $(S)-208$ leading to stereoselective Michael addition (Scheme 33). The thus-formed Michael adduct 221 subsequently undergoes a regioselective nitro-Michael reaction to the enal under iminium activation with secondary amine $(S)$-209 producing 222. This intermediate undergoes a base-promoted aldol cyclization to generate the desired product 219. Control experiments suggested that the iminium catalyzed nitro-Michael addition is also basepromoted, and therefore that both catalysts work cooperatively. Moreover, there are putative matched and mismatched combinations of catalysts and reaction intermediates and an amplification of enantioselectivity for the matching cases.
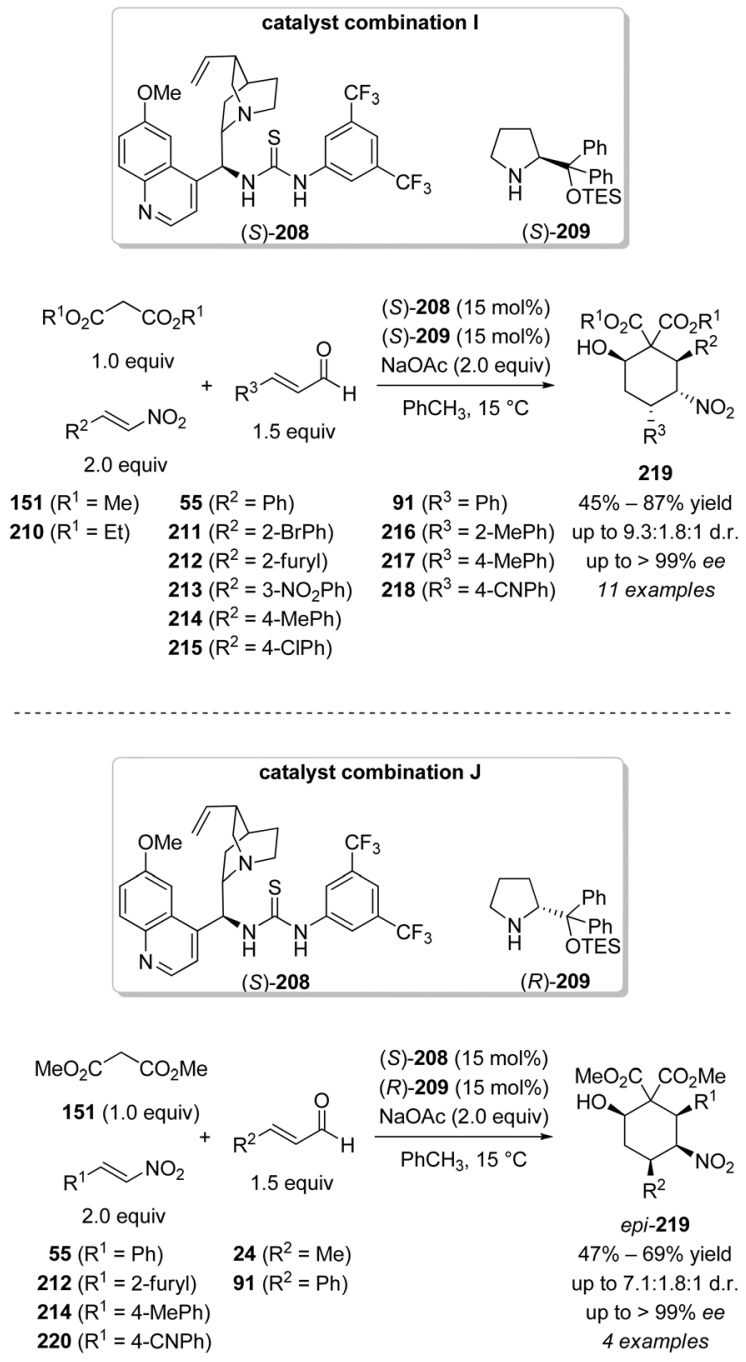

Scheme 32 Combination of bifunctional thiourea and amino catalysis reported by Dixon et al.; TES = triethylsilyl.

One year later, Dixon and $\mathrm{Xu}$ reported a similar bifunctional thiourea (S)-223/secondary amine $(S)$-209 catalyzed tandem reaction (Scheme 34). Different aldehydes, nitroolefins, and tosyl-protected imines 226-230 were employed producing the fully substituted piperidines $\mathbf{2 3 1}$ or epi-231 in moderate to good yields $(47-71 \%)$ and excellent enantioselectivities, usually $>99 \%$ ee. ${ }^{96}$ The reaction is initiated by the Michael addition of enamine-activated aldehydes with cooperatively hydrogen bonding activated nitroalkenes. Following thiourea $(S)$-223 catalyzed nitro-Michael reaction of the corresponding Michael adducts and the imines through bifunctional base/Brønsted acid catalysis gives the substituted aminoaldehyde, and final cyclization leads to the $N$-tosyl protected hemiaminals 231 and epi-231.

\section{Combination of thiourea catalysts with Brønsted acids and bases}

In 2010, Barbas et al. reported the organocatalytic synthesis of carbohydrate derivatives through sequential Michael-Henry reactions employing thiourea $(1 R, 2 R)-\mathbf{2 3 2}$ and either triethylamine or 1,8-diazabicyclo[5.4.0] undec-7-ene (DBU, 237; Schemes 35 and 36). ${ }^{97,98}$ The $(1 R, 2 R)-232$ catalyzed Michael reaction of 


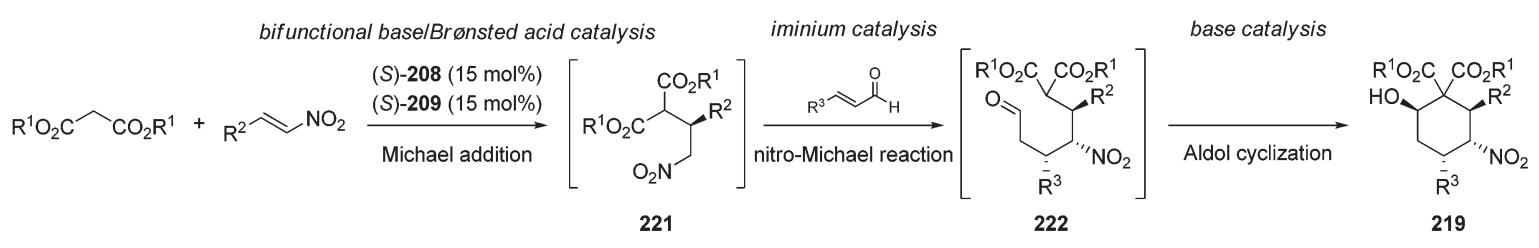

Scheme 33 Pathway for the reaction shown in Scheme 32.

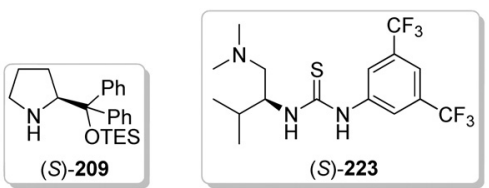

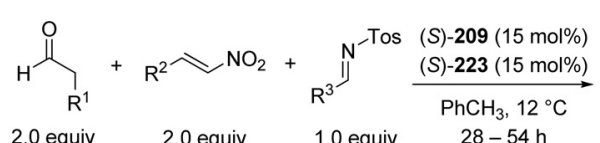<smiles>[R]C1C([R])[C@H]([N+](=O)[O-])N([18OH])[C@H]1O</smiles>

Tos

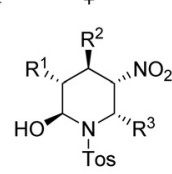

$\begin{array}{lll}54\left(R^{1}=M e\right) & 211\left(R^{2}=2-B r P h\right) & 227\left(R^{3}=4-M e P h\right.\end{array}$

$162\left(R^{1}=B n\right) \quad 212\left(R^{2}=2\right.$-furyl $) \quad 228\left(R^{3}=4-C N P h\right)$

$224\left(\mathrm{R}^{1}=n\right.$-pentyl) $214\left(\mathrm{R}^{2}=4-\mathrm{MePh}\right) \quad 229\left(\mathrm{R}^{3}=3-\mathrm{FPh}\right)$

$225\left(R^{2}=3-\mathrm{CIPh}\right) \quad 230\left(R^{3}=2\right.$-furyl)

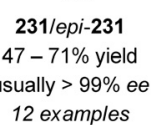

12 examples

Scheme 34 Synthesis of fully substituted piperidines via the merger of enamine and bifunctional base/Brønsted acid catalysis. TES $=$ triethylsilyl.

aldehyde 233 with $\beta$-nitrostyrene (55) thus generated intermediate 234a $(\mathrm{R}=\mathrm{Ph})$. Upon addition of triethylamine this Michael adduct underwent a Henry reaction with remaining aldehyde 233 affording 3,4-dideoxy-D-talose derivative 235a in $68 \%$ yield with $98 \%$ ee, which is in equilibrium with its open form $\mathbf{2 3 6}$ a in solution due to a 1,3-diaxial interaction between the nitro group and the alkoxy substituent. Indeed, only small amounts of the D-manno-isomer epi-235a formed (Scheme 35). Other nitrostyrenes with both electron-withdrawing and electron-donating groups on the aromatic ring were used affording the desired products 235b-235d in good yields and high enantioselectivities (62-67\% yield, up to $98 \%$ ee). Heteroaromatic substituents could be introduced as shown for $\mathbf{2 3 5 f}$. However, 236e was present only in the open form and required an equimolar amount of triethylamine for the Henry reaction to proceed. Nitroalkenes bearing smaller substituents afforded products $\mathbf{2 3 5 g}$ and $\mathbf{2 3 5 h}$ exclusively as their cyclized form. The use of DBU (237) as base catalyst under otherwise identical conditions led to a complete epimerization at the stereogenic center bearing the nitro group thus afforded the corresponding 3,4-dideoxy-D-mannose derivatives epi-235 (Scheme 36; only the cyclized form was observed). ${ }^{97}$ Except for 2,6-dichloronitrostyrene, all previously tested nitroolefins were applicable affording products epi-235 via the anti-Michael/syn-Henry/epimerization reaction sequence. To increase the utility of the reaction other aldehydes were tested as acceptors for the Henry reaction. For example, the use of glyoxylate 244 gave carbohydrate derivatives 245 and epi-245 in moderate yield but high enantioselectivity (98\% ee) under the developed conditions (Scheme 37).

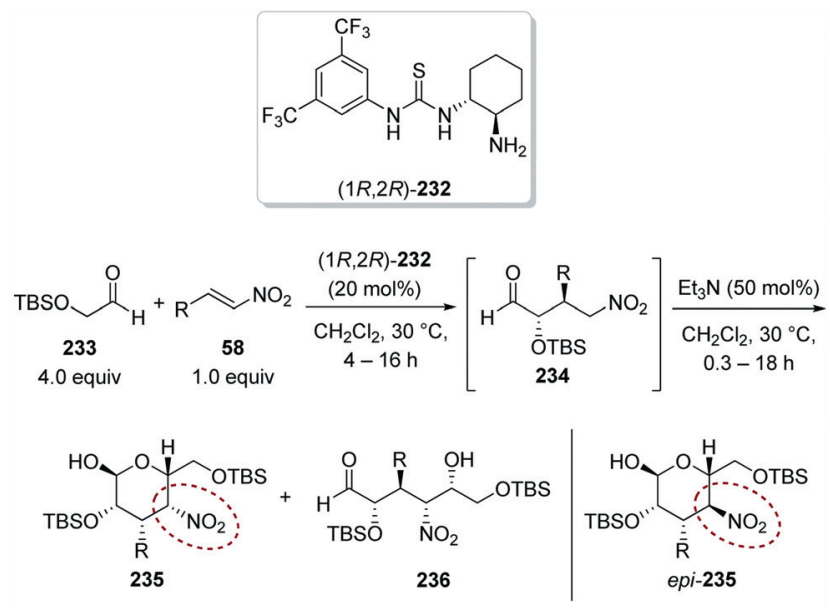

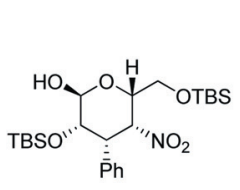

$235 a / 236 a(3: 1)$

$68 \%$ yield

$>10: 1$ d.r., $98 \%$ ee

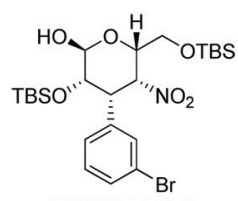

235d/236d (6:1)

$68 \%$ yield

$>10: 1$ d.r., $97 \%$ ee

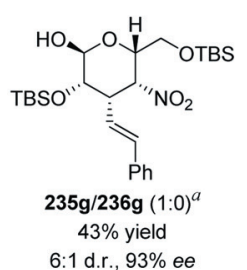

$6: 1$ d.r., $93 \%$ ee
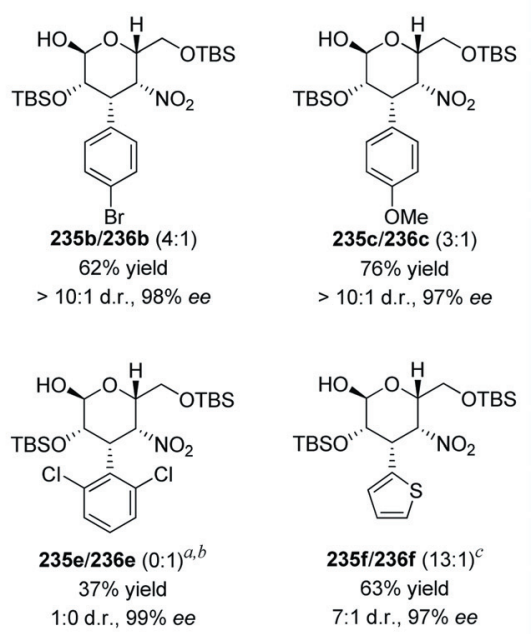

235f/236f $(13: 1)^{c}$

$63 \%$ yield 7:1 d.r., $97 \%$ ee

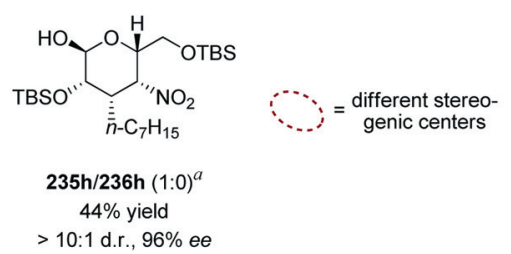

Scheme 35 Sequential Michael-Henry reaction for the synthesis of 3,4-dideoxy-D-talose derivatives 235. ${ }^{a}$ Reaction performed with $50 \mathrm{~mol} \%$ $(1 R, 2 R)-232 .{ }^{b} 100 \mathrm{~mol} \%$ triethylamine used. ${ }^{c} 30 \mathrm{~mol} \%$ triethylamine used.

Moreover, the group disclosed an example for an intermolecular syn-Michael/Henry reaction sequence (Scheme 38). The synMichael reaction was accomplished using isovaleraldehyde (99), $\beta$-nitrostyrene (55), and diphenylprolinol silyl ether $(S)-7$ as first 

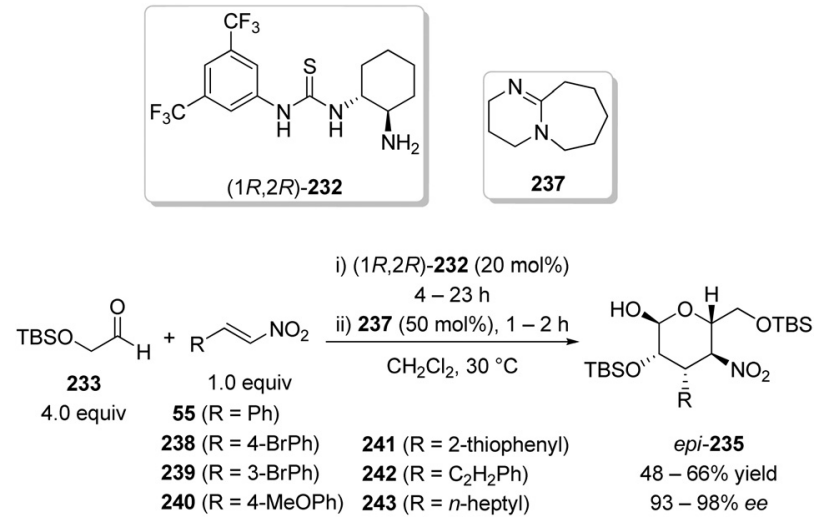

Scheme 36 Sequential Michael-Henry reaction for the synthesis of 3,4-dideoxy-D-mannose derivatives epi-235. ${ }^{a}$ Reaction was performed with $50 \mathrm{~mol} \%(1 R, 2 R)-\mathbf{2 3 2}$.

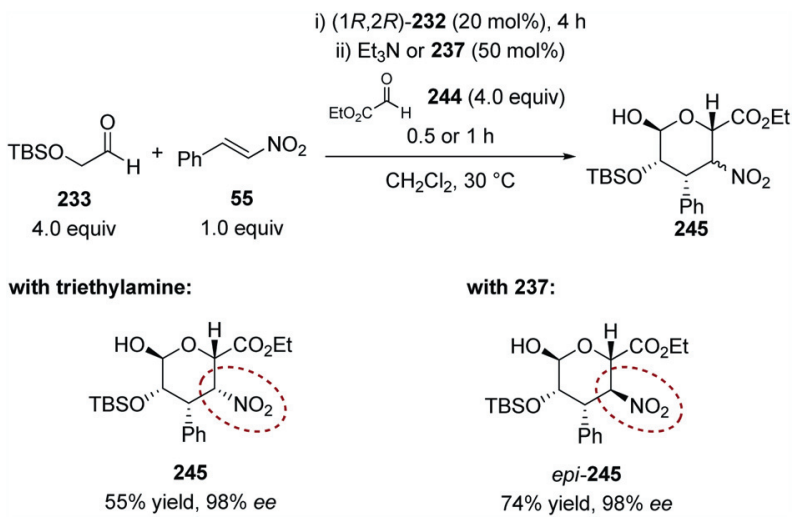

Scheme 37 Sequential Michael-Henry reaction for the synthesis of carbohydrate derivatives 245 and epi-245.
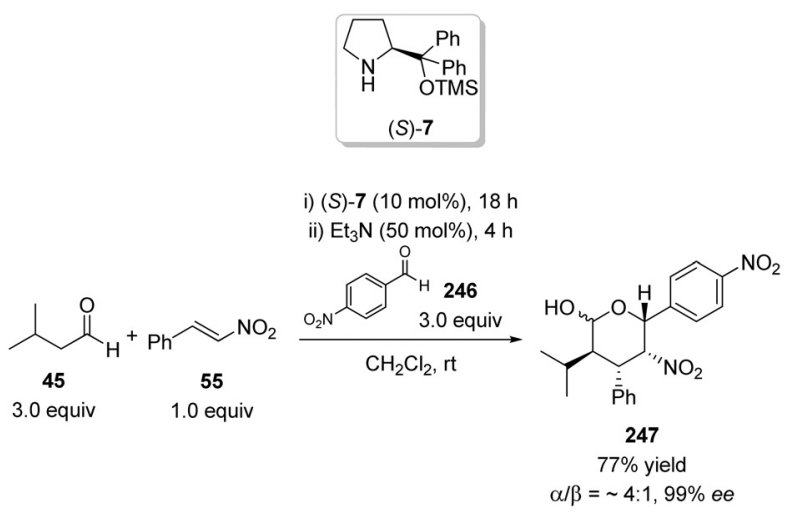

Scheme 38 Sequential syn-Michael-Henry reaction for the synthesis of carbohydrate derivative 247 .

catalyst. The sequential addition of para-nitrobenzaldehyde (246) and triethylamine produced $\mathbf{2 4 7}$ in $77 \%$ yield and excellent $99 \%$ ee as a $4: 1$ mixture of the corresponding $\alpha / \beta$-isomers. The reactions presented in Schemes 35-37 are good examples testifying that even simple catalysts such as triethylamine and DBU (237) may provide a direct entry to different diastereomeric forms of a desired product.
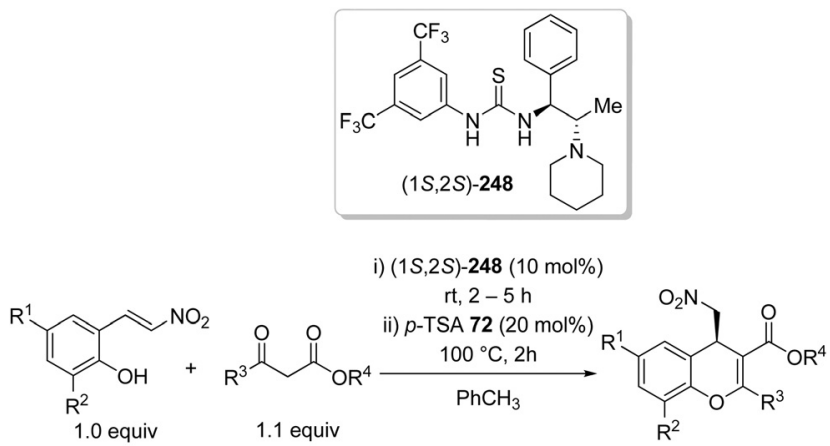

$$
\begin{array}{ll}
249\left(R^{1}=R^{2}=H\right) & 152\left(R^{3}=M e ; R^{4}=E t\right) \\
250\left(R^{1}=B r ; R^{2}=H\right) & 154\left(R^{3}=R^{4}=M e\right) \\
251\left(R^{1}=C O_{2} M e ; R^{2}=H\right) & 157\left(R^{3}=M e ; R^{4}=t-B u\right) \\
252\left(R^{1}=N_{2} ; R^{2}=H\right) & 255\left(R^{3}=M e ; R^{4}=i-P r\right) \\
253\left(R^{1}=H ; R^{2}=M e\right) & 256\left(R^{3}=M e ; R^{4}=\left(C H_{2}\right)_{2} O M e\right. \\
254\left(R^{1}=H ; R^{2}=O M e\right) & 257\left(R^{3}=P h ; R^{4}=E t\right)
\end{array}
$$




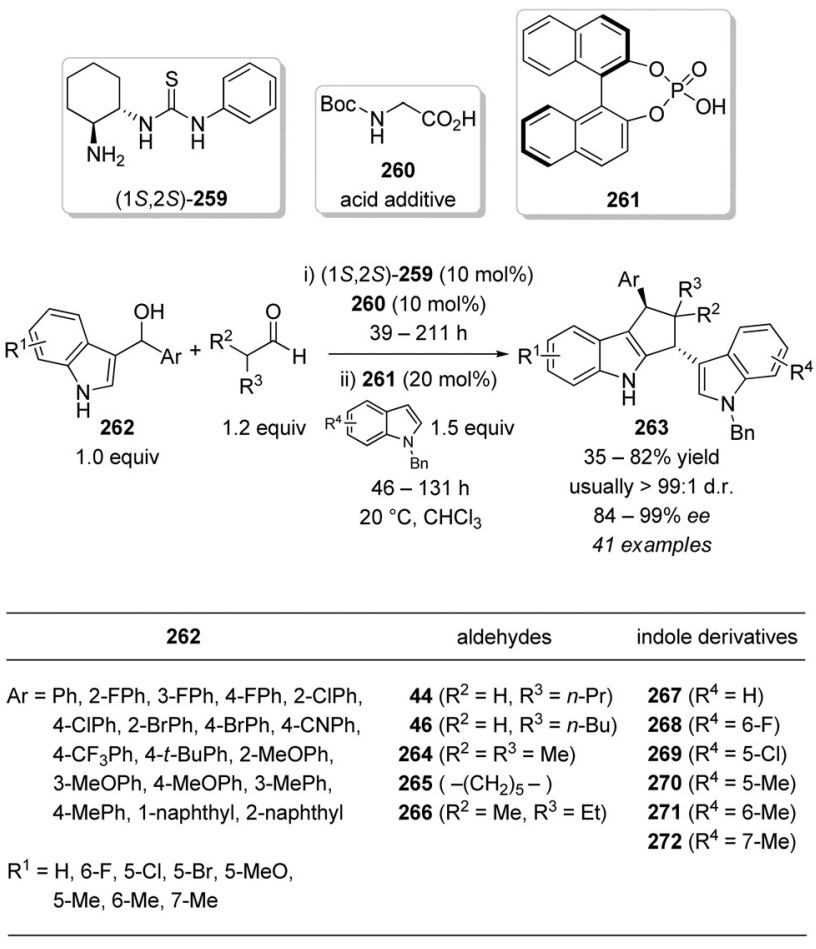

Scheme 40 Synthesis of cyclopenta[ $[b]$ indoles 263 via $\alpha$-alkylation and two consecutive Friedel-Crafts alkylations.

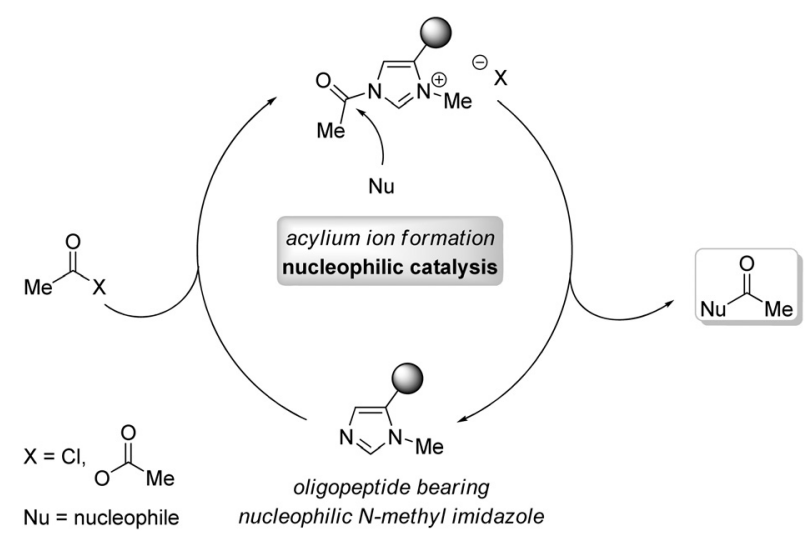

Fig. 9 General representation for acyl transfer reactions with $N$-methylimidazole derivatives.

Oligopeptides bearing nucleophilic catalytic moieties, such as $\mathrm{N}$-alkylimidazoles, showed to be highly efficient catalysts in the kinetic resolution of racemic substrates as well as the desymmetrization of meso compounds through acyl group transfer. ${ }^{104}$ Thus, the nucleophilic catalyst forms an acylium cation salt with the corresponding counterion ${ }^{105}$ with an acyl donor (e.g., acetic anhydride or acetyl chloride; Fig. 9). ${ }^{104}$ This acylium ion allows transferring the acetyl group onto a nucleophile (e.g., alcohol, amine, thiol) affording the product. Depending on the $\mathrm{p} K_{\mathrm{a}}$ values of the protonated imidazole and the counterion ( $\mathrm{X}$ in Fig. 9) the addition of base may be necessary to prevent catalyst protonation and deactivation. ${ }^{104}$
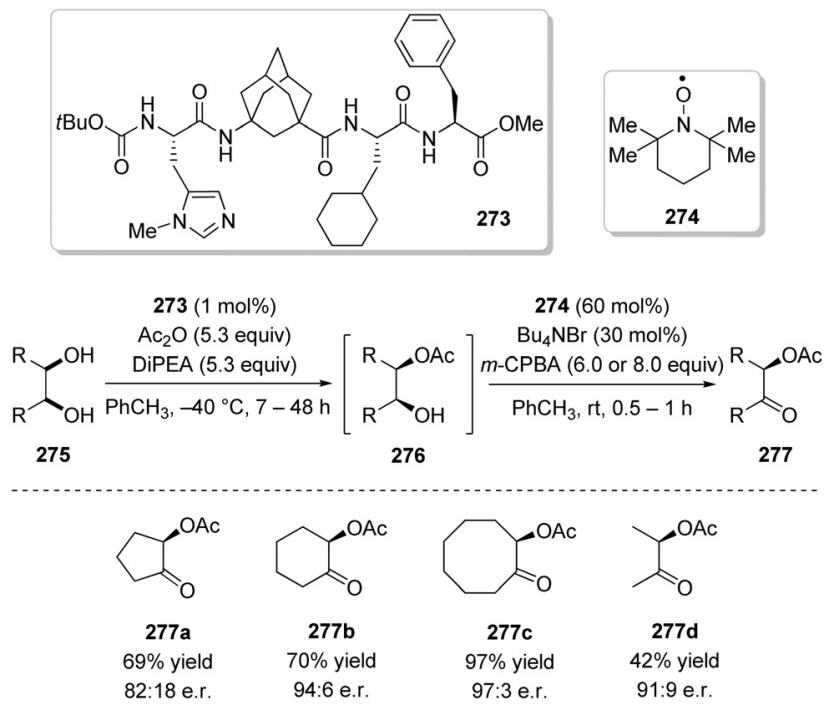

Scheme 41 Oligopeptide 273 catalyzed desymmetrization of mesoalkane-1,2-diols and one-pot TEMPO (274) oxidation.

In 2008, Müller et al. introduced tetrapeptide 273 (Boc-LPmh- ${ }^{\mathrm{A}}$ Gly-L-Cha-L-Phe-OMe) ${ }^{106}$ equipped with $\pi$-methyl histidine $(\mathrm{Pmh})$ as catalytic moiety. The incorporation of a rigid nonnatural $\gamma$-amino adamantane carboxylic acid $\left({ }^{\mathrm{A}} \mathrm{Gly}\right)^{107}$ into the backbone led to a more lipophilic and structurally less flexible oligopeptide. ${ }^{106}$ Hence, this approach did not follow conventional design principles for oligopeptide catalysts which usually emphasize the importance of secondary structures (stabilized by intramolecular hydrogen bonding) for activity and selectivity. ${ }^{102}$ Catalyst 273 was first applied for the acylative kinetic resolution $^{104}$ of racemic trans-cycloalkane-1,2-diols, a substance class previously challenging to resolve, achieving $>99 \%$ ee for the remaining diol enantiomers and $S$-values ${ }^{108}$ of typically $>50 .{ }^{106,109}$ Later, oligopeptide $\mathbf{2 7 3}$ was applied for the desymmetrization ${ }^{104}$ of meso-alkane-1,2-diols $\mathbf{2 7 5}$. $^{110}$ Owing to racemization of the monoacetylated products $\mathbf{2 7 6}$ through intramolecular transesterification during work-up, Müller et al. envisioned the direct one-pot oxidation ${ }^{111}$ of intermediate 276 using TEMPO (2,2,6,6-tetramethylpiperidin-1-oxyl; 274) which then would lead to the valuable enantiomerically enriched $\alpha$-acetoxy ketones 277 (Scheme 41). Under optimized conditions, the desymmetrization was performed using only $1 \mathrm{~mol} \%$ 273, acetic anhydride and Hünig's base (5.3 equivalents each). The sequential addition of TEMPO (274; $60 \mathrm{~mol} \%)$, tetrabutylammonium bromide (30 mol\%) and meta-chloroperbenzoic acid ( $m$-CPBA, 6.0 or 8.0 equivalents) as co-oxidant then initiated the second catalytic cycle. Thus, the corresponding $\alpha$-acetoxy ketones $\mathbf{2 7 7}$ were afforded with moderate to excellent yields and high enantiomeric ratios (up to $97 \%$ yield and $97: 3$ d.r. for 277c).

\section{Multicatalyst approaches}

Inspired by their sequential multicatalysis approach (Scheme 41$),{ }^{110}$ Müller et al. envisioned a multicatalyst system to perform the entire reaction sequence (Scheme 42). Indeed, by 

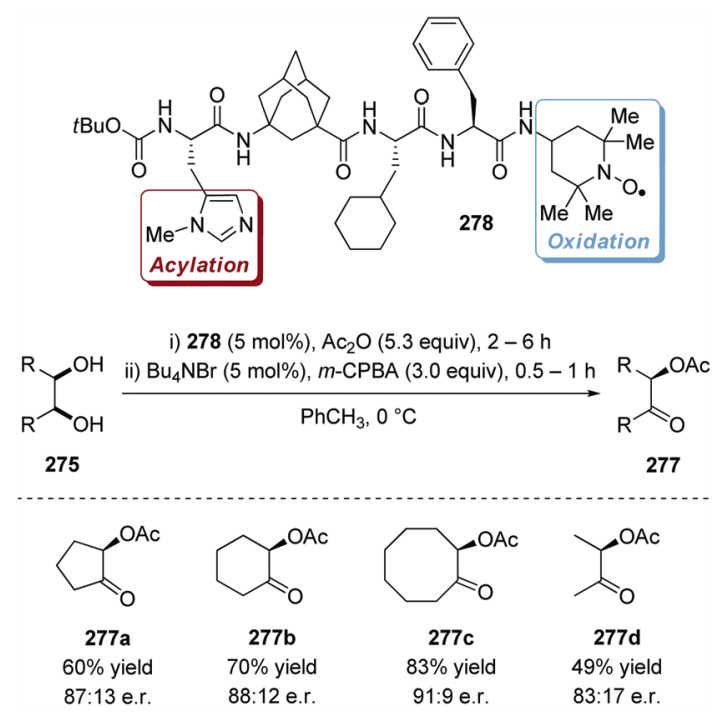

Scheme 42 Oligopeptide based multicatalyst 278 for the one-pot desymmetrization and subsequent oxidation of meso-alkane-1,2-diols.

replacing the C-terminal methyl ester group of peptide $\mathbf{2 7 3}$ with a TEMPO-amide functionality they obtained the first member of organic multicatalysts $\mathbf{2 7 8}$ (Boc-L-Pmh- ${ }^{\mathrm{A}}$ Gly-L-Cha-L-PheNH-TEMPO), bearing two orthogonal catalytic moieties (Scheme 42). ${ }^{13,112}$ Remarkably, this proof-of-principle study revealed that the multicatalyst $\mathbf{2 7 8}$ shows an increased oxidation activity compared to TEMPO itself. As a result, the amounts of $m$-CPBA (3.0 instead of up to 8.0 equivalents) and tetrabutylammonium bromide ( $5 \mathrm{~mol} \%$ instead of $30 \mathrm{~mol} \%$ ) could be significantly reduced. Moreover, $5 \mathrm{~mol} \%$ of multicatalyst 278 and, therefore, only $5 \mathrm{~mol} \%$ of TEMPO-analogue (instead of $60 \mathrm{~mol}$ $\%$ TEMPO), were sufficient to perform the second reaction at $0{ }^{\circ} \mathrm{C}$ without affecting the reaction time. The desymmetrization step showed only a slight decrease in selectivity compared to the two-catalyst approach. Indeed, a molecular force-field analysis revealed that the conformation of peptide $\mathbf{2 7 8}$ is not affected upon introduction of the TEMPO moiety, therefore maintaining selectivity.

Applying the concept of retrocatalysis, the same group developed a new peptide-based multicatalyst (Scheme 43) bearing $\beta$-aspartate and $\pi$-methyl histidine (Pmh) as catalytic moieties (step-oriented approach; see introduction). ${ }^{113}$ Multicatalyst 279 in conjunction with hydrazinium sulfate (280) enabled the synthesis of enantiomerically enriched trans-1,2-alkanediols $(S, S)$-283 and monoacetylated diols $(R, R)$-284 employing simple symmetrical alkenes 281, hydrogen peroxide, water, and acetic anhydride. Hence, the epoxidation of alkenes 281 catalyzed by the aspartate moiety ${ }^{114}$ proceeds via intramolecular anhydride formation using $N, N^{\prime}$-diisopropyl carbodiimide (DIC) as dehydrating agent. Anhydride cleavage by hydrogen peroxide generates the catalytically active monoperacid that enables the epoxidation to 282. Addition of $\mathbf{2 8 0}$ as additional Brønsted acid catalyst, water, and toluene (the epoxide opening proceeds slower in polar solvents) for the subsequent epoxide hydrolysis produces racemic trans-1,2-alkanediol ( \pm )-283. Final kinetic resolution through acylation by multicatalyst 279 completes the reaction sequence and affords the corresponding enantiomerically enriched diols $(S, S)$-283 and monoacetylated diols $(R, R)$ 284 with moderate to good yields (the maximum would be 50\%) and $S$-values up to 26 (corresponding to $99 \%$ ee for $(S, S)-283 \mathrm{c}$ and $68 \%$ ee for $(R, R)-\mathbf{2 8 4 c})$. Due to protonation of the basic histidine residue by the bisulfate the addition of Hünig's base is necessary for the acetylation step.

\section{Miscellaneous examples of oligopeptide catalyzed reactions}

Two related reaction sequences were reported in the same publication. ${ }^{113}$ Preparing the bisulfate salt $\mathbf{2 8 5}$ as an analogue of $\mathbf{2 8 0}$
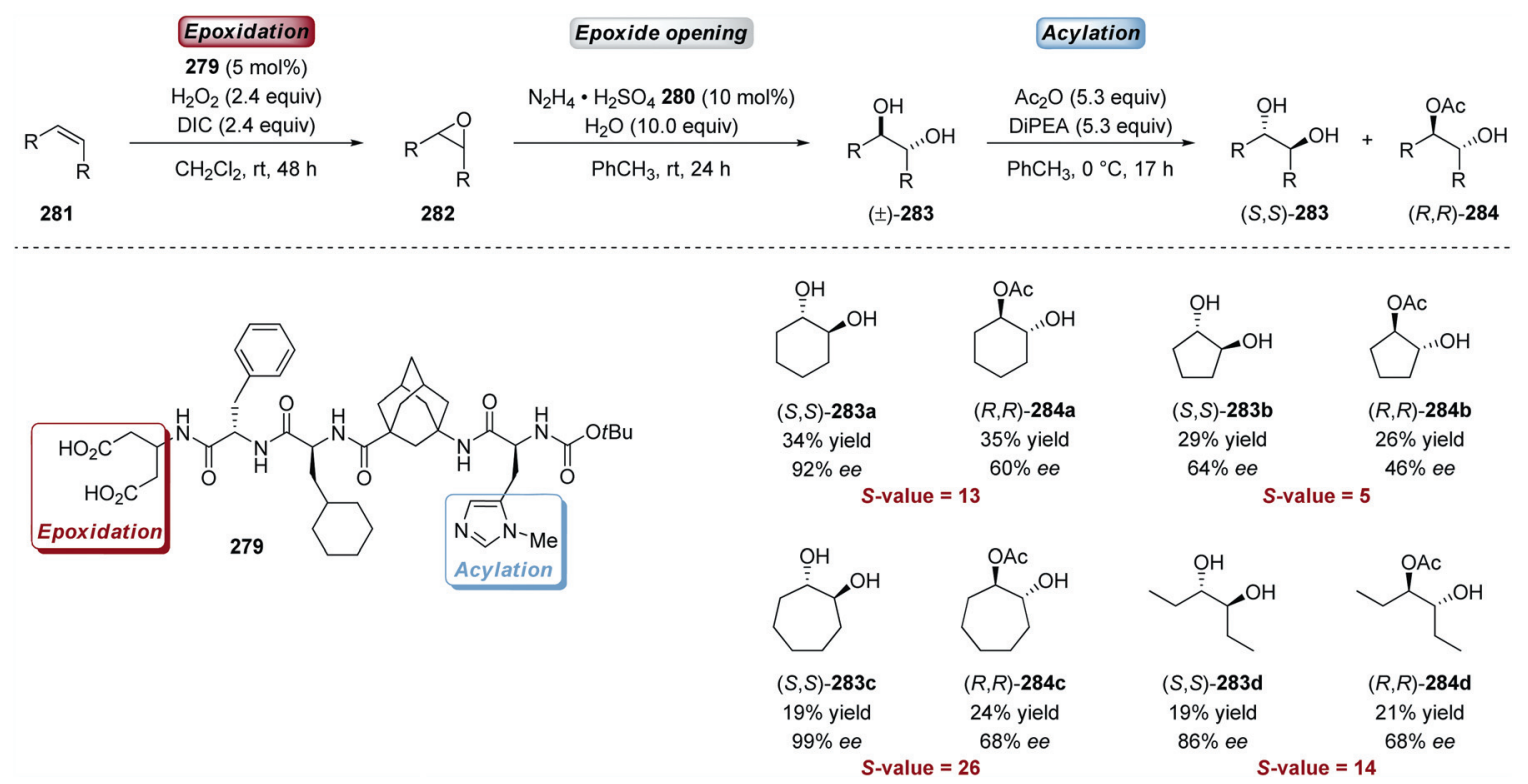

Scheme $\mathbf{4 3}$ Performance of multicatalyst $\mathbf{2 7 9}$ in conjunction with catalyst $\mathbf{2 8 0}$ for the three-step one-pot synthesis of enantiomerically enriched trans-1,2-alkanediols $(S, S)$-283 and monoacylated trans-1,2-diols $(R, R)$-284. 
(due to its acid lability the Boc-protecting group was exchanged by an acetyl group) allowed the epoxide opening (Scheme 44). Addition of Hünig's base in the next step releases the acylation catalyst, thus enables the subsequent kinetic resolution of ( \pm )-283. The corresponding trans-1,2-alkanediols $(S, S)$-283 were produced with excellent enantioselectivities (usually $>99 \%$ ee,
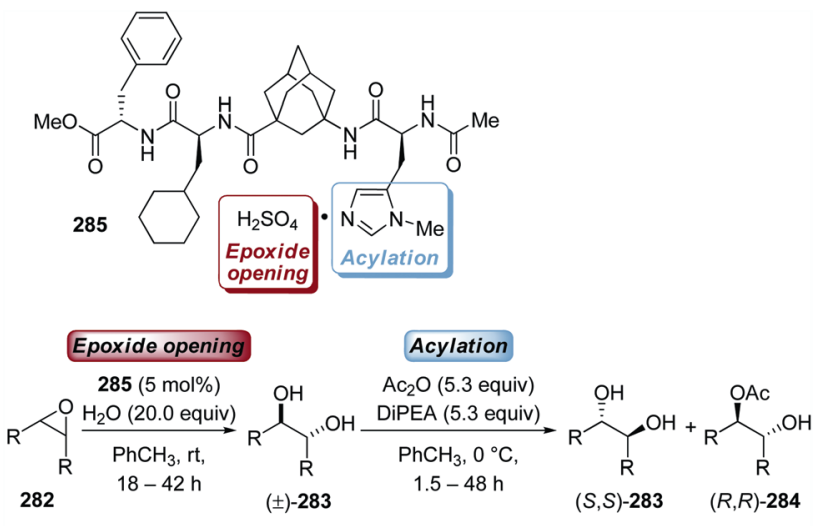

$(S, S)-\mathbf{2 8 3} \mathbf{a}^{a}$

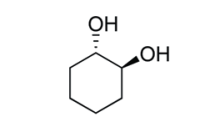
$>99 \%$ ee $(>99 \%$ ee $) \quad 74 \%$ ee $(65 \%$ ee $)$ $C=57 \%$

(S,S)-283a: $25 \%$ yield; $(R, R)-284 a: 54 \%$ yield $S$-value $=48(33)$

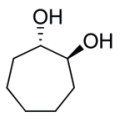

$(S, S)-283 c$ $>99 \%$ ee C $=58 \%$

S-value $=40$

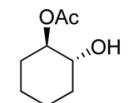

R,R)-284a

$$
\text { (33) }
$$

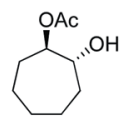

$(R, R)-284 \mathrm{c}$ $70 \%$ ee

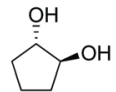

$(S, S)-283 b$

$78 \%$ ee

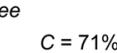

S-value $=4$

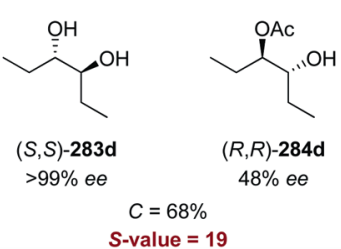

Scheme 44 Performance of peptide salt $\mathbf{2 8 5}$ in an epoxide hydrolysis/ kinetic resolution reaction sequence. ${ }^{a}$ Values in parentheses indicate a preparative experiment on $1.0 \mathrm{mmol}$ scale. except for $(S, S)$-283b). Thereby, the monoacetylated products $(R, R)-\mathbf{2 8 4}$ formed with good enantioselectivities (up to $74 \%$ ee for $(R, R)$-284a) leading to $S$-values of up to 48 (at $57 \%$ conversion). ${ }^{113}$ Indeed, 285 is not a multicatalyst in that sense. Referring to the terminology of Fogg and dos Santos ${ }^{4}$ this example can be labelled as assisted tandem reaction. However, this reaction sequence was further expanded using phthalic acid (286) as additional epoxidation catalyst and peptide salt $\mathbf{2 8 5}$ as catalyst for the subsequent reaction steps (Scheme 45). Starting from cyclohexene (281a) this three-step reaction sequence furnished $(S, S)$-283a and $(R, R)$-284a with $>99 \%$ ee and $73 \%$ ee, respectively, corresponding to an excellent $S$-value of 45 (an experiment at preparative scale gave a $S$-value of 26 ; Scheme 45$).{ }^{113}$

\section{Conclusions}

In only one decade, the field of organocatalysis, an area ideally suited for green chemistry approaches, has seen tremendous progress. The development of new catalyst classes with orthogonal reactivities and their implementation in one-pot multistep processes led to considerable increase of reaction efficiency, selectivity, and sustainability.

From the beginning organomulticatalysis provided a powerful tool for the synthesis of complex molecules with increased efficiency and diminished effort. The prevalent organocatalyst classes and their specific activation modes, secondary amine catalysts, $N$-heterocyclic carbenes, thiourea derivatives, as well as synthetic oligopeptides equipped with nucleophilic $\pi$-methyl imidazole, respectively, have been applied in conjunction with other catalysts. As for any other rapidly developing discipline, it is difficult to forecast what the future of multicatalysis will look like but it is clear that this concept is likely to meet many of the demands that will become increasingly important in the future, e.g., reaction and resource efficiency as well as sustainability. Organomulticatalysis is therefore likely to become one of the prevailing methodologies in organic synthesis. As there are so many different organocatalysts, the number of theoretically possible combinations seems to be limitless, and we have only begun recently to explore its potential. Most reactions discussed herein

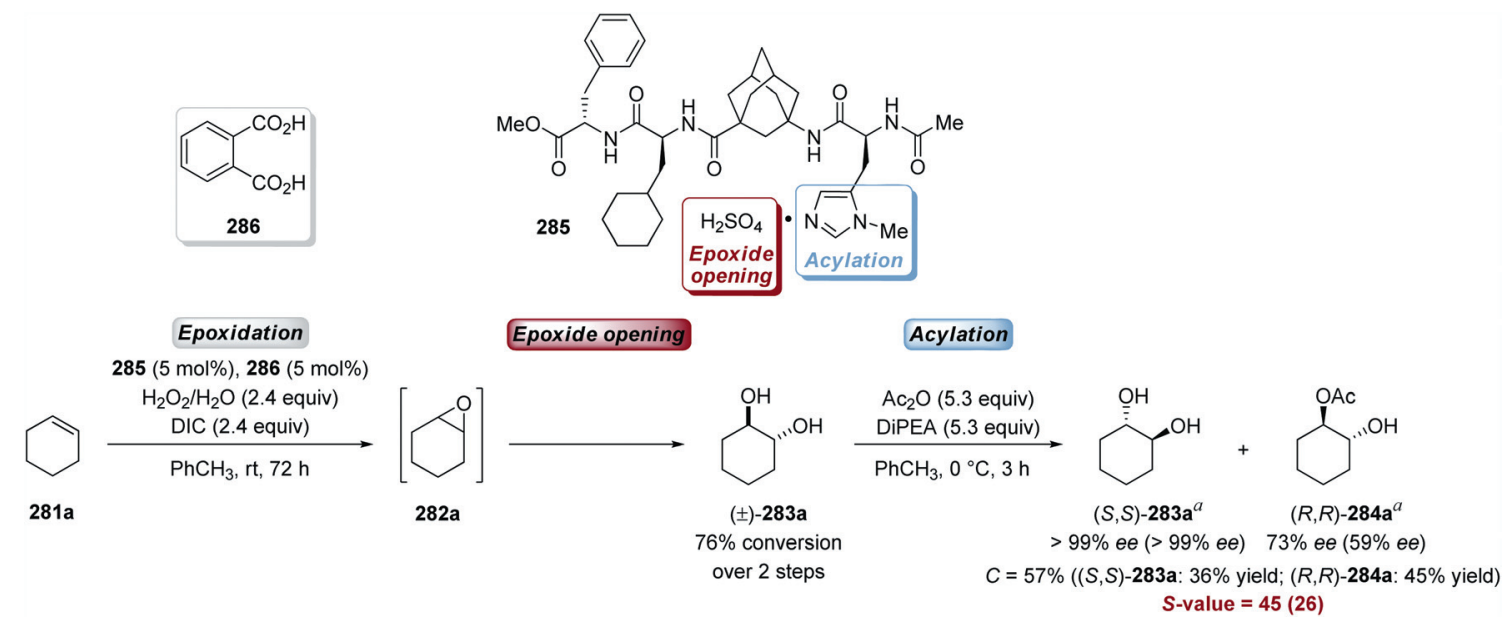

Scheme 45 Performance of peptide salt $\mathbf{2 8 5}$ in conjunction with phthalic acid (286) in the epoxidation/epoxide hydrolysis/kinetic resolution reaction sequence. ${ }^{a}$ Values in parentheses indicate a preparative experiment on $1.0 \mathrm{mmol}$ scale. 
utilize only a very limited number of catalytically active moieties (mainly two) so that the main developments are in expanding the number of catalyzed reaction steps that can be carried out in one pot.

Oligopeptides offer an excellent platform for the development of novel multicatalysts. Applying the complementary strategies of retrosynthesis and retrocatalysis, a reasonable but yet elusive goal would be to enable entire syntheses of highly complex molecules (e.g., natural products) by one-pot multicatalyst systems. A clear testament to the potential and importance of this approach has recently been made by Anastas and Eghbali: "If the same catalyst could be used for various independent reactions or achieve an entire synthesis in one pot, it will bring chemistry to a new level as more complex molecules could be made with higher material and energy efficiency". ${ }^{29}$

\section{Acknowledgements}

We gratefully acknowledge financial support by the Deutsche Forschungsgemeinschaft (SPP1179 Organocatalysis). R. C. W. thanks Christian E. Müller for fruitful discussions.

\section{Notes and references}

1 For general reviews on multicatalysis, see: (a) L. M. Ambrosini and T. H. Lambert, ChemCatChem, 2010, 2, 1373; (b) J. Zhou, Chem.-Asian J., 2010, 5, 422.

2 For selected authorative reviews covering the field of asymmetric organocatalysis, see: (a) A. Berkessel and H. Gröger, Asymmetric Organocatalysis: from Biomimetic Concepts to Applications in Asymmetric Synthesis, Wiley-VCH, Weinheim, 2005; (b) J. Seayad and B. List, Org. Biomol. Chem., 2005, 3, 719; (c) P. I. Dalko, Enantioselective Organocatalysis: Reactions and Experimental Procedures, Wiley-VCH, Weinheim, 2007; (d) R. M. de Figueiredo and M. Christmann, Eur. J. Org. Chem., 2007, 2575; (e) M. J. Gaunt, C. C. C. Johansson, A. McNally and N. T. Vo, Drug Discovery Today, 2007, 12, 8; (f) H. Pellissier, Tetrahedron, 2007, 63, 9267; (g) D. W. C. MacMillan, Nature, 2008, 455, 304; (h) E. Marqués-López, R. P. Herrera and M. Christmann, Nat. Prod. Rep., 2010, 27, 1138; (i) A. Moyano and R. Rios, Chem. Rev., 2011, 111, 4703; $(j)$ F. Giacalone, M. Gruttadauria, P. Agrigento and R. Noto, Chem. Soc. Rev., 2012, 41, 2406.

3 (a) L. F. Tietze, Chem. Rev., 1996, 96, 115; (b) K. C. Nicolaou, T. Montagnon and S. A. Snyder, Chem. Commun., 2003, 551; (c) J.C. Wasilke, S. J. Obrey, R. T. Baker and G. C. Bazan, Chem. Rev., 2005, 105, 1001; (d) H. C. Guo and J. A. Ma, Angew. Chem., Int. Ed., 2006, 45, 354; (e) K. C. Nicolaou, D. J. Edmonds and P. G. Bulger, Angew. Chem., Int. Ed., 2006, 45, 7134; $(f)$ L. F. Tietze, G. Brasche and K. Gericke, Domino Reactions in Organic Synthesis, Wiley-VCH, Weinheim, 2006; (g) C. J. Chapman and C. G. Frost, Synthesis, 2007, 1; (h) K. C. Nicolaou and J. S. Chen, Chem. Soc. Rev., 2009, 38, 2993.

4 For a general classification of cascade/domino and tandem reactions, see: D. E. Fogg and E. N. dos Santos, Coord. Chem. Rev., 2004, 248, 2365.

5 A. M. Walji and D. W. C. MacMillan, Synlett, 2007, 1477.

6 For selected general reviews on multicomponent reactions, see: (a) D. J. Ramón and M. Yus, Angew. Chem., Int. Ed., 2005, 44, 1602; (b) J. Zhu and H. Bienaymé, Multicomponent Reactions, Wiley-VCH, Weinheim, 2005; (c) E. Ruijter, R. Scheffelaar and R. V. A. Orru, Angew. Chem., Int. Ed., 2011, 50, 6234.

7 For recent reviews on organocatalytic cascade/domino reactions, see: (a) D. Enders, C. Grondal and M. R. M. Hüttl, Angew. Chem., Int. Ed., 2007, 46, 1570; (b) X. Yu and W. Wang, Org. Biomol. Chem., 2008, 6, 2037; (c) A.-N. Alba, X. Companyó, M. Viciano and R. Rios, Curr. Org. Chem., 2009, 13, 1432; (d) C. Grondal, M. Jeanty and D. Enders, Nat. Chem., 2010, 2, 167; (e) B. Westermann, M. Ayaz and S. S. van Berkel, Angew. Chem., Int.Ed., 2010, 49, 846; $(f)$ H. Pellissier, Adv. Synth. Catal., 2012, 354, 237.
8 For $N$-heterocyclic carbene catalyzed domino reactions, see: A. Grossmann and D. Enders, Angew. Chem., Int. Ed., 2012, 51, 314.

9 For a review on asymmetric organocatalytic multicomponent reactions, see: G. Guillena, D. J. Ramón and M. Yus, Tetrahedron: Asymmetry, 2007, 18, 693.

10 For a general classification and overview of organocatalytic one-pot reactions, see: Ł. Albrecht, H. Jiang and K. A. Jørgensen, Angew. Chem., Int. Ed., 2011, 50, 8492.

11 N. T. Patil, V. S. Shinde and B. Gajula, Org. Biomol. Chem., 2012, 10, 211.

12 For a recent highlight on one-pot syntheses, see: C. Vaxelaire, P. Winter and M. Christmann, Angew. Chem., Int. Ed., 2011, 50, 3605.

13 For multicatalyst approaches employing heterodimetallic complexes, see for example: (a) A. Zanardi, R. Corberán, J. A. Mata and E. Peris, Organometallics, 2008, 27, 3570; (b) A. Zanardi, J. A. Mata and E. Peris, J. Am. Chem. Soc., 2009, 131, 14531; (c) A. Zanardi, J. A. Mata and E. Peris, Chem.-Eur. J., 2010, 16, 10502; (d) A. Zanardi, J. A. Mata and E. Peris, Chem.-Eur. J., 2010, 16, 13109.

14 The expression retrocatalysis was first mentioned in context with the development of a multicatalyst in ref. 113.

15 (a) W. Schrader, P. P. Handayani, C. Burstein and F. Glorius, Chem. Commun., 2007, 716; (b) G. W. Amarante, M. Benassi, H. M. S. Milagre, A. A. C. Braga, F. Maseras, M. N. Eberlin and F. Coelho, Chem.-Eur. J., 2009, 15, 12460; (c) W. Schrader, P. P. Handayani, J. Zhou and B. List, Angew. Chem., Int. Ed., 2009, 48, 1463; (d) A. Berkessel, S. Elfert, K. Etzenbach-Effers and J. H. Teles, Angew. Chem., Int. Ed., 2010, 49, 7120; (e) D. A. Bock, C. W. Lehmann and B. List, Proc. Natl. Acad. Sci. U. S. A., 2010, 107, 20636; (f) O. V. Maltsev, A. O. Chizhov and S. G. Zlotin, Chem.-Eur. $J ., 2011,17,6109 ;(g)$ M. W. Alachraf, P. P. Handayani, M. R. M. Hüttl, C. Grondal, D. Enders and W. Schrader, Org. Biomol. Chem., 2011, 9, 1047; (h) J. Mahatthananchai, P. Zheng and J. W. Bode, Angew. Chem., Int. Ed., 2011, 50, 1673; (i) M. B. Schmid, K. Zeitler and R. M. Gschwind, J. Am. Chem. Soc., 2011, 133, 7065; (j) M. B. Schmid, K. Zeitler and R. M. Gschwind, J. Org. Chem., 2011, 76, 3005; (k) G. Tárkányi, P. Király, T. Soós and S. Varga, Chem.-Eur. J., 2012, 18, 1918.

16 P. H.-Y. Cheong, C. Y. Legault, J. M. Um, N. Çelebi-Ölçüm and K. N. Houk, Chem. Rev., 2011, 111, 5042.

17 S. Piovesana, D. M. Scarpino Schietroma and M. Bella, Angew. Chem., Int. Ed., 2011, 50, 6216.

18 For selected publications on cooperative organocatalysis, see: (a) T. Weil, M. Kotke, C. M. Kleiner and P. R. Schreiner, Org. Lett., $2008,10,1513 ;(b)$ R. S. Klausen and E. N. Jacobsen, Org. Lett., 2009, 11, 887; (c) P. R. Schreiner, Science, 2010, 327, 965; (d) H. Xu, S. J. Zuend, M. G. Woll, Y. Tao and E. N. Jacobsen, Science, 2010, 327, 986; (e) K. Yoshida, T. Inokuma, K. Takasu and Y. Takemoto, Synlett, 2010, 1865; $(f)$ G. Bergonzini, S. Vera and P. Melchiorre, Angew. Chem., Int. Ed., 2010, 49, 9685; (g) S. Č́íhalová, P. Dziedzic, A. Córdova and J. Veselý, Adv. Synth. Catal., 2011, 353, 1096; (h) S. Lin, L. Deiana, G.-L. Zhao, J. Sun and A. Córdova, Angew. Chem., Int. Ed., 2011, 50, 7624; (i) Z. Zhang, K. M. Lippert, H. Hausmann, M. Kotke and P. R. Schreiner, J. Org. Chem., 2011, 76, 9764; (j) X. Zhao, D. A. DiRocco and T. Rovis, J. Am. Chem. Soc., 2011, 133, 12466.

19 For selected publications on organocatalysis with bifunctional and multifunctional organocatalysts, see: (a) A. Berkessel, F. Cleemann, S. Mukherjee, T. N. Müller and J. Lex, Angew. Chem., Int. Ed., 2005, 44, 807; (b) A. Berkessel, S. Mukherjee, F. Cleemann, T. N. Müller and J. Lex, Chem. Commun., 2005, 1898; (c) B. Vakulya, S. Varga, A. Csampai and T. Soós, Org. Lett., 2005, 7, 1967; (d) J. Lubkoll and H. Wennemers, Angew. Chem., Int. Ed., 2007, 46, 6841; (e) S. J. Zuend and E. N. Jacobsen, J. Am. Chem. Soc., 2007, 129, 15872; $(f)$ Y.Q. Fang and E. N. Jacobsen, J. Am. Chem. Soc., 2008, 130, 5660; (g) C. Rabalakos and W. D. Wulff, J. Am. Chem. Soc., 2008, 130, 13524; (h) P. Galzerano, G. Bencivenni, F. Pesciaioli, A. Mazzanti, B. Giannichi, L. Sambri, G. Bartoli and P. Melchiorre, Chem.-Eur. J., 2009, 15, 7846; (i) J.-M. Garnier and F. Liu, Org. Biomol. Chem., 2009, 7, 1272; $(j)$ H. Huang, F. Yu, Z. Jin, W. Li, W. Wu, X. Liang and J. Ye, Chem. Commun., 2010, 46, 5957; $(k)$ V. N. Wakchaure and B. List, Angew. Chem., Int. Ed., 2010, 49, 4136; (l) Y. Wei and M. Shi, Acc. Chem. Res., 2010, 43, 1005; (m) J. Alemán, A. Parra, H. Jiang and K. A. Jørgensen, Chem.-Eur. J., 2011, 17, 6890; (n) W.-Y. Siau and J. Wang, Catal. Sci. Technol., 2011, 1, 1298; (o) B. Tan, N. R. Candeias and C. F. Barbas III, Nat. Chem., 2011, 3, 473; ( $p$ ) Z. Zhang, G. Jakab 
and P. R. Schreiner, Synlett, 2011, 1262; (q) X. Jiang, X. Shi, S. Wang, T. Sun, Y. Cao and R. Wang, Angew. Chem., Int. Ed., 2012, 51, 2084; (r) C. Palacio and S. J. Connon, Chem. Commun., 2012, 48, 2849.

20 For selected different examples of dual catalysis, see: (a) C. E. Aroyan, M. M. Vasbinder and S. J. Miller, Org. Lett., 2005, 7, 3849; (b) H. U. Vora and T. Rovis, J. Am. Chem. Soc., 2007, 129, 13796; (c) M. Binanzer, S.-Y. Hsieh and J. W. Bode, J. Am. Chem. Soc., 2011, 133, 19698; (d) N. Z. Burns, M. R. Witten and E. N. Jacobsen, J. Am. Chem. Soc., 2011, 133, 14578; (e) C. K. De, N. Mittal and D. Seidel, J. Am. Chem. Soc., 2011, 133, 16802; (f) S. Iwahana, H. Iida and E. Yashima, Chem.-Eur. J., 2011, 17, 8009; (g) H. Rahaman, Á. Madarász, I. Pápai and P. M. Pihko, Angew. Chem., Int. Ed., 2011, 50, 6123.

21 (a) B. List, Tetrahedron, 2002, 58, 5573; (b) S. K. Panday, Tetrahedron: Asymmetry, 2011, 22, 1817.

22 S. J. Connon, Chem. Commun., 2008, 2499.

23 (a) S. H. McCooey and S. J. Connon, Angew. Chem., Int. Ed., 2005, 44, 6367; (b) T. Marcelli, J. H. van Maarseveen and H. Hiemstra, Angew. Chem., Int. Ed., 2006, 45, 7496; (c) T. Marcelli and H. Hiemstra, Synthesis, 2010, 1229.

24 (a) Y. Takemoto, Org. Biomol. Chem., 2005, 3, 4299; (b) S. J. Connon, Chem.-Eur. J., 2006, 12, 5418; (c) M. Kotke and P. R. Schreiner, in Hydrogen Bonding in Organic Synthesis, ed. P. M. Pihko, Wiley-VCH, Weinheim, 2009, p. 141; (d) S. J. Connon, Synlett, 2009, 354; (e) Y. Takemoto, Chem. Pharm. Bull., 2010, 58, 593; ( $f$ ) K. Hof, K. M. Lippert and P. R. Schreiner, in Science of Synthesis - Asymmetric Organocatalysis 2 - Brønsted Base and Acid Catalysts, and Additional Topics, ed. K. Maruoka, Thieme, Stuttgart, NY, 2011, p. 297.

25 T. Okino, Y. Hoashi and Y. Takemoto, J. Am. Chem. Soc., 2003, 125, 12672.

26 A. E. Allen and D. W. C. MacMillan, Chem. Sci., 2012, 3, 633.

27 (a) P. T. Anastas and J. C. Warner, Green Chemistry: Theory and Practice, Oxford University Press, New York, 1998; (b) P. T. Anastas and M. M. Kirchhoff, Acc. Chem. Res., 2002, 35, 686.

28 R. A. Sheldon, I. W. C. E. Arends and U. Hanefeld, Green Chemistry and Catalysis, Wiley-VCH, Weinheim, 2007, and references therein.

29 P. Anastas and N. Eghbali, Chem. Soc. Rev., 2010, 39, 301.

30 R. A. Sheldon, Chem. Soc. Rev., 2012, 41, 1437.

31 The twelve principles of Green Chemistry were more recently captured in the mnemonic 'PRODUCTIVELY': S. L. Y. Tang, R. L. Smith and M. Poliakoff, Green Chem., 2005, 7, 761.

32 (a) R. A. Sheldon, Chem. Ind. (London), 1992, 903; (b) R. A. Sheldon, Green Chem., 2007, 9, 1273.

33 (a) B. M. Trost, Science, 1991, 254, 1471; (b) B. M. Trost, Angew. Chem., Int. Ed. Engl., 1995, 34, 259.

34 (a) P. A. Wender, S. T. Handy and D. L. Wright, Chem. Ind. (London), 1997, 765; (b) P. A. Wender, V. A. Verma, T. J. Paxton and T. H. Pillow, Acc. Chem. Res., 2008, 41, 40.

35 N. Z. Burns, P. S. Baran and R. W. Hoffmann, Angew. Chem., Int. Ed., 2009, 48, 2854.

36 T. Newhouse, P. S. Baran and R. W. Hoffmann, Chem. Soc. Rev., 2009, 38, 3010.

37 (a) R. W. Hoffmann, Synthesis, 2006, 3531; (b) I. S. Young and P. S. Baran, Nat. Chem., 2009, 1, 193.

38 P. A. Clarke, S. Santos and W. H. C. Martin, Green Chem., 2007, 9, 438.

39 B. M. Trost, Science, 1983, 219, 245.

40 For a review on multicatalysis employing transition-metal catalysts, see: (a) J. M. Lee, Y. Na, H. Han and S. Chang, Chem. Soc. Rev., 2004, 33, 302. For a recent highlight, see: (b) A. Duschek and S. F. Kirsch, Angew. Chem., Int. Ed., 2008, 47, 5703.

41 For selected recent reviews on multienzymatic reactions, see: (a) F. Lopez-Gallego and C. Schmidt-Dannert, Curr. Opin. Chem. Biol., 2010, 14, 174; (b) E. Ricca, B. Brucher and J. H. Schrittwieser, $A d v$. Synth. Catal., 2011, 353, 2239; (c) P. A. Santacoloma, G. Sin, K. V. Gernaey and J. M. Woodley, Org. Process Res. Dev., 2011, 15, 203.

42 A. Bruggink, R. Schoevaart and T. Kieboom, Org. Process Res. Dev., 2003, 7, 622 .

43 For selected reviews and highlights on combined organo-metal multicatalysis, see: (a) Z. Shao and H. Zhang, Chem. Soc. Rev., 2009, 38, 2745; (b) A. S. K. Hashmi and C. Hubbert, Angew. Chem., Int. Ed., 2010, 49, 1010; (c) M. Rueping, R. M. Koenigs and I. Atodiresei, Chem.-Eur. J., 2010, 16, 9350; (d) C. Zhong and X. Shi, Eur. J. Org. Chem., 2010, 2999. For selected recent examples, see: (e) J. Alemán, V. del Solar, C. Martín-Santos, L. Cubo and C. Navarro Ranninger, J.
Org. Chem., 2011, 76, 7287; (f) I. Ibrahem, S. Santoro, F. Himo and A. Córdova, Adv. Synth. Catal., 2011, 353, 245; (g) C. C. J. Loh, J. Badorrek, G. Raabe and D. Enders, Chem.-Eur. J., 2011, 17, 13409; (h) S. Lin, G.-L. Zhao, L. Deiana, J. Sun, Q. Zhang, H. Leijonmarck and A. Córdova, Chem.-Eur. J., 2010, 16, 13930; (i) A. Quintard and A. Alexakis, Adv. Synth. Catal., 2010, 352, 1856; $(j)$ A. Quintard, A. Alexakis and C. Mazet, Angew. Chem., Int. Ed., 2011, 50, 2354; (k) L. Ren, T. Lei, J.-X. Ye and L.-Z. Gong, Angew. Chem., Int. Ed., 2012, 51, 771; (l) M. Rueping, J. Dufour and M. S. Maji, Chem. Commun., 2012, 48, 3406. For combinations of enzymes and metal catalysts, see: (m) O. Pàmies and J.-E. Bäckvall, Chem. Rev., 2003, 103, 3247; (n) J. H. Lee, K. Han, M.-J. Kim and J. Park, Eur. J. Org. Chem., 2010, 999.

44 For recent reviews on aminocatalysis, see: (a) B. List, Chem. Commun., 2006, 819; (b) A. Erkkilä, I. Majander and P. M. Pihko, Chem. Rev., 2007, 107, 5416; (c) S. Mukherjee, J. W. Yang, S. Hoffmann and B. List, Chem. Rev., 2007, 107, 5471; (d) P. Melchiorre, M. Marigo, A. Carlone and G. Bartoli, Angew. Chem., Int. Ed., 2008, 47, 6138; (e) S. Bertelsen and K. A. Jørgensen, Chem. Soc. Rev., 2009, 38, 2178; (f) J. B. Brazier and N. C. O. Tomkinson, Top. Curr. Chem., 2010, 291, 281; $(g)$ P. M. Pihko, I. Majander and A. Erkkilä, Top. Curr. Chem., 2010, 291, 29; (h) M. Nielsen, D. Worgull, T. Zweifel, B. Gschwend, S. Bertelsen and K. A. Jørgensen, Chem. Commun., 2011, 47, 632.

45 Y. Huang, A. M. Walji, C. H. Larsen and D. W. C. MacMillan, J. Am. Chem. Soc., 2005, 127, 15051.

46 For selected reviews on metal-free transfer hydrogenation reactions, see: (a) S. G. Ouellet, A. M. Walji and D. W. C. Macmillan, Acc. Chem. Res., 2007, 40, 1327; (b) M. Rueping, J. Dufour and F. R. Schoepke, Green Chem., 2011, 13, 1084.

47 G.-L. Zhao and A. Córdova, Tetrahedron Lett., 2006, 47, 7417.

48 (a) M. Marigo, T. C. Wabnitz, D. Fielenbach and K. A. Jørgensen, Angew. Chem., Int. Ed., 2005, 44, 794; (b) Y. Hayashi, H. Gotoh, T. Hayashi and M. Shoji, Angew. Chem., Int. Ed., 2005, 44, 4212.

49 J. Vesely, I. Ibrahem, R. Rios, G.-L. Zhao, Y. Xu and A. Córdova, Tetrahedron Lett., 2007, 48, 2193.

50 B. Simmons, A. M. Walji and D. W. C. MacMillan, Angew. Chem., Int. Ed., 2009, 48, 4349.

51 (-)-Aromadendranediol is a sequiterpene, isolated from the marine coral Sinularia mayi and from the leaves of the Amazonian tree Xylopia brasiliens; see: (a) C. M. Beechan, C. Djerassi and H. Eggert, Tetrahedron, 1978, 34, 2503; (b) I. C. Moreira, J. H. G. Lago, M. C. M. Young and N. F. Roque, J. Braz. Chem. Soc., 2003, 14, 828.

52 Y. Chi, S. T. Scroggins and J. M. J. Fréchet, J. Am. Chem. Soc., 2008, 130, 6322.

53 S. T. Scroggins, Y. Chi and J. M. J. Fréchet, Angew. Chem., Int. Ed., 2010, 49, 2393.

54 P. Galzerano, F. Pesciaioli, A. Mazzanti, G. Bartoli and P. Melchiorre, Angew. Chem., Int. Ed., 2009, 48, 7892.

55 A. Desmarchelier, J. Marrot, X. Moreau and C. Greck, Org. Biomol. Chem., 2011, 9, 994.

56 J. Franzén, M. Marigo, D. Fielenbach, T. C. Wabnitz, A. Kjærsgaard and K. A. Jørgensen, J. Am. Chem. Soc., 2005, 127, 18296.

57 J. Peña, A. B. Antón, R. F. Moro, I. S. Marcos, N. M. Garrido and D. Díez, Tetrahedron, 2011, 67, 8331.

58 For a comprehensive review on multicatalysis and multicomponent reactions developed by the Ramachary group, see: D. B. Ramachary and S. Jain, Org. Biomol. Chem., 2011, 9, 1277.

59 U. Eder, G. Sauer and R. Wiechert, Angew. Chem., Int. Ed. Engl., 1971, 10, 496.

60 Z. G. Hajos and D. R. Parrish, J. Org. Chem., 1974, 39, 1615.

61 D. B. Ramachary and M. Kishor, J. Org. Chem., 2007, 72, 5056.

62 D. B. Ramachary and M. Kishor, Org. Biomol. Chem., 2008, 6, 4176.

63 D. B. Ramachary and R. Sakthidevi, Org. Biomol. Chem., 2008, 6, 2488.

64 D. B. Ramachary and R. Sakthidevi, Chem.-Eur. J., 2009, 15, 4516.

65 S. Bertelsen, R. L. Johansen and K. A. Jørgensen, Chem. Commun., $2008,3016$.

66 Ł. Albrecht, B. Richter, C. Vila, H. Krawczyk and K. A. Jørgensen, Chem.-Eur. J., 2009, 15, 3093.

67 J. L. García Ruano, V. Marcos, J. Antonio Suanzes, L. Marzo and J. Alemán, Chem.-Eur. J., 2009, 15, 6576.

68 B. Lygo, B. Allbutt and S. R. James, Tetrahedron Lett., 2003, 44, 5629.

69 T. Ooi and K. Maruoka, Angew. Chem., Int. Ed., 2007, 46, 4222.

70 H. Jiang, P. Elsner, K. L. Jensen, A. Falcicchio, V. Marcos and K. A. Jørgensen, Angew. Chem., Int. Ed., 2009, 48, 6844. 
71 (a) D. A. Nicewicz and D. W. C. MacMillan, Science, 2008, 322, 77; (b) D. A. Nagib, M. E. Scott and D. W. C. MacMillan, J. Am. Chem. Soc., 2009, 131, 10875; (c) H.-W. Shih, M. N. Vander Wal, R. L. Grange and D. W. C. MacMillan, J. Am. Chem. Soc., 2010, 132, 13600.

72 M. Neumann, S. Füldner, B. König and K. Zeitler, Angew. Chem., Int. Ed., 2011, 50, 951.

73 (a) D. Enders and T. Balensiefer, Acc. Chem. Res., 2004, 37, 534; (b) K. Zeitler, Angew. Chem., Int. Ed., 2005, 44, 7506; (c) D. Enders, O. Niemeier and A. Henseler, Chem. Rev., 2007, 107, 5606; (d) N. Marion, S. Díez-González and S. P. Nolan, Angew. Chem., Int. Ed., 2007, 46, 2988; (e) A. T. Biju, N. Kuhl and F. Glorius, Acc. Chem. Res., 2011, 44, 1182; $(f)$ V. Nair, R. S. Menon, A. T. Biju, C. R. Sinu, R. R. Paul, A. Jose and V. Sreekumar, Chem. Soc. Rev., 2011, 40, 5336.

74 D. Seebach, Angew. Chem., Int. Ed. Engl., 1979, 18, 239.

75 R. Breslow, J. Am. Chem. Soc., 1958, 80, 3719.

76 G.-L. Zhao and A. Córdova, Tetrahedron Lett., 2007, 48, 5976.

77 K. Y.-K. Chow and J. W. Bode, J. Am. Chem. Soc., 2004, 126, 8126.

78 M. S. Kerr, J. R. de Alaniz and T. Rovis, J. Org. Chem., 2005, 70, 5725 .

79 H. Jiang, B. Gschwend, Ł. Albrecht and K. A. Jørgensen, Org. Lett., $2010,12,5052$.

80 Very recently, Jørgensen and co-workers reported the enantioselective one-pot synthesis of $\gamma$-nitroesters by a Michael addition/oxidative esterification of $\alpha, \beta$-unsaturated aldehydes employing $(S)$-7 and $N$-bromosuccinimide (NBS). The desired $\gamma$-nitroesters were formed in good yields (54-78\%) and high enantioselectivities (93-96\% ee). However, overstoichiometric amounts (1.5 or 3.0 equivalents) of NBS were necessary to perform the oxidative esterification step; see: K. L. Jensen, P. H. Poulsen, B. S. Donslund, F. Morana and K. A. Jørgensen, Org. Lett., 2012, 14, 1516.

81 L. Deiana, P. Dziedzic, G.-L. Zhao, J. Vesely, I. Ibrahem, R. Rios, J. Sun and A. Córdova, Chem.-Eur. J., 2011, 17, 7904.

82 S. P. Lathrop and T. Rovis, J. Am. Chem. Soc., 2009, 131, 13628.

83 K. E. Ozboya and T. Rovis, Chem. Sci., 2011, 2, 1835.

84 M. S. Kerr and T. Rovis, J. Am. Chem. Soc., 2004, 126, 8876.

85 D. Enders, A. Grossmann, H. Huang and G. Raabe, Eur. J. Org. Chem., 2011, 4298 .

86 C. B. Jacobsen, K. L. Jensen, J. Udmark and K. A. Jørgensen, Org. Lett., 2011, 13, 4790.

87 L. A. Warren and S. Smiles, J. Chem. Soc., 1930, 1327.

88 An example for a multicatalytic asymmetric Diels-Alder/cross-benzoin reaction sequence was reported by Melchiorre et al. during the revision of this manuscript. The use of $(S)-\mathbf{7}$ and $\mathbf{1 1 9}$ as catalyst pair enabled the synthesis of densely functionalized trans-fused tetracyclic products in moderate to good yields (40-66\%) and with high stereoselectivities (up to $8: 1$ d.r., $97-99 \%$ ee); see: Y. Liu, M. Nappi, E. C. Escudero-Adán and P. Melchiorre, Org. Lett., 2012, 14, 1310.

89 C. M. Filloux, S. P. Lathrop and T. Rovis, Proc. Natl. Acad. Sci. U. S. A., 2010, 107, 20666.

90 (a) M.-J. Fan, G.-Q. Li, L.-H. Li, S.-D. Yang and Y.-M. Liang, Synthesis, 2006, 2286; (b) M.-J. Fan, G.-Q. Li and Y.-M. Liang, Tetrahedron, 2006, 62, 6782 .

91 The observation that catechols enhance the catalytic efficiency of $N$ heterocyclic carbenes in Stetter reactions was confirmed recently; see: D. A. DiRocco and T. Rovis, J. Am. Chem. Soc., 2011, 133, 10402.

92 Related non-asymmetric multicatalytic variants were reported recently: (a) M. Padmanaban, A. T. Biju and F. Glorius, Org. Lett., 2011, 13, 5624; (b) J. F. Franz, P. J. W. Fuchs and K. Zeitler, Tetrahedron Lett., $2011, \mathbf{5 2}, 6952$.

93 For selected reviews and highlights on hydrogen bonding in organocatalysis, see: (a) P. R. Schreiner, Chem. Soc. Rev., 2003, 32, 289; (b) P. M. Pihko, Angew. Chem., Int. Ed., 2004, 43, 2062; (c) M. S. Taylor and E. N. Jacobsen, Angew. Chem., Int. Ed., 2006, 45, 1520; (d) A.
G. Doyle and E. N. Jacobsen, Chem. Rev., 2007, 107, 5713; (e) X. Yu and W. Wang, Chem.-Asian J., 2008, 3, 516.

94 (a) Z. Zhang and P. R. Schreiner, Chem. Soc. Rev., 2009, 38, 1187; (b) A.-F. Li, J.-H. Wang, F. Wang and Y.-B. Jiang, Chem. Soc. Rev., 2010, 39, 3729. For selected examples, see: (c) M. Kotke and P. R. Schreiner, Tetrahedron, 2006, 62, 434; (d) M. Kotke and P. R. Schreiner, Synthesis, 2007, 779 .

95 Y. Wang, R.-G. Han, Y.-L. Zhao, S. Yang, P.-F. Xu and D. J. Dixon, Angew. Chem., Int. Ed., 2009, 48, 9834.

96 Y. Wang, D.-F. Yu, Y.-Z. Liu, H. Wei, Y.-C. Luo, D. J. Dixon and P.F. Xu, Chem.-Eur. J., 2010, 16, 3922.

97 H. Uehara, R. Imashiro, G. Hernández-Torres and C. F. Barbas III, Proc. Natl. Acad. Sci. U. S. A., 2010, 107, 20672.

98 A variant for the synthesis of iminosugar derivatives has been published by Barbas and co-workers employing $(1 R, 2 R)-\mathbf{2 3 2}$ and $N, N, N^{\prime}, N^{\prime}$-tetramethylguanidine (TMG) in conjunction with acetic acid as co-catalyst. The $(1 R, 2 R)-\mathbf{2 3 2}$ catalyzed anti-Michael reaction of $\mathbf{2 3 3}$ with various nitrostyrenes $\mathbf{5 8}$ and subsequent TMG and acetic acid promoted intermolecular anti-aza-Henry reaction with tosyl-protected imine $\mathbf{2 2 6}$ provided the desired products in up to $69 \%$ yield and with high stereoselectivities (up to $10: 1$ d.r. and $99 \%$ ee). However, the use of substoichiometric amounts of base did not form the desired products in reasonable yields; see: R. Imashiro, H. Uehara and C. F. Barbas III, Org. Lett., 2010, 12, 5250.

99 D. Enders, G. Urbanietz and G. Raabe, Synthesis, 2011, 1905.

100 During the revision of this manuscript Enders et al. reported a multicatalytic Michael/lactonization reaction sequence employing thiourea derivative (S)-208 and $p$-TSA (72) for the asymmetric synthesis of functionalized chromans: D. Enders, G. Urbanietz, R. Hahn and G. Raabe, Synthesis, 2012, 44, 773.

101 B. Xu, Z.-L. Guo, W.-Y. Jin, Z.-P. Wang, Y.-G. Peng and Q.-X. Guo, Angew. Chem., Int. Ed., 2012, 51, 1059.

102 For selected reviews on organocatalysis with oligopeptides, see: (a) E. R. Jarvo and S. J. Miller, Tetrahedron, 2002, 58, 2481; (b) S. J. Miller, Acc. Chem. Res., 2004, 37, 601; (c) E. A. C. Davie, S. M. Mennen, Y. Xu and S. J. Miller, Chem. Rev., 2007, 107, 5759.

103 For a recent highlight on asymmetric catalysis employing synthetic peptides, see: H. Wennemers, Chem. Commun., 2011, 47, 12036.

104 For a recent review on organocatalyzed kinetic resolution and desymmetrization reactions through acyl transfer, see: C. E. Müller and P. R. Schreiner, Angew. Chem., Int. Ed., 2011, 50, 6012.

105 V. Lutz, J. Glatthaar, C. Würtele, M. Serafin, H. Hausmann and P. R. Schreiner, Chem.-Eur. J., 2009, 15, 8548.

106 (a) C. E. Müller, L. Wanka, K. Jewell and P. R. Schreiner, Angew. Chem., Int. Ed., 2008, 47, 6180; (b) R. Hrdina, C. E. Müller and P. R. Schreiner, Chem. Commun., 2010, 46, 2689.

107 L. Wanka, C. Cabrele, M. Vanejews and P. R. Schreiner, Eur. J. Org. Chem., 2007, 1474.

108 H. B. Kagan and J. C. Fiaud, Top. Stereochem., 1988, 18, 249.

109 The hypothesis that tetrapeptide $\mathbf{2 7 3}$ does not form a stable secondary structure which is stabilized by intramolecular hydrogen bonding and the stereochemical outcome of the reaction was confirmed by Shinisha and Sunoj using ONIOM computations: C. B. Shinisha and R. B. Sunoj, Org. Lett., 2009, 11, 3242.

110 C. E. Müller, D. Zell and P. R. Schreiner, Chem.-Eur. J., 2009, 15, 9647.

111 R. A. Sheldon and I. Arends, Adv. Synth. Catal., 2004, 346, 1051.

112 C. E. Müller, R. Hrdina, R. C. Wende and P. R. Schreiner, Chem.-Eur. J., 2011, 17, 6309 .

113 R. Hrdina, C. E. Müller, R. C. Wende, L. Wanka and P. R. Schreiner, Chem. Commun., 2012, 48, 2498.

114 G. Peris, C. E. Jakobsche and S. J. Miller, J. Am. Chem. Soc., 2007, 129, 8710 